\title{
Inventory Agility upon Demand Shocks: Empirical Evidence from the Financial Crisis
}

\author{
Submission ID OPEMAN-D-16-00165-R4
}

\author{
Maximiliano Udenio \\ KU Leuven \\ Naamsesstraat 69, 3000 Leuven, Belgium \\ Maxi.Udenio@kuleuven.be \\ Kai Hoberg* \\ Kühne Logistics University - KLU \\ Großer Grasbrook 17, 20457 Hamburg, Germany \\ Kai.Hoberg@the-klu.org \\ Jan C. Fransoo \\ Kühne Logistics University - KLU \\ Großer Grasbrook 17, 20457 Hamburg, Germany
}

August 1, 2018

* Corresponding author. Tel. +49 40 328707-276, Mob. +49 16094764441 


\title{
Blinded for Peer Review
}

\section{Inventory Agility upon Demand Shocks: Empirical Evidence from the Financial Crisis}

\begin{abstract}
The objective of this paper is to identify antecedents of inventory agility (i.e., the capability to quickly adapt inventories to changes in demand) upon demand shocks based on the awareness-motivation-capability (AMC) framework and to explore the link between inventory agility and financial performance. We introduce an empirical measure of inventory agility based on the deviation of relative inventories (i.e., inventory days) from their forecasted values. We hypothesize that firms with higher awareness, motivation, and capabilities are associated with higher inventory agility in the presence of demand shocks. We define two empirical measures for each of the three dimensions of the AMC framework in the context of inventory agility: awareness (i.e., market orientation and technology orientation), motivation (i.e., gross margin and liquidity), and capabilities (i.e., inventory management capability and resource availability). In addition, we incorporate the constraining factor model (CFM) into the AMC framework, thus allowing for complementarity among the different measures. In this view, the influence of each of the measures on inventory agility varies according to which of the measures is the constraining factor for a given firm. The 2008 financial crisis may have tested firms' inventory agility more than any other crisis since the Great Depression, as an unprecedented collapse of demand coincided with a reduction in credit availability. Therefore, for our analysis, we use firm-level empirical data from 1,263 public U.S. manufacturing firms for the 2005-2011 period. We find that firms' motivation and capabilities are key factors associated with inventory agility. Through the CFM, we show that identifying the constraining factors leads to a more refined understanding of the moderating effects of the antecedents of inventory agility. In a separate analysis, we find that inventory agility is positively associated with a number of financial performance metrics during crisis periods. We distinguish between inventory underages and overages and find that, during the crisis, they are both associated with lower financial performance. Furthermore, we find evidence that higher underages (overages) magnify the effect of overages (underages). Among other managerial insights, our findings suggest that the use of inventory reductions as a quick way to increase liquidity must be gauged against their potential impact on other aspects of financial performance.
\end{abstract}

Key words: Inventory Management; Empirical Operations Management; Financial Crisis; Inventory Agility.

\section{Introduction}

In this paper, we identify the antecedents of inventory agility as a response to demand shocks, i.e., the extent to which firms can maintain relative inventory levels following demand shocks. Furthermore, we explore the link between inventory agility and financial performance using firm-level data from the financial crisis, and we use two theory-based empirical frameworks-the awareness, motivation, capabilities (AMC) framework and the constraining factor model (CFM)-to test six hypothesis related to inventory agility. Then, we test two hypotheses regarding the relationship 


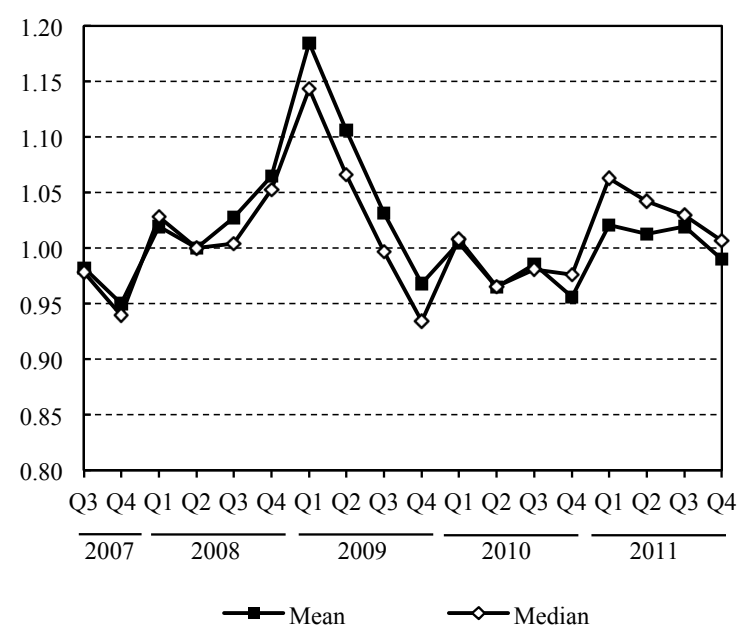

Figure 1 Relative inventory (normalized inventory days) in the manufacturing sector.

Note: Values normalized in Q2/2008.

between inventory overage/underage and financial performance.

Lehman Brothers-the fourth-largest U.S. investment bank at that time-declared bankruptcy on September 2008. This bankruptcy, the largest bankruptcy filing in U.S. history, precipitated the worst financial panic since the Great Depression (Ivashina and Scharfstein 2010). The collapse of Lehman Brothers sent a shockwave through the financial world and triggered an unprecedented decline in the global economy (Duncan 2008). Manufacturing industries were hit particularly hard, as aggregate sales in manufacturing declined by $39 \%$ within three quarters of the Lehman collapse (see also Udenio et al. 2015).

When sales decline, firms with high inventory agility can adapt their inventories to these new realities and hold their relative inventories constant, thus avoiding inventory-related costs such as cost of capital and obsolescence costs.

Figure 1 shows the evolution of normalized relative inventories, measured by mean and median inventory days, in the manufacturing sector. Median inventory days at the beginning of the financial crisis increased by $14 \%$ relative to the previous year, and mean inventory days increased by $18 \%$, suggesting an increase in the right skewness of the distribution of inventory days for that period.

Although inventory days return to normal within 18 months, there is considerable variability at the firm level, as illustrated by three firms in the transportation equipment industry (NAICS code 336). Figure 2 shows the sales and inventory developments of Harley-Davidson Inc., Dana Holding Corp., and Ford Motor Company. This industry was hit particularly hard by the financial crisis (Van Biesebroeck and Sturgeon 2010). While all three companies experienced a comparable collapse in sales, they exhibited significantly different levels of inventory agility. At Harley-Davidson, relative 

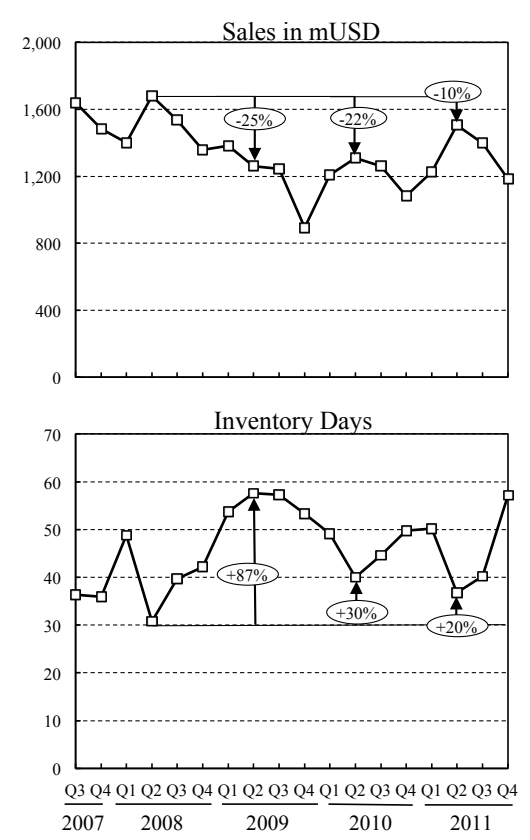

(a) Harley-Davidson Inc.
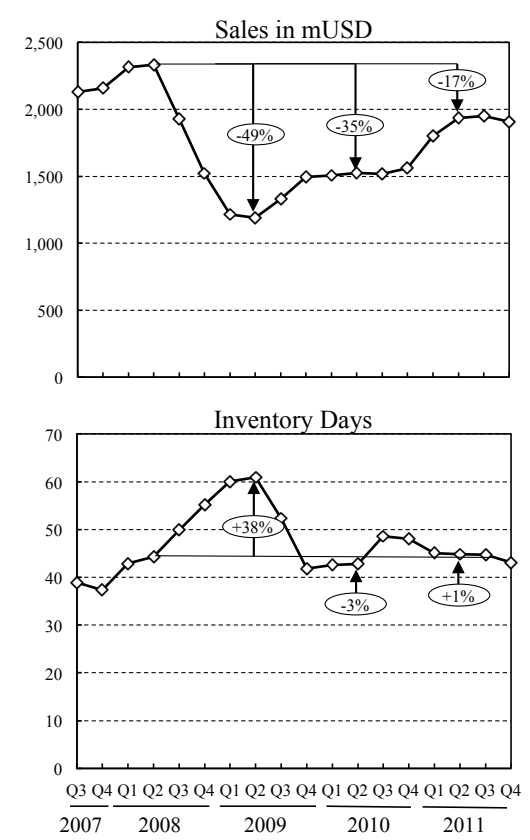

(b) Dana Holding Corp.
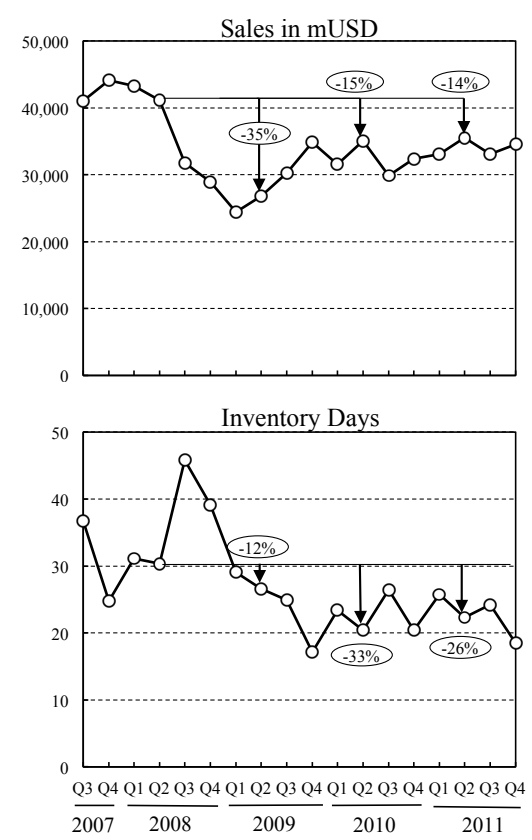

(c) Ford Motor Company

Figure 2 Sales and relative inventories at Harley-Davidson Inc, Dana Holding Corporation, and Ford Motor Company.

inventories settled at 30\% above pre-crisis levels in Q2/2010, two years after the crisis. At Dana, the inventory surge was less pronounced and relative inventories returned more rapidly to the pre-crisis level. At Ford, relative inventories decreased by $33 \%$ one year after the start of the crisis. These results suggest that each company reacted to the crisis with a different strategy: Harley-Davidson maintained high inventory, Dana kept inventory close to pre-crisis levels, and Ford actively reduced its inventory.

These observations motivate our research. Given the importance of inventory management capabilities in crisis situations (Steinker et al. 2016), our objective is to investigate inventory agility in response to demand shocks. With this study, we address three research questions: (i) How did firms react to the significant decline in demand and align their inventory to the new situation?, (ii) What are the antecedents of inventory agility during the crisis? And finally, (iii) what are the financial implications of inventory dynamics?

We leverage the AMC framework (Chen 1996) as a theoretical lens to investigate inventory agility. The AMC framework was originally devised to study inter-firm rivalry. It aims to characterize a focal firm's structural competitive tension with that of its rivals based on three key behavioral drivers. Simply stated, a firm can respond to an action only if it is aware of the action, motivated to react, and capable of responding (Chen and Miller 2012). Awareness specifically refers to a firm's 
alertness with regard to the market and the signals it receives (Levinthal and Rerup 2006, Lamberg et al. 2009). Motivation relates to the incentives that drive a firm to undertake actions (Smith et al. 2001). Finally, capabilities relate to the cognitive and resource-based factors that influence the firm's ability to take action (Smith et al. 2001). We contend that the drivers specified in the AMC framework provide a solid conceptual basis for firm-level, theory-based constructs regarding a firm's decision to react in an agile manner and maintain stable relative inventories during times of crisis. We propose measures based upon the operations and finance literature to assess each of the AMC components. The analysis suggests that the antecedents of inventory agility are consistent across the panel: A firms's motivation and capabilities play important roles in achieving inventory agility during the crisis.

In addition to the AMC framework, we adopt the CFM used by Siemsen et al. (2008) to better understand how the interaction among the AMC components affects a firm's inventory agility. By building on the AMC framework with the CFM model, we explicitly allow for "bottlenecks" in the antecedents of inventory agility. Using the CFM, the effect of any of the AMC components on the agility of a given firm is regulated as a function of its most critical component. Thus, our methodology allows us to distinguish between, for example, the effect of motivation on inventory agility if awareness is critical for a firm and the effect of motivation on inventory agility if capabilities are critical for a firm.

To assess the link between inventory agility and financial performance, we measure the short, medium, and long-term impacts of inventory dynamics on various aspects of a firm's financial performance: profitability, market performance, and financial health. To do so, we explicitly distinguish between inventory overages and underages. We find that inventory overages and underages are generally negatively associated with financial performance, and that the magnitude of this effect varies according to the perfomance dimension under study. This finding is consistent with, and expands upon, the empirical study of Eroglu and Hofer (2011) that found an 'inverted U' relationship between inventory leanness and firm performance in numerous industries. Our results suggest that using inventory reductions to increase liquidity in the short term (Udenio et al. 2015, Steinker et al. 2016) needs to be gauged carefully against the tradeoffs between different dimensions of longterm financial performance. Our results, however, also indicate that the marginal effect of overages (underages) is conditional on the level of underage (overage) a firm exhibits during the period of analysis, i.e., the marginal effect of overage (underage) on financial performance is larger for firms with higher underages (overages). 
The remainder of the paper is structured as follows. In Section 2, we provide an overview of the relevant literature on inventory management in crisis situations. In Section 3, we develop a series of hypotheses based on existing theory. Then, in Section 4, we introduce the models and methodology used to test our hypotheses and describe the empirical dataset. In Section 5, we present our results, and finally, we conclude and summarize our findings in Section 6.

\section{Literature review}

Our research builds on three streams of research, namely, the empirical operations management literature that analyzes firm-level inventory decisions, the macroeconomic and financial literature that investigates the link between economic conditions and inventory investments, and the strategic management literature on AMC that we use to identify the antecedents of inventory agility.

\subsection{The operations perspective}

Over the past decade, research in empirical operations management advanced considerably due to a rich stream of literature-supported by secondary data-that studies multiple facets of firmlevel inventory investment. Key findings include that (1) inventory levels in many sectors have significantly decreased over the past decades (Chen et al. 2005), (2) most insights gained from analytical single-product inventory models also hold for aggregate firm-level inventory (Rumyantsev and Netessine 2007b), and (3) inventory levels can convey important information on a firm's future sales (Kesavan et al. 2010). Additionally, a number of papers identify relationships between inventory investment and the underlying driving factors. Examples of such relationships include production flexibility and the number of dealerships in the case of the automotive industry (Cachon and Olivares 2010); the time relative to the fiscal year end in publicly traded firms (Lai 2008, Hoberg et al. 2017); and sales characteristics, gross margins, and capital intensity in the retail industry (Gaur et al. 2005). We refer the reader to Eroglu and Hofer (2011), Steinker et al. (2016), and Bendig et al. (2018) for recent reviews of different aspects of the empirical inventory literature and focus on the studies that are most immediately relevant to our topic.

The objective of numerous empirical operations management papers is to identify the optimal level of inventory that a firm should hold. Research suggests the existence of a 'sweet spot' for firmlevel inventory, above or below which performance tends to decrease (Isaksson and Seifert 2014). Chen et al. (2005) apply a portfolio approach to review the link between firm inventories and stock returns. They find that firms with the lowest inventories have only ordinary returns, while firms with abnormally high inventories show abnormally poor returns. Firms with slightly below-average inventories exhibit the highest stock returns. Rumyantsev and Netessine (2007a) analyze the impact 
of responsive inventory management on financial performance. Responsive inventory management refers to a close match between sales and inventory dynamics - a responsive firm will maintain constant relative inventory levels. These authors find that large deviations from constant inventory days are associated with lower profitability. Eroglu and Hofer (2011) introduce an empirical leanness indicator (ELI) that takes into account industry-specific inventory management characteristics. ELI is defined as the difference between a firm's inventory turnover and the estimated inventory turnover curve for its industry (see Ballou 2010, for a discussion on inventory turnover curve estimation). Their findings suggest an optimum level of inventory leanness: in approximately half of the considered industries, inventory leanness increases firm performance up to a certain point, beyond which the incremental effect becomes negative. Eroglu and Hofer (2014) expand on their previous findings by further examining the moderating effect of environmental dynamism on the relationship between ELI and financial performance. Their findings suggest that innovative intensity amplifies the effect of leanness and competition moderates it. In a recent study, Bendig et al. (2017) show that inventory leanness also has a positive and concave relationship with credit ratings. Additionally, Hendricks and Singhal (2009) analyze the impact of public inventory-surplus announcements on shareholder value. They find that firms that experience excess inventory situations underperform their peers and that the stock market partially anticipates the negative effects of holding surplus inventory.

The aforementioned studies were conducted in periods of relative stability. However, it seems reasonable to conclude that firms should also minimize deviations from optimal relative inventory levels during crisis periods (see also Kahn and McConnell 2002). For periods with external shocks, this suggestion would imply that firms should seek to regain appropriate inventory levels shortly after temporary deviations. This reasoning, however, does not factor in credit and financial limitations that can, in such situations, steer inventory investment decisions. While there is recent evidence suggesting that demand jumps have an impact on the break even point of investments geared toward reducing lead-times (Bicer et al. 2018), to the best of our knowledge, no study explicitly addresses a manufacturer's inventory management capabilities in times of crises or the causes and effects of the resulting inventory dynamics. The contribution most related to our topic is a recent paper by Kesavan and Kushwaha (2014), who study retail inventory investment during macroeconomic expansions and contractions. They find that retailers' service level has significant explanatory power for inventory investment. In periods of contraction (expansion), low (high) service level retailers decrease (increase) their inventory investment more than high (low) service level retailers. In a related study, Kesavan et al. (2016) show that the negative financial impact of excess and shortage inventory costs is related to inventory turns; the financial impact being substantially more severe for low inventory turn retailers compared to high inventory turn retailers. 


\subsection{The financial perspective}

Macroeconomic and financial research adopts a different perspective on this topic. From the macroeconomic perspective, changes in inventory investment are important inasmuch as they play a significant role in explaining GDP fluctuations. Blinder and Maccini (1991) emphasize this point and draw attention to the fact that, while it has been known since the 1950s, this relationship was underrepresented for decades in the economics literature. The mainstream view came to view inventories as an 'adjustment' variable rather than as a driver of production decisions. This shift was due, in part, to the widespread use of production smoothing models based on Holt et al. (1960), which assume that production costs are dominant. See Blinder (1986) for an in-depth discussion of the production smoothing model's (in)ability to explain empirical observations. A large body of macroeconomic and financial research has examined the role of inventory investments in the business cycle (e.g., Sichel 1994, Carpenter et al. 1994, Hendel 1996, Carpenter et al. 1998, Dimelis 2001, Rubio and Schuh 2017). Kahn and McConnell (2002) note that firms' efforts to hold relative inventory levels constant in times of crisis leads to pro-cyclical absolute inventory movements. The authors estimate that overall inventory disinvestments accounted for $24.5 \%$ of the overall slowdown in GDP growth during postwar recessions. As firms disinvest in inventories, they amplify reductions in own sales up the supply chain. Guariglia (1999) highlights this 'accelerator effect' as being particularly strong for inventories with low adjustment costs. We refer the reader to Chikán et al. (2018) for a recent review of the literature on inventories from a macroeconomic perspective. A general argument for reducing inventories during recessions is that constraints on external finance will make firms more reliant on internal financing and, hence, reduce their inventory investments to meet financial requirements. Firms that are relatively dependent on external finance must thereby implement much larger inventory reductions than less-constrained companies (see Kashyap et al. 1994, Tribó 2001, Heisz and LaRochelle-Côté 2004, Duchin et al. 2010). In addition, there are indications that smaller companies must take more drastic measures when their external finance is constrained (Bagliano and Sembenelli 2004). Zaman (2017) argues that better IT infrastructure has enabled firms in recent years to decrease or delay their inventory investments, thus enhancing the liquidity of firms. For the financial crisis, economic research suggests that inventory investment is positively correlated with changes in production and follows the latter with a lag of two to three quarters (Abrahamsen and Hartwig 2011).

\subsection{The awareness-motivation-capability perspective}

Chen (1996) originally introduced the AMC framework for analyzing inter-firm competition in a strategic management context. The three elements (awareness, motivation, and capabilities) were 
previously discussed individually in diverse streams of research on organizational change, learning, and decision making. However, these elements manifested in a range of different and sometimes overlapping components (Chen et al. 2007) and had not been considered in a combined way to predict interfirm rivalry (Miller and Chen 1994). The promise of the AMC perspective lies particularly in its integrative consideration of all three antecedents and their joint influence on perceived competitive tension. There are different ways to operationalize the three AMC elements. For examples, awareness often relates to the rival's scale compared to the focal firm (Chen et al. 2007), to the volume of actions (Derfus et al. 2008), or to firm age (Miller and Chen 1996). Motivation could describe the extent to which the focal firm's markets are under attack by the rival (Ferrier 2001), the firm's financial situation (Ferrier et al. 2002), or to the firm's prior performance (Miller and Chen 1996). Finally, capability can relate to the operational capability of the rival to challenge the focal firm (Chen et al. 2007), the top management team's (TMT) socio-behavioral integration (Chen et al. 2010) or to slack resources (Miller and Chen 1996). In recent years, the AMC framework has been widely applied to analyze competitors' actions and responses (see Chen and Miller 2012, for a comprehensive overview). Miller et al. (2011) discuss the behavior driven by TMT members' consensual comprehension of the competitive arena. Bennett and Pierce (2016) compare the pure capabilities view and the AMC framework and test those predictions in the U.S. car leasing market. These authors find that motivation appears to be a critical factor in explaining the competitive dynamics of the market. The AMC framework has also been further adapted to different managerial contexts. Among others, Meyer and Sinani (2009) use a meta-analysis to extend the AMC framework to explain cross-contextual variations in local firms' productivity upgrading in response to foreign entry; Livengood and Reger (2010) examine the effects of organizational identity on firms' competitive dynamics; Stadtler and Lin (2017) build an AMC framework to analyze a firm's drivers with regards to environmental alliances; and Chen et al. (2017) use the AMC framework to study the effect of a rival's innovation on firms' product strategy. In this paper, we leverage the AMC framework to build a model of the antecedents of inventory agility given a context of demand shocks.

\section{Hypotheses development}

Based on the operations and supply chain management literature, we identify a number of relationships associated with inventory agility during the crisis period. First, we develop six hypotheses on the antecedents of inventory agility during the crisis based on the awareness, motivation and capability framework. Next, we develop two hypotheses on the relationship between inventory performance and financial performance. Figure 3 summarizes our conceptual model, and Table 1 summarizes the construct definitions and literature support. The different specific measures employed are detailed in Section 4. 


\subsection{Awareness-motivation-capability and inventory agility}

We leverage the AMC framework (Chen 1996) to develop six hypotheses on the antecedents of inventory agility upon demand shocks as firms need to become aware of their individual demand changes, require the motivation to adopt inventories quickly, and must be capable of doing so.

Awareness. To adapt their inventories during the financial crisis, firms first had to become aware of the forthcoming (and ongoing) demand contraction as early as possible. While there is general consensus among economists and managers that the economic downturn accelerated in Q3/2008 after the collapse of Lehman Brothers (Ivashina and Scharfstein 2010, Campello et al. 2010), each firm needed to identify the individual consequences of the downturn for its specific customers and markets. There are different mechanisms that affect the extent to which firms sense market developments and are aware of demand changes. We focus on market orientation and technology orientation. Unknown or changing market requirements generally represent a major source of uncertainty for firms across industries (Moser et al. 2017). Firms require market orientation to acquire and assimilate relevant information in order to become aware of the changing customer needs and how they should be served (Narver and Slater 1990, Brady and Cronin Jr 2001). Market orientation describes a firm's capability to actively engage in the organization-wide generation of, dissemination of, and responsiveness to market intelligence (Kohli and Jaworski 1990). A large body of prior literature

\section{Table 1 Construct definitions and literature support.}

\begin{tabular}{|c|c|c|}
\hline $\begin{array}{l}\text { Inventory } \\
\text { agility }\end{array}$ & $\begin{array}{l}\text { The extent to which a firm quickly adjusts } \\
\text { its relative inventory level to meet chang- } \\
\text { ing demand realities, thus avoiding inven- } \\
\text { tory underage and overage. }\end{array}$ & $\begin{array}{l}\text { Sharifi and Zhang (1999), } \\
\text { Swafford et al. (2006), Gligor } \\
\text { et al. (2013) }\end{array}$ \\
\hline $\begin{array}{l}\text { Market } \\
\text { orientation }\end{array}$ & $\begin{array}{l}\text { The extent to which a firm is able to un- } \\
\text { derstand potential customer needs and re- } \\
\text { quirements. }\end{array}$ & $\begin{array}{l}\text { Kohli and Jaworski (1990), } \\
\text { Narver and Slater (1990), } \\
\text { Grawe et al. (2009) }\end{array}$ \\
\hline $\begin{array}{l}\text { Techn } \\
\text { orient }\end{array}$ & $\begin{array}{l}\text { The extent to which a firm is able to un- } \\
\text { derstand technological solutions, products } \\
\text { and services. }\end{array}$ & $\begin{array}{l}\text { Hamel and Prahalad (1991), } \\
\text { Gatignon and Xuereb (1997), } \\
\text { Grinstein (2008) }\end{array}$ \\
\hline Gross margin & $\begin{array}{l}\text { The difference between revenues and cost } \\
\text { of goods sold while accounting for the cost } \\
\text { of supplies, labor and overhead used for } \\
\text { production. }\end{array}$ & $\begin{array}{l}\text { Gaur et al. (2005), Rumyant- } \\
\text { sev and Netessine (2007b), } \\
\text { Kesavan et al. (2010), }\end{array}$ \\
\hline Liq & $\begin{array}{l}\text { The extent to which a firm is able to pro- } \\
\text { vide cash to fulfill its future financial obli- } \\
\text { gations. }\end{array}$ & $\begin{array}{l}\text { Carpenter et al. (1998), } \\
\text { Ellinger et al. (2011), Steinker } \\
\text { et al. (2016) }\end{array}$ \\
\hline $\begin{array}{l}\text { Inventory } \\
\text { management } \\
\text { capability }\end{array}$ & $\begin{array}{l}\text { The extent to which a firm can control } \\
\text { its relative inventory level to avoid unpre- } \\
\text { dictable variations under normal economic } \\
\text { conditions. }\end{array}$ & $\begin{array}{l}\text { Thomas and Zhang (2002), } \\
\text { Hendricks and Singhal (2005b, } \\
\text { 2009), Steinker et al. (2016) }\end{array}$ \\
\hline $\begin{array}{l}\text { Resource } \\
\text { availability }\end{array}$ & $\begin{array}{l}\text { The availability of resources such as plan- } \\
\text { ners or IT systems that allow a firm to } \\
\text { manage its inventories. }\end{array}$ & $\begin{array}{l}\text { George (2005), Rumyantsev } \\
\text { and Netessine (2007b), Gaur } \\
\text { and Kesavan (2008) }\end{array}$ \\
\hline
\end{tabular}




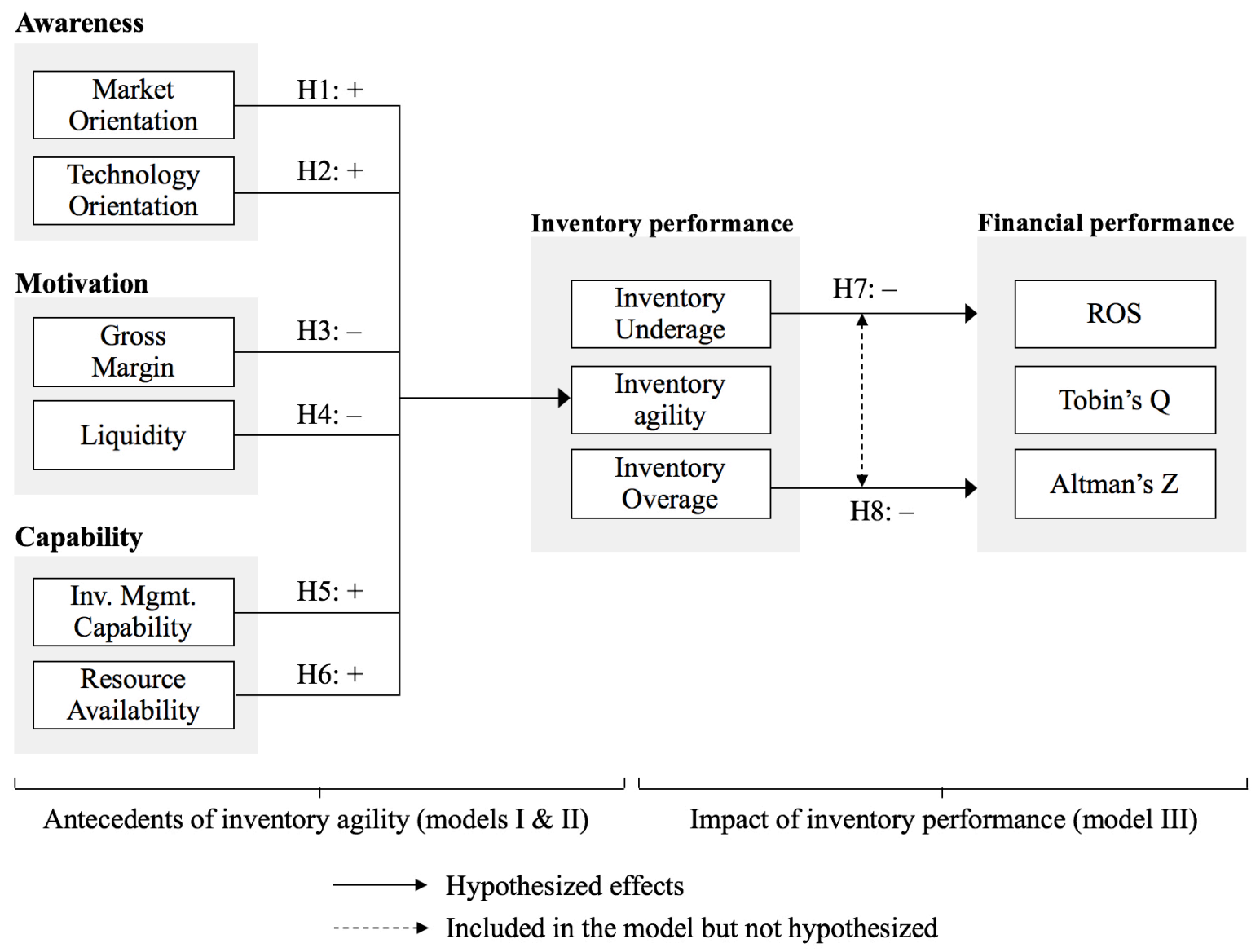

Figure 3 Conceptual model and hypotheses.

has shown that market orientation reflects an organizational culture that enables superior financial performance (Cano et al. 2004, Kirca et al. 2005, Srinivasan et al. 2005).

Market orientation in times of normal economic conditions enable firms to sense their customers' changing needs. Moreover, it also enables firms to become aware of new demand realities and, in particular, to identify the severity of the situation in an economic crisis due to a better understanding of the customer and his actions. We expect market-oriented firms to obtain a better picture of the upcoming changes in demand based on market intelligence resources, such as customer interaction, extensive market research, frequent customer surveys, and interviews. Therefore, we predict the following:

HYPOTHESIS 1. Market orientation in the periods preceding the crisis is positively associated with a firm's inventory agility during the crisis.

In addition to market orientation, the strategy literature identifies technology orientation as a second potential strategic orientation related to firms' performance (Venkatraman 1989, Slater and 
Narver 2000, Grinstein, 2008). Technology orientation refers to the firm's ability to use its technical knowledge to build a new technical solution to meet the needs of users (Gatignon and Xuereb 1997). This ability to generate creative ideas for new innovative products in response to changing market and customer needs is key to the success of many firms (Im and Workman Jr. 2004).

While a technology-oriented firm certainly requires a strong research and development skill set to continuously provide new technological solutions, products and services, the firm must also closely follow market developments and identify latest trends to proactivity develop new offerings. This argument is in line with the concept of strategic foresight, i.e., the ability to anticipate discontinuities in the business environment, market, or IT space (Sambamurthy et al. 2003). Accordingly, firms with a higher technology orientation will realize demand shifts in the market more quickly. In addition, firms with high technology orientation should have more advanced processes in place (e.g., due to closer collaboration in developments with customers) that enable them to sense market changes. These processes will also help firms to become aware of changes in the market during the financial crisis. Therefore, we predict the following:

HYPOTHESIS 2. Technology orientation in the periods preceding the crisis is positively associated with a firm's inventory agility during the crisis.

Motivation. Once firms became aware of an ongoing decline in demand, they required incentives to manage inventory in an agile manner and adjust inventory levels in line with the new demand realities. Certain firms might not have the motivation to keep relative inventory stable, even though they might not have had difficulty keeping absolute inventories at pre-crisis levels.

Prior research on inventories provides evidence that the operational motivation expressed by the product margins (i.e., the difference between the sales price and cost of goods sold) is an important determinant of inventory investment (Kesavan et al. 2010, Rumyantsev and Netessine 2007a). Firms with lower product margins have a higher motivation to execute much tighter control over their inventories compared to peers with higher gross margins. In line with stochastic inventory theory and the critical ratio in the newsvendor model (Cachon and Terwiesch 2009), firms are expected to avoid excess inventories with high holding or obsolescence costs if gross margins are low. In situations with rapidly declining customer demand, firms with lower gross margins should be carefully watching developments and manage inventories in a timely and proactive manner. Firms with higher gross margins typically have higher inventories to avoid stock-outs and to provide higher service levels, thus reflecting a lower operational motivation (Kesavan and Kushwaha 2014). Ultimately, these firms with higher gross margins can also be expected to reduce relative inventories if demand declines. 
However, they are expected to react with less agility, erring on the side of caution to avoid having too little inventory. Firms with higher gross margins are accustomed to higher inventory levels (Gaur et al. 2005) and have an interest in avoiding stock-out situations if demand recovers earlier than expected. Therefore, we posit a relationship between a firm's gross margin before the crisis that acts as a motivation and inventory agility during the crisis as follows:

Hypothesis 3. Gross margins during the periods preceding the crisis are negatively associated with a firm's inventory agility during the crisis.

Another important motivation to tightly manage inventory is associated with the firm's financial situation. The finance literature generally distinguishes two sources of financing operations and future growth: external financing, such as credit or equity obtained from outside the firm, and internal financing, such as current assets or retained earnings obtained from within the firm (Brealey 2012). A key characteristic of the financial crisis was the reduced access to loans faced by many firms, which acted as a negative shock to the supply of external finance (Ivashina and Scharfstein 2010). In particular, firms with low liquidity were affected most by the limited availability of credit. While corporate investment declined significantly, the decline was greatest for firms with financial constraints, such as those with low cash reserves or high net short-term debt (Duchin et al. 2010). Many firms bypassed attractive investment opportunities, with $86 \%$ of the CFOs of financially constrained U.S. firms reporting that their investment in attractive projects was restricted during the financial crisis (Campello et al. 2010).

Inventories are often seen as an important component of a firm's working capital that the firm can reduce to allow for self-financing (Hofmann et al. 2011). Converting inventory into cash seems to be particularly important if no external financing is available. Carpenter et al. (1998) find evidence that firms' inventory investment decreases when they face cash flow constraints. Steinker et al. (2016) analyze the inventory behavior of firms in financial distress and show that firms with lower liquidity reduce inventories to avoid bankruptcy. Udenio et al. (2015) observe this behavior for a chemical company that was affected by the financial crisis.

Given these arguments, we posit a relationship between a firm's financial motivation before the crisis and its inventory agility during the crisis in the following hypothesis:

HYPOTHESIS 4. Liquidity during the periods preceding the crisis is negatively associated with a firm's inventory agility during the crisis..

Capabilities. Even if firms are aware of the changing demand realities and have a strong motivation to manage inventories in line with the contracting demand, they still require the capabilities 
to do so. Firms with good inventory management capabilities are those that can actively manage inventories according to their specific 'sweet spots' (Eroglu and Hofer 2011), avoiding large inventory build-ups and shortages.

Recent research highlights the financial consequences of poor inventory management capabilities, which lead to supply-demand mismatches: excess inventories are costly and bear the risk of obsolescence (Hendricks and Singhal 2009), while inventory shortages result in poor customer service and have negative implications for current and future sales (Hendricks and Singhal 2005a). However, aggregate firm inventories typically fluctuate throughout the year due to a number of factors (Steinker and Hoberg 2013). Some of these fluctuations can be traced back to seasonality or growth (e.g., anticipation inventory, demand patterns, or reporting periods) and can be considered stable inventory fluctuations. Other inventory fluctuations stem from positive or negative sales surprises, long production lead times, or poor supply chain setups and occur because firms do not have the capabilities to keep inventories stable. Thomas and Zhang (2002) document negative abnormal returns associated with such abnormal inventory growth. Considering the findings of Rumyantsev and Netessine (2007a), Hendricks and Singhal (2009) and Eroglu and Hofer (2011), firms should manage inventory according to the relevant 'sweet spots,' thus minimizing deviations from their individual (dynamic) optimal levels. Temporary deviations from these preferred levels (i.e., abnormal inventory growth and abnormal inventory decline) can be taken as indicators of a firm's limited inventory management capabilities in normal economic conditions. As a result, we expect firms with lower inventory capabilities that were not able to achieve stable inventories before the crisis to be particularly affected during the crisis. Accordingly, we hypothesize the following:

Hypothesis 5. Inventory management capability during the periods preceding the crisis is positively associated with a firm's inventory agility during the crisis.

The level of resources of a firm, in related literature typically measured by firm size, has often been associated with improved inventory performance. Rumyantsev and Netessine (2007a), Gaur and Kesavan (2008), and Gaur and Kesavan (2015) empirically confirm the existence of economies of scale in inventory management and provide evidence for lower (relative) inventory levels in larger firms.

In addition to the benefits derived from economies of scale and inventory pooling, larger firms also have potentially superior inventory management practices. Larger firms generally have more financial resources to fund expensive investments in inventory and logistics systems, information technology, and flexible production and warehousing systems (Gaur et al. 2005). These investments 
enable tighter control of inventories: Mishra et al. (2013) and Liu et al. (2013) show that higher IT capabilities are related to a firm's supply chain agility and reduce inventory-related costs. Moreover, higher IT integration with supply chain partners and the resulting enhanced demand and supply visibility enable firms to take better control of their inventories, allowing them to react more swiftly to impending market changes (Lee and Whang 2000, Zhou and Benton Jr 2007). However, while it is evident that larger firms have more resources at their disposal, these resources are not necessarily available (Bromiley and Rau 2016). Therefore, integrating existing resources and leveraging them effectively leads to competitive advantages (Newbert 2008, Hitt et al. 2016). Accordingly, firms with more available resources should be able to manage inventory more swiftly when facing demand shocks.

Firms with more resource availability are also likely to benefit from formal processes. For example, lean management implementations enable reductions of relative inventory levels and more agile inventory management (Lieberman et al. 1999, Demeter and Matyusz 2011). Likewise, more formal processes and investments in technology reduce inventory inaccuracy, which in turn improves inventory management performance (Heese 2007, DeHoratius and Raman 2008, Uçkun et al. 2008). Finally, planners' training and skill development will further improve the usage and efficiency of inventory management tools (Farasyn et al. 2011). Under conditions of high environmental uncertainty, the efficient management of resources has the potential to increase value creation (Sirmon et al. 2007) ${ }^{1}$.

Thus, we expect a positive relationship between resource availability and inventory agility during the crisis and put forward the following hypothesis:

HYPOTHESIS 6. Resource availability during the periods preceding the crisis is positively associated with a firm's inventory management agility during the crisis.

\subsection{Financial performance and inventory agility}

Inventory management is widely considered to have a significant impact on firm and supply chain performance (Shapiro and Wagner 2009, Capkun et al. 2009). Firms should manage inventories in line with demand to avoid costly supply-demand mismatches; insufficient inventory (i.e., inventory underage) and excess inventory (i.e., inventory overage) lead to increased costs (Cachon and Terwiesch 2009). Rumyantsev and Netessine (2007a) emphasize that inventory underage typically leads

${ }^{1}$ We recognize, however, that larger firms might need to deal with more complex structures, policies, and managerial ideologies resulting in greater structural inertia and would therefore display less agile inventory management (see, e.g., Miller and Chen 1994, Nadkarni et al. 2016). Despite these mitigating factors, We nevertheless follow the dominant line in the operations literature and anticipate that the inventory management benefits associated with higher resources will dominate over structural inertia. 
to explicit (e.g., express shipments, overtime work, and compensation for customers) and implicit (e.g., loss of goodwill and future business) costs. Similarly, inventory overage also triggers explicit (e.g., cost of capital, physical holding cost, and obsolescence) and implicit (e.g., markdowns and price protection) costs. Thus, all deviations from optimal inventory levels are penalized and should be reflected in the financial performance of a company. (See, e.g., Axsäter 1990, Berling and Rosling 2005, Huh et al. 2009, Yin et al. 2009, Ak and Patatoukas 2016, Chuang and Oliva 2016, for a selection of studies focused on different explicit and implicit cost considerations on inventory models.) In classical inventory theory, the tension between insufficient and excess inventory is often analyzed through the newsvendor model (first modeled by Arrow et al. 1951), with the objective of balancing overage and underage costs given a firm's financial parameters and desired service levels. The relative impact of overages and underages, however, is not necessarily the same for all firms and is itself the subject of a substantial amount of research (see, e.g., Su 2008, Moritz et al. 2013, Gavirneni and Robinson 2017, for recent contributions to the newsvendor literature).

In the context of a negative demand shock, inventory overages are caused by firms reducing inventories too slowly, whereas inventory underages are caused by firms reducing inventories too quickly or by failing to react to a subsequent increase in demand. Neither situation is desirable. The empirical operations literature provides substantial evidence for this line of argumentation. For example, Chen et al. (2005) find that abnormally low or high inventories have a significant performance impact for manufacturing firms, while Kesavan and Mani (2013) highlight the consequences of abnormal inventory growth (i.e., the deviation of actual inventory growth from expected inventory growth) for retailers. Moreover, Eroglu and Hofer (2011) find that a 'relative-inventory sweet spot' exists and that it depends on the specific industry in which a company operates.

Numerous different measures of a firm's financial performance are typical of the empirical operations management literature. We broadly distinguish three performance categories: profitability, market performance, and financial health. Profitability relates to the income generated based on the revenues and expenses in a period. Common profitability metrics such as return on sales or return on assets are widely applied in the operations literature (e.g., Kovach et al. 2015). They provide a direct perspective on the firm's current financial performance. Market performance, expressed by share prices, market capitalization, or aggregate metrics such as Tobin's Q, relates to investor expectations of a firm's future trajectory derived from available public and private information. Market performance has been found to be affected by inventory efficiency (see e.g., Chen et al. 2005, Kesavan and Mani 2013). Financial health embodies a firm's ability to meet its financial obligations, given its assets and liabilities. Financial health is typically measured while accounting 
for multiple dimensions to provide a holistic perspective. The contemporary operations literature frequently quantifies financial health through the Altman's Z-score when analyzing the impact of inventory decisions (e.g., Swamidass 2007, Steinker et al. 2016).

In line with theoretical, empirical, and experimental operations management research, we expect that firms that react slowly to a negative demand shock - and therefore accumulate inventory overages - suffer related explicit and implicit costs as detailed above; i.e., increased holding costs (Nahmias and Olsen 2015) and potential obsolescence (Song and Lau 2004) and/or markdown (Ferguson et al. 2007) costs. The impact of these costs, in turn, will be reflected in the different financial performance dimensions. Increased costs directly impact margins and, as a consequence, profitability, market performance, and financial health.

Due to the focus on credit availability and liquidity during the crisis and the resulting financial constraints on inventory management (Buzacott and Zhang 2004, Baños-Caballero et al. 2014), we expect this effect to be particularly severe during the period immediately following the demand shock. Furthermore, due to the medium- to long-term nature of supply chain setup investments (e.g., production footprint, distribution network, and IT systems), which cannot be altered rapidly after the start of a crisis, we expect overages observed at the beginning of the crisis to also have a negative impact on the financial performance in the medium- to long-term. Thus, we hypothesize the following:

HyPOTHESIS 7. Inventory overages during the crisis period are negatively associated with financial performance during the crisis.

Similarly, firms that reduce their inventories too quickly as a reaction to a negative demand shock are expected to accumulate explicit and implicit costs as a consequence of inventory underages. Following a similar line of reasoning as above, we expect said costs to negatively impact financial performance. Underages impact margins through mechanisms such as express shipments (Olbert et al. 2016), emergency lateral transshipments (Paterson et al. 2011), and service penalties (Nahmias and Olsen 2015). These mechanisms, in turn, reduce profitability and negatively impact market and financial health performance metrics. Furthermore, given that underages are particularly relevant in a context in which demand recovers after an initial negative shock (Steinker et al. 2016), and considering the potential secondary effects related to the implicit costs discussed above (e.g., loss of customer goodwill; Aksen 2007), we expect the effect of inventory underages to be particularly relevant in the medium- to long-term after the initial shock. Thus, we hypothesize the following:

HyPOTHESIS 8. Inventory underages during the crisis period are negatively associated with financial performance during the crisis. 


\section{Methodology}

To test our conceptual model, we use quarterly financial data for U.S. publicly listed firms from the manufacturing sector (NAICS 31-33). All data are obtained from Standard \& Poor's COMPUSTAT North America database accessed via Wharton Research Data Services (WRDS). To study the inventory performance in the financial crisis, we select firm data for seven consecutive years from Q2/2005 to Q2/2011. We clean the raw dataset in several ways. First, we require firms to be reported for the entire period. Next, we exclude firms with observations with negative values for total assets, the cost of goods sold, and inventory or less than one million $\$$ in reported sales. To avoid distortion in computations of seasonality or double coverage of performance figures, we remove companies that change their fiscal end month during the observation timeframe, thereby assuring that the quarterly data for all companies is always exactly three months apart. Most firms report results in December, March, June, and September. Some companies, however, issue their reports one (106 firms) or two (74 firms) months later. For the sake of simplicity, we merge the quarterly reports of every three months to periods, assuming that the few later reports have been issued simultaneously with the majority. In line with standard financial economics literature, we winsorize relative metrics at the $1 \%$ level to control for outliers and erroneous data (Gompers et al. 2005, Larson et al. 2015). The above criteria resulted in a sample of 1,263 firms and a total of 30,312 firm-quarter observations. (See Table 8 in the Appendix for summary statistics by segment.)

\subsection{Variable operationalization}

The timing and magnitude of effects following a shock will, most likely, differ over different firms and industries. It is thus essential to define a common 'crisis timeline' for the analysis to yield comparable results. Accordingly, we distinguish between pre-crisis (Q3/2005 to Q2/2008) and crisis (Q3/2008 to Q2/2011) time periods. The former enables us to use the 'normal' firm behavior (before the outbreak of the crisis) as a baseline. We select Q2/2008 as a cutoff date, as Q3/2008 relates to the first quarter with a reduction in aggregate sales. In addition, the collapse of Lehmann Brothers on September 15, 2008-widely seen as the trigger of the financial crisis-falls into this quarter. We use the subscript $p$ to denote the time period, i.e., a quarter. We adopt the convention that a negative $p$ refers to a pre-crisis time period and positive periods $p$ refer to crisis time periods (thus, $p \in[-12, \ldots,-1] \cup[1, \ldots, 12]) . p=-1$ is the last pre-crisis period, and $p=1$ the subsequent period, defined as the onset of the crisis. We define the pre-crisis baseline, used to compute all aggregate metrics before the onset of the crisis, as the 2 years immediately preceding the onset of the crisis (i.e., $-8 \leq p \leq-1$ ). The results reported are robust to a 3 -year baseline. We use the subscript $i$ to distinguish firm-specific variables $(i=1, \ldots, 1263)$. Table 2 provides a summary of all the variables used in this study. 
Table 2 Description of variables.

\begin{tabular}{|c|c|c|c|}
\hline Variable & & Description & Reference \\
\hline \multicolumn{4}{|c|}{ Dependent variables: inventory performance } \\
\hline Inventory agility & $\left(\operatorname{Inv} A g_{i}^{P}\right)$ & $\begin{array}{l}\text { Maximum integral positive error (IPE) of inventory in the sample } \\
\text { minus the firms' normalized IPE of inventory; all metrics measured } \\
\text { from } p=1 \text { to } P \text {. }\end{array}$ & (Hoberg et al. 2007) \\
\hline Absolute inventory agility & $\left(A b \operatorname{Inv} A g_{i}^{P}\right)$ & $\begin{array}{l}\text { Maximum absolute IPE of inventory in the sample minus the firms' } \\
\text { absolute IPE of inventory; all metrics measured from } p=1 \text { to } P \text {. }\end{array}$ & (Hoberg et al. 2007) \\
\hline \multicolumn{4}{|l|}{ Independent variables: awareness } \\
\hline Market orientation & $(M k t O)$ & $\begin{array}{l}\text { Ratio of selling, general, and administrative (SGA) expenses to } \\
\text { total sales over } 12 \text { periods preceding the crisis. }\end{array}$ & $\begin{array}{l}\text { (Bahadir et al. } \\
2008, \text { Modi and } \\
\text { Mishra 2011) }\end{array}$ \\
\hline Technology orientation & $(\operatorname{TechO})$ & $\begin{array}{l}\text { Ratio of research and development }(\mathrm{R} \& \mathrm{D}) \text { expenses to total sales } \\
\text { averaged over } 12 \text { periods preceding the crisis. }\end{array}$ & $\begin{array}{l}\text { (Chen 2008, Vissa } \\
\text { et al. 2010) }\end{array}$ \\
\hline \multicolumn{4}{|l|}{ Independent variables: motivation } \\
\hline Gross Margin & $($ Gross $M)$ & $\begin{array}{l}\text { Total sales less cost of goods sold divided by total sales, averaged } \\
\text { over } 12 \text { periods preceding the crisis. }\end{array}$ & $\begin{array}{l}\text { (Rumyantsev and } \\
\text { Netessine 2007b) }\end{array}$ \\
\hline Liquidity & $(L i q)$ & $\begin{array}{l}\text { Ratio of current assets to current liabilities, averaged over } 12 \text { pe- } \\
\text { riods preceding the crisis. }\end{array}$ & $\begin{array}{l}\text { (Serpa and Krish- } \\
\text { nan 2017) }\end{array}$ \\
\hline \multicolumn{4}{|l|}{ Independent variables: capabilities } \\
\hline Inventory Management Capability & $(\operatorname{Inv} C a p)$ & $\begin{array}{l}\text { Predictability of inventories measured as } 1 \text { minus the ratio of in- } \\
\text { ventory days forecast error to total inventory days, averaged over } \\
12 \text { periods preceding the crisis. }\end{array}$ & (Kovach et al. 2015) \\
\hline Resource Availability & $(\operatorname{Res} A v)$ & $\begin{array}{l}\text { Resource availability (total invested capital less property, plant, } \\
\text { and equipment) averaged over } 12 \text { periods preceding the crisis. }\end{array}$ & (George 2005) \\
\hline \multicolumn{4}{|c|}{ Dependent variables: financial performance } \\
\hline Baseline Profitability & $\left(\mathrm{ROS}^{0}\right)$ & $\begin{array}{l}\text { Ratio of net income before extraordinary items to total sales aver- } \\
\text { aged over } 12 \text { periods preceding the crisis. }\end{array}$ & $\begin{array}{l}\text { (Hendricks and } \\
\text { Singhal 2005a) }\end{array}$ \\
\hline Crisis Profitability & $\left(\operatorname{ROS}^{P}\right)$ & $\begin{array}{l}\text { Ratio of net income before extraordinary items to total sales aver- } \\
\text { aged over } P \text { periods following the crisis. }\end{array}$ & $\begin{array}{l}\text { (Hendricks and } \\
\text { Singhal 2005a) }\end{array}$ \\
\hline Baseline Market Performance & $\left(\operatorname{TobQ}^{0}\right)$ & Tobin's Q, averaged over 12 periods preceding the crisis. & (Chen et al. 2005) \\
\hline Crisis Market Performance & $\left(\operatorname{TobQ}^{P}\right)$ & Tobin's $Q$, averaged over $P$ periods following the crisis. & (Chen et al. 2005) \\
\hline Baseline Financial Health & $\left(\mathrm{AltZ}^{0}\right)$ & Altman's Z score, averaged over 12 periods preceding the crisis. & $\begin{array}{l}\text { (Randall et al. } \\
2006)\end{array}$ \\
\hline Crisis Financial Health & $\left(\mathrm{AltZ}^{P}\right)$ & Altman's Z score, averaged over $P$ periods following the crisis. & $\begin{array}{l}\text { (Randall et al. } \\
2006)\end{array}$ \\
\hline \multicolumn{4}{|c|}{ Independent variables: financial performance } \\
\hline Cumulative inventory overage & $\left(|N I D|_{+}^{P}\right)$ & Mean of normalized inventory days IPE from $p=1$ to $P$. & (Hoberg et al. 2007) \\
\hline Cumulative inventory underage & $\left(|N I D|_{-}^{P}\right)$ & $\begin{array}{l}\text { Mean of normalized inventory days integral negative error (INE) } \\
\text { from } p=1 \text { to } P \text {. }\end{array}$ & (Hoberg et al. 2007) \\
\hline IPE of Sales & $\left(|N S A L E|_{+}^{P}\right)$ & Mean of normalized sales IPE from $p=1$ to $P$. & (Hoberg et al. 2007) \\
\hline INE of Sales & $\left(|N S A L E|_{-}^{P}\right)$ & Mean of normalized sales INE from $p=1$ to $P$. & (Hoberg et al. 2007) \\
\hline \multicolumn{4}{|l|}{ Control variables } \\
\hline Baseline Inventory Days & $(I D)$ & $\begin{array}{l}\text { Inventory days (ratio of total inventory to total cost of goods sold } \\
\text { multiplied by the average number of days in a quarter) averaged } \\
\text { over } 12 \text { periods preceding the crisis. }\end{array}$ & (Gaur et al. 2005) \\
\hline Baseline Lead Time & $(L T)$ & $\begin{array}{l}\text { Mean days accounts payable (ratio of total cost of goods sold to } \\
\text { total accounts payable multiplied by average number of days in a } \\
\text { quarter) over the } 12 \text { periods preceding the crisis. }\end{array}$ & $\begin{array}{l}\text { (Rumyantsev and } \\
\text { Netessine 2007b) }\end{array}$ \\
\hline Environmental Uncertainty & (EnvUncert) & $\begin{array}{l}\text { Unpredictability of the environment measured as the ratio of sales } \\
\text { forecast error to total sales, averaged over } 12 \text { periods preceding the } \\
\text { crisis. }\end{array}$ & (Kovach et al. 2015) \\
\hline Market Share & (MktShare) & $\begin{array}{l}\text { Market share of a firm defined as the ratio between firm sales and } \\
\text { total industry sales at the 3-digit NAICS level. }\end{array}$ & $\begin{array}{l}\text { (York and Miree } \\
2004)\end{array}$ \\
\hline Capital Intensity & (CapInt) & $\begin{array}{l}\text { A measure of utilization of resources calculated as the ratio be- } \\
\text { tween total assets and revenues. }\end{array}$ & (Gaur et al. 2005). \\
\hline Industry Dummies & $($ Ind $)$ & $\begin{array}{l}\text { Dummies defined at the } 3 \text {-digit NAICS level. (See Table } 8 \text { in the } \\
\text { Appendix.) }\end{array}$ & $\begin{array}{l}\text { (Rumyantsev and } \\
\text { Netessine 2007b) }\end{array}$ \\
\hline
\end{tabular}

\subsubsection{Normalizing and forecasting sales and inventories}

We denote the mean inventory days for firm $i$ in period $p$ as $I D_{i p}$. We compute this metric for a given period as the ratio of total ending inventory to total cost of goods sold times the 
average number of days per period. The inventory days metric is a common measure in operations management and is often referred to as a key performance indicator for inventory and supply chain planners, as inventory levels must reflect sales.

While the relative inventory in days of supply provides the basis for analyzing inventory dynamics in a single-firm setting, comparing the performance of multiple firms in the crisis requires an additional normalization to account for differences in relative inventories. Therefore, we compute the normalized inventory days $N I D_{i p}$ based on the 4-period mean pre-crisis inventory levels. We note that there are alternative measures for pre-crisis inventories that could be considered for the denominator of the normalization. For robustness, we tested our hypotheses using the inventory days measured in period $p=-1$. The results are consistent with those reported in this paper. Likewise, we define $N S A L E_{i p}$ as the normalized sales metric used to compare sales developments across firms.

Firm inventories and sales are dynamic figures that often follow a natural trend and seasonality. Over time, sales tend to increase due to regular growth, new product launches or new market introduction, whereas relative inventories tend to decrease due to better inventory management or lean management initiatives. Further, sales often peak in the fourth financial quarter due to sales incentives, and inventories are reduced for stock keeping and cash flow optimization. To quantify the effect of the credit crisis on sales and inventories, we need to control for these natural dynamics. Therefore, we use the pre-crisis baseline to estimate a forecasting model for inventories and sales for each firm and use an out-of-sample forecast to project what the expected sales and inventory dynamics would have been in the absence of a crisis. We apply different standard linear and seasonal forecasting approaches and select the approach with the best fit for the pre-crisis baseline (see the Appendix for a detailed discussion). Using this methodology, we estimate the projected inventory days for each crisis period $\left(\widehat{I D}_{i p}\right)$, as well as the projected normalized inventory days $\left(\widehat{N I D}_{i p}\right)$, projected sales $\left(\widehat{S A L E}_{i p}\right)$, and projected normalized sales $\left(\widehat{N S A L} E_{i p}\right)$.

\subsubsection{Dependent measures: inventory performance}

We use four different metrics to quantify firms' dynamic response to the onset of the crisis, i.e., the integral positive error (IPE) of inventories, the IPE of sales, the integral negative error (INE) of inventories, and the INE of sales. Similarly, we use three different metrics to quantify the dynamic aspect of firms' profitability, market performance, and financial health, i.e., Return-on-sales, Tobin's Q, and Altman's Z. In all cases, we follow a common approach from the control-theoretic inventory management literature (e.g., Hoberg and Thonemann 2015); we compute each metric for every quarter in the sample, and aggregate over different periods to capture their dynamics. Below, we describe the measurement procedure for each metric in detail. 
Integral Errors. The integral error is widely used to quantify the speed of response of a dynamic system (Nise 2011). The intuition behind this metric is that, following a shock, any deviation from the target state should be penalized. Thus, the integral error is defined for any arbitrary time span as the sum of all the deviations from the target state. Hoberg et al. (2007) detail the application of integral errors as a way to measure the inventory and order response of an inventory system, which we adopt. Using the projected normalized inventory days $\left(\widehat{N I D}_{i p}\right)$ as the target state for the in-crisis period, the integral error for inventory allows us to evaluate the inventory agility of any given firm. As the integral error lowers, the firm's agility increases. Similarly, we use the projected normalized sales $\left(\widehat{N S A L} E_{i p}\right)$ to calculate the integral error for sales and thus evaluate the sales surprise during the crisis.

In contrast to the operations management literature (see, e.g., Hoberg et al. 2007, Eroglu and Hofer 2011) and due to the crisis context, we distinguish between positive and negative deviations from the inventory targets. We measure the IPE as the mean sum over $P$ periods of the positive deviations between actual values and projections, and the INE as the sum over $P$ periods of the corresponding negative deviations. The IPE metric that quantifies surplus in normalized inventory days is formally defined as follows:

$$
\left|N I D_{i}\right|_{+}^{P}=\sum_{p=1}^{P} \max \left(0, N I D_{i p}-\widehat{N I D}_{i p}\right),
$$

where $\left|N I D_{i}\right|_{+}^{P}$ is the IPE of normalized inventory days for firm $i$ up to period $P$. Likewise, we use the negative deviations from the projections to compute the INE of normalized inventory days $\left(\left|N I D_{i}\right|_{-}^{P}\right)$ and define the measures of IPE of absolute inventory days $\left(\left|I D_{i}\right|_{+}^{P}\right)$, INE of absolute inventory days $\left(\left|I D_{i}\right|_{-}^{P}\right)$, normalized sales surplus $\left|N S A L E_{i}\right|_{+}^{P}$, and normalized sales deficit $\left|N S A L E_{i}\right|_{-}^{P}$ correspondingly. Figure 4 illustrates the intuition behind these metrics. IPE measures cumulative surplus from the onset of the crisis up to time $P$, while INE measures cumulative deficits. We capture the dynamics of the response by varying the aggregation time period $P$. Setting $P=\{4,8,12\}$ we quantify the short-, medium-, and long-term performance of a given firm during the crisis.

Note that in this way, $\left|N I D_{i}\right|_{+}^{P}$ and $\left|N I D_{i}\right|_{-}^{P}$ provide a direct measure of the cumulative invetory overage and underage (respectively) from the start of the crisis up to time $P$. Furthermore, as Figure 4 shows, it's possible for a firm to have both overages and underages over a given aggregation time period; with simultaneous high values for overage and underage indicating substantial inventory dynamics. 


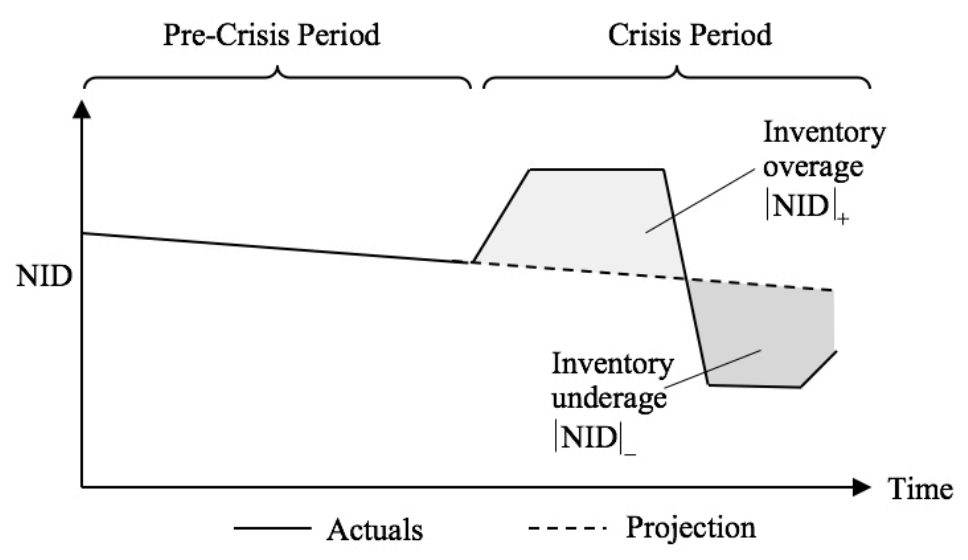

Figure 4 Concept of inventory performance metrics.

Inventory agility (InvAg). Figure 1 shows that inventory days increased with the onset of the crisis. Thus, we quantify the inventory agility of firm $i$ in response to the crisis over $P$ periods $\left(\operatorname{InvAg_{i}^{P}}\right)$ as $\left|N I D_{i}\right|_{+}^{\max }-\left|N I D_{i}\right|_{+}^{P}$, with $\left|N I D_{i}\right|_{+}^{\text {max }}$ the maximum IPE of normalized inventory days in the sample. We define the absolute inventory agility $\left(A b \operatorname{Inv} A g_{i}^{P}\right)$ accordingly, using the IPE of absolute inventory days.

Profitability (ROS). We measure profitability with the return on sales (ROS) metric. ROS is an accounting-based metric that measures the operating profit of a firm as the ratio of profit to sales (Kovach et al. 2015). We use Compustat data to determine the $R O S$ of firm $i$ in period $p$ $\left(R O S_{i p}\right)$ as the ratio of the net income in period $p$ and the average sales reported in periods $p$ and $p-1$. We calculate the mean $R O S$ during the 8 quarters preceding the crisis to establish a baseline of profitability per company, $R O S_{i}^{0}$. We establish snapshots of the profitability after the onset of the crisis by measuring the mean $R O S$ over $P$ crisis periods, $R O S_{i}^{P}$. We use this approach for all remaining dependent variables (market performance and financial health).

Market performance (TobQ). In line with operations management research (e.g., Chen et al. 2005), we use Tobin's Q to assess the market performance and expectations of a firm. Introduced by Brainard and Tobin (1968), Tobin's Q measures a firm's 'intangible assets' by calculating the ratio of the total market value of a firm to its total assets. A high (low) Q ratio indicates a firm that is valued by the market at a higher (lower) price than it is indicated purely by value of its assets, which indicates a positive (negative) sentiment from the markets.

Financial health (AltZ). Following research in the field (e.g., Sudarsanam and Lai 2001), we use Altman's Z score to assess the financial health of a firm. This metric quantifies a firm's probability of bankruptcy — as the score decreases, the bankruptcy probability increases (Altman 1968). We 
compute Altman's Z score using data from Compustat following the methodology of Randall et al. (2006). Alt $Z_{i p}$ is the Altman's Z score for firm $i$ in period $p$, and all the financial variables are as reported by company $i$ in period $p$.

\subsubsection{Independent measures: awareness}

Based on prior literature, we identify two measures that allow us to capture relevant dimensions of the awareness of a firm; market orientation and technology orientation. Market orientation is measured by taking the mean marketing intensity of a firm during the pre-crisis baseline. Technological awareness is measured by taking the mean $\mathrm{R} \& \mathrm{D}$ intensity of a firm during the pre-crisis baseline.

Market Orientation (MktO). Marketing enables firms to establish their brand in the market and to develop products and services that are aligned with consumers' expectations. To quantify the extent to which a firm uses marketing instruments, we adopt the concept of Market Orientation (MktO), widely studied in the marketing literature (Gupta et al. 2017). Formally, MktO refers to a firm's active investigation of its customers and competitors ("Market Intelligence") as well as its timely response to emerging opportunities and threats ("Market Responsiveness") (Özturan et al. 2014). Firms with high MktO build up capabilities to track and react to market changes and downstream demand signals. We argue that such firms are aware not only of the behavior of their consumers, but also of the relevant developments in their marketspace. Of particular relevance to this study, is the observation that MktO and advertising spending are of particular value to firms in times of economic contraction (see e.g., Srinivasan et al. 2005, Steenkamp and Fang 2011, Özturan et al. 2014, Gyulavári and Kolos 2015).

Consistent with prior research in marketing and operations (e.g., Wuyts et al. 2004, Lin et al. 2006, Bahadir et al. 2008, Modi and Mishra 2011), we use firms' selling, general, and administrative (SGA) expenses as a measure of their marketing capabilities. While SGA also includes items that are not strictly within the domain of marketing, researchers in the marketing field argue that "it is a good proxy for the amount the firm spends on its market research, sales effort, trade expenses, and other related activities" (Dutta et al. 1999). We compute the marketing intensity of a given firm through the ratio of SGA expenses to its sales, and capture the pre-crisis Market Orientation $\left(M k t O_{i}\right)$ of firm $i$ as its average marketing intensity during the pre-crisis baseline. A high (low) $M k t O_{i}$ indicates a firm with a high (low) percentage of its revenues invested in marketing its products/services and, thus, a high (low) awareness of the developments in their market.

Technology Orientation (TechO). Prior research has established that investments in R\&D resources are not only associated with product performance and innovativeness but also with a firm's capabilities to develop products aligned with the requirements of the customer base and to speed 
up product developments (Song et al. 2011). Similarly, firms that dedicate considerable resources to $R \& D$ processes are likely to be aware of their positioning, at the product line and technology levels, with regard to their competition.

Consistent with prior research (e.g., Chen 2008, Vissa et al. 2010), we compute R\&D intensity as the ratio of total $\mathrm{R} \& \mathrm{D}$ expenses to sales. We capture the technology orientation of firm $i$ prior to the crisis $\mathrm{Tech}_{i}$ as its average $\mathrm{R} \& \mathrm{D}$ intensity during the pre-crisis baseline. A high (low) Tech $O_{i}$ indicates a firm with a high (low) percentage of its revenues invested in developing new products and/or processes and, thus, a high (low) awareness of their positioning within the market with regard to their technological development.

\subsubsection{Independent measures: motivation}

We developed two constructs to capture a firm's motivation to manage inventories in an agile manner, i.e., operational motivation and liquidity motivation. The operational motivation is inversely proportional to the mean gross margin of a firm during the pre-crisis baseline. The financial motivation is inversely proportional to the mean current ratio of a firm during the pre-crisis baseline.

Gross Margin (GrossM). Operations management literature supports a relationship between the gross margin and the optimal inventory level. Following the classical newsvendor logic (Rumyantsev and Netessine 2007b), an increase (decrease) in the gross margin implies an increase (decrease) in the penalty cost of stockouts relative to the holding cost of surplus inventories. This finding indicates that, when faced with a sudden decrease in demand, a firm with low gross margins faces more pressure than a firm with high gross margins to align its inventory level to the new realities.

Following existing research (e.g., Gaur et al. 2005), we compute the gross margin as the percentage difference between net sales and the cost of goods sold over the pre-crisis baseline. A high (low) Gross $_{i}$ indicates a firm prone to avoiding any inventory overage (underage) and, thus, a motivation (indifference) to manage inventories in an agile manner.

Liquidity ( $\mathbf{L i q}$ ). Recent research in the operations management and economics literature supports the argument that inventory decisions in times of crisis are driven, to a certain extent, by liquidity considerations (see, e.g., Escaith et al. 2010, Steinker et al. 2016). Inventory liquidations are a source of cash. Thus, a firm with low liquidity is motivated to react in an agile way to a decrease in demand by quickly transforming inventories into cash on hand. We assess the liquidity $L i q_{i}$ of a firm as its mean current ratio (the ratio between current assets to current liabilities) during the pre-crisis baseline. A firm with a high $\operatorname{LiqM}_{i}$ is motivated to respond in an agile manner at the onset of a crisis, generating cash through inventory disinvestment. 


\subsubsection{Independent measures: capabilities}

We developed two measures to capture the capabilities of a firm to manage inventories in an agile manner, i.e., inventory management capability and resource availability. Consistent with the operations management literature, we assess the capability to manage inventories through the inventory predictability of a firm during the pre-crisis baseline. Consistent with the strategic management literature, we measure resource capabilities through slack resources.

Inventory Management Capability (InvCap). We assess the capability of a firm to control inventories by measuring the predictability of inventories during the pre-crisis baseline. Consistent with the extant literature (e.g., Chen and Lee 2009, Kovach et al. 2015), we argue that controlling unexpected variability (i.e., uncertainty) is an indicator of superior performance. A firm with high inventory predictability (low uncertainty) thus exhibits the ability to adapt their inventory levels to exogenous (unexpected variability). We follow current literature (Kovach et al. 2015) and compute the inventory unpredictability as the absolute value of the difference between projected inventory days and actual inventory days, scaled by actual inventory days. Next, we assess the inventory management capability of a given firm by measuring its complement (i.e., 1-inventory unpredictability) during the pre-crisis baseline period. A high InvCap indicates a firm with high capabilities to control inventory uncertainty.

Resource availability (ResAv). Slack resources have been widely used in the strategic management literature to measure the amount of resources available for a firm and have been found to increase firm performance under certain conditions. In line with George (2005), we compute the availability of a firms' resources as the total invested capital (i.e., long-term debt plus preferred stock plus minority interest plus common equity) less production resources (i.e., plant, property, and equipment), averaged during the pre-crisis baseline. A high ResAv $v_{i}$ indicates significant slack, i.e., available financial resources to fund potential investments. Conversely, a lower ResAvi suggests a firm that has a large portion of its capital invested in production resources and, thus, unavailable for investment.

\subsubsection{Control variables}

In addition to the independent variables outlined above, we include the following firm-level and industry-level control variables that may further affect firms' inventory agility.

Inventory Days (ID). Firms that normally operate with lower inventory days could be more responsive during the crisis. We measure the baseline for inventory days as the mean inventory days for each firm during the pre-crisis baseline. 
Lead Time (LT). Rumyantsev and Netessine (2007b) show that lead time can explain a significant portion of inventory changes. Hence, we adopt their methodology and construct an estimate of the baseline lead time for each firm. We estimate the lead time for a given firm in a given period as the ratio of total cost of goods sold to accounts payable multiplied by the average number of days in a period, i.e., the days accounts payable. We measure the baseline lead time as the mean days accounts payable per firm during the pre-crisis baseline.

Environmental Uncertainty (EnvUncert). We evaluate the environmental uncertainty of a firm by measuring the unpredictability of its environment. In line with Kovach et al. (2015), we measure firm-level unpredictability as the portion of sales during a period that historically have been difficult to forecast (calculated as described in Table 2). We capture the environmental uncertainty of a firm as the average unpredictability during the pre-crisis baseline aggregated at the industry level.

Market Share (MktShare). It is possible that firms with dominant market positions adjust their investments and priorities differently than firms in less dominant positions. Thus, we control for differences related to market share. We measure the market share of each firm in the sample relative to its 3-digit NAICS industry level.

Capital Intensity (CapInt). To control for differences in the utilization of resources of different firms, we use capital intensity as a control variable, calculated as the ratio between total assets and total revenues (Gaur et al. 2005).

Industry Dummies (Ind). To control for inherent differences between industries by including a segment (based on 3-digit NAICS) dummy variable as a control. See Table 8 for the detailed composition of each segment. We use the Food, Beverage, and Tobacco industry (comprised of NAICS codes 311 and 312) as the baseline.

\subsection{Descriptive statistics}

Table 3(a) summarizes the inventory performance metrics per segment. The corresponding sales metrics are in Table 9 in the Appendix. There is significant heterogeneity in the responses of the different subsectors (a Kruskal-Wallis $\mathrm{H}$ test revealed a statistically significant difference at the $p<0.05$ level for $|N I D|_{-}^{12}$ and at the $p<0.01$ level for all others). Some subsectors (e.g., Food, Beverage, \& Tobacco) are more responsive than others (e.g., Machinery). Interestingly, the segments with above-average sales decreases $\left(|N S A L E|_{-}\right)$also exhibit an above-average inventory overage $\left(|N I D|_{+}\right)$and a below-average inventory underage $\left(|N I D|_{-}\right)$. This finding implies that the magnitude of the shock limits the responsiveness of a firm. A possible explanation for this effect is related to the evolution of the different inventory components. Work in process (WIP) inventories are the most 
agile (see Table 10 in the Appendix), and as demand continues to fall, firms are unable to adapt their inventories of raw material and finished goods. Note, however, that there is also heterogeneity in firms' responses in a particular segment, as indicated by the simultaneous positive indicators of inventory underage and overage, and signals that firms responded to the crisis in different ways.

Heterogeneity is also present in financial performance. Table 3(b) summarizes the financial metrics per segment (a Kruskal-Wallis H test revealed a statistically significant difference at the $p<0.05$ level for $A l t Z_{\text {crisis }}^{4}$ and at the $p<0.01$ level for all others). On one hand, the pre-crisis financial metrics appear to be good indicators of relative performance during the crisis (i.e., sectors such as Chemicals 8 Plastics, which generally had above-average pre-crisis indicators, also had aboveaverage crisis indicators). On the other hand, performance over time varied greatly across segments. Some (e.g., Food, Beverage, \& Tobacco) weathered the crisis with relative stability, while others (e.g., Computer, Electronics, \& Equipment) suffered higher volatility.

Table 4 shows the summary statistics and correlation for all the variables in our sample dataset. Detailed summary statistics per segment are available for other firm variables in Table 8 in the appendix. As expected, pre- and post-crisis metrics exhibit a relatively high degree of correlation in certain cases. Otherwise, correlation is not a major concern. We tested for multicollinearity among the predictors in every model specification. In all cases, tolerance (1/Variance Inflation Factor)> 0.25 , which suggests that multicollinearity is not a major problem in our dataset.

\subsection{Model specification}

\subsubsection{Inventory agility - base model}

We develop two regression models to test the proposed inventory performance hypotheses. A base model (hereafter, model I) that assumes no interactions among the independent variables and a constraining factor model (model II) that allows for a more subtle analysis of the performance.

In line with previous operations management research (Gaur et al. 2005, Rumyantsev and Netessine 2007a), we test our base model through multiplicative regressions: using normalized inventory days and one using absolute inventory days as a dependent variable. Accordingly, we propose the following specification to model the inventory agility during the crisis time period for firm $i$ :

$$
\begin{aligned}
D P M=\beta_{0} & +\beta_{1} \log (M k t O)+\beta_{2} \log (\text { TechO })+\beta_{3} \log (\operatorname{Gross} M)+\beta_{4} \log (\operatorname{Liq})+\beta_{5} \log (\operatorname{Inv} \text { Cap })+\beta_{6} \log (\operatorname{ResAv}) \\
& +\beta_{7} \log (I D)+\beta_{8} \log (\text { LT })+\beta_{9} \log (\text { EnvUncert })+\beta_{10} \log (\text { MktShare })+\beta_{11} \log (\text { CapInt }) \\
& +\beta_{12} \log \left(|N S A L E|_{+}^{P}\right)+\beta_{13} \text { Ind }+\epsilon
\end{aligned}
$$

where the subscript $i$ on the variables is omitted for notational ease and $D P M$ refers to one of the performance metrics $\left(D P M=\left\{\log (\operatorname{Inv} A g)^{P}, \log (A b s \operatorname{Inv} A g)^{P}\right\}\right)$ at the time aggregation level $P=\{4,8,12\}$. We use a log-log specification because it can account for heteroscedasticity in the 
Table 3 Descriptive statistics of inventory and financial performance measures.

\begin{tabular}{|c|c|c|c|c|c|c|}
\hline Industry & $\begin{array}{c}|N I D|_{+}^{4} \\
\text { Mean } \\
\text { (Median, SD) }\end{array}$ & $\begin{array}{c}|N I D|_{+}^{8} \\
\text { Mean } \\
\text { (Median, SD) }\end{array}$ & $\begin{array}{c}\mid \text { NID }\left.\right|_{+} ^{12} \\
\text { Mean } \\
\text { (Median, SD) }\end{array}$ & $\begin{array}{c}|N I D|_{-}^{4} \\
\text { Mean } \\
\text { (Median, SD) }\end{array}$ & $\begin{array}{c}\mid \text { NID }\left.\right|_{-} ^{8} \\
\text { Mean } \\
\text { (Median, SD) }\end{array}$ & $\begin{array}{c}\mid \text { NID }\left.\right|_{-} ^{12} \\
\text { Mean } \\
\text { (Median, SD) }\end{array}$ \\
\hline Food, Beverage, \& Tobacco & $\begin{array}{c}0.41 \\
(0.1,0.74)\end{array}$ & $\begin{array}{c}0.76 \\
(0.23,1.54)\end{array}$ & $\begin{array}{c}1.32 \\
(0.39,3.26)\end{array}$ & $\begin{array}{c}0.37 \\
(0.21,0.49)\end{array}$ & $\begin{array}{c}0.97 \\
(0.54,1.14)\end{array}$ & $\begin{array}{c}1.66 \\
(1.16,1.81)\end{array}$ \\
\hline Textiles, Apparel, \& Leather & $\begin{array}{c}0.33 \\
(0.19,0.41)\end{array}$ & $\begin{array}{c}0.57 \\
(0.31,0.75)\end{array}$ & $\begin{array}{c}1.13 \\
(0.6,1.33)\end{array}$ & $\begin{array}{c}0.30 \\
(0.14,0.54)\end{array}$ & $\begin{array}{c}0.88 \\
(0.55,1.36)\end{array}$ & $\begin{array}{c}1.33 \\
(0.73,2.32)\end{array}$ \\
\hline Paper \& Publishing & $\begin{array}{c}0.58 \\
(0.35,0.66)\end{array}$ & $\begin{array}{c}1.10 \\
(0.58,1.36)\end{array}$ & $\begin{array}{c}1.91 \\
(0.87,2.42)\end{array}$ & $\begin{array}{c}0.14 \\
(0.04,0.22)\end{array}$ & $\begin{array}{c}0.39 \\
(0.14,0.44)\end{array}$ & $\begin{array}{c}0.67 \\
(0.15,0.76)\end{array}$ \\
\hline Chemicals \& Plastics & $\begin{array}{c}0.79 \\
(0.35,1.61)\end{array}$ & $\begin{array}{c}1.70 \\
(0.52,3.44)\end{array}$ & $\begin{array}{c}2.84 \\
(0.78,6.17)\end{array}$ & $\begin{array}{c}0.28 \\
(0.12,0.42)\end{array}$ & $\begin{array}{c}0.78 \\
(0.48,1.02)\end{array}$ & $\begin{array}{c}1.40 \\
(0.77,1.81)\end{array}$ \\
\hline Metal & $\begin{array}{c}1.05 \\
(0.56,1.51)\end{array}$ & $\begin{array}{c}1.89 \\
(0.98,2.91)\end{array}$ & $\begin{array}{c}2.85 \\
(1.13,5.06)\end{array}$ & $\begin{array}{c}0.2 \\
(0.1,0.27)\end{array}$ & $\begin{array}{c}0.59 \\
(0.38,0.68)\end{array}$ & $\begin{array}{c}1.10 \\
(0.65,1.28)\end{array}$ \\
\hline Machinery & $\begin{array}{c}0.93 \\
(0.67,1.00)\end{array}$ & $\begin{array}{c}1.58 \\
(1.1,1.66)\end{array}$ & $\begin{array}{c}2.19 \\
(1.28,2.5)\end{array}$ & $\begin{array}{c}0.21 \\
(0.06,0.37)\end{array}$ & $\begin{array}{c}0.62 \\
(0.23,0.9)\end{array}$ & $\begin{array}{c}1.22 \\
(0.57,1.62)\end{array}$ \\
\hline Computer, Electr., \& Equip. & $\begin{array}{c}0.98 \\
(0.51,1.45)\end{array}$ & $\begin{array}{c}1.88 \\
(0.92,3.18)\end{array}$ & $\begin{array}{c}3.09 \\
(1.38,5.7)\end{array}$ & $\begin{array}{c}0.30 \\
(0.08,0.58)\end{array}$ & $\begin{array}{c}0.9 \\
(0.35,1.44)\end{array}$ & $\begin{array}{c}1.6 \\
(0.53,2.54)\end{array}$ \\
\hline Transportation Equipment & $\begin{array}{c}1.12 \\
(0.62,1.35)\end{array}$ & $\begin{array}{c}1.86 \\
(1.05,2.14)\end{array}$ & $\begin{array}{c}2.78 \\
(1.57,3.36)\end{array}$ & $\begin{array}{c}0.11 \\
(0,0.22)\end{array}$ & $\begin{array}{c}0.45 \\
(0.12,0.73)\end{array}$ & $\begin{array}{c}0.94 \\
(0.24,1.42)\end{array}$ \\
\hline Other & $\begin{array}{c}0.71 \\
(0.44,0.89)\end{array}$ & $\begin{array}{c}1.38 \\
(0.77,2.08)\end{array}$ & $\begin{array}{c}2.21 \\
(1.01,3.7)\end{array}$ & $\begin{array}{c}0.3 \\
(0.1,0.49)\end{array}$ & $\begin{array}{c}0.81 \\
(0.36,1.18)\end{array}$ & $\begin{array}{c}1.45 \\
(0.63,2.11) \\
\end{array}$ \\
\hline To & $\begin{array}{c}0.84 \\
(0.44,1.31)\end{array}$ & $\begin{array}{c}1.60 \\
(0.72,2.73)\end{array}$ & $\begin{array}{c}2.58 \\
(1.06,4.84)\end{array}$ & $\begin{array}{c}0.27 \\
(0.09,0.48)\end{array}$ & $\begin{array}{c}0.78 \\
(0.37,1.18)\end{array}$ & $\begin{array}{c}1.4 \\
(0.63,2.08)\end{array}$ \\
\hline
\end{tabular}

(a) Inventory performance

\begin{tabular}{|c|c|c|c|c|c|c|c|c|c|}
\hline Industry & $\begin{array}{c}R^{\prime} O S^{4} \\
\text { Mean } \\
\text { (Median, SD) }\end{array}$ & $\begin{array}{c}R O S^{8} \\
\text { Mean } \\
\text { (Median, SD) }\end{array}$ & $\begin{array}{c}R S^{12} \\
\text { Mean } \\
\text { (Median, SD) }\end{array}$ & $\begin{array}{c}\text { TobQ } Q^{4} \\
\text { Mean } \\
\text { (Median, SD) }\end{array}$ & $\begin{array}{c}T o b Q^{8} \\
\text { Mean } \\
\text { (Median, SD) }\end{array}$ & $\begin{array}{c}T o b Q^{12} \\
\text { Mean } \\
\text { (Median, SD) }\end{array}$ & $\begin{array}{c}\text { Alt } Z^{4} \\
\text { Mean } \\
\text { (Median, SD) }\end{array}$ & $\begin{array}{c}\text { Alt } Z^{8} \\
\text { Mean } \\
\text { (Median, SD) }\end{array}$ & $\begin{array}{c}\text { Alt } Z^{12} \\
\text { Mean } \\
\text { (Median, SD) }\end{array}$ \\
\hline Food, Beverage, \& Tobacco & $\begin{array}{c}0.07 \\
(0.07,0.11)\end{array}$ & $\begin{array}{c}0.08 \\
(0.08,0.11)\end{array}$ & $\begin{array}{c}0.08 \\
(0.08,0.12)\end{array}$ & $\begin{array}{c}1.23 \\
(0.95,0.77)\end{array}$ & $\begin{array}{c}1.31 \\
(1.09,0.80)\end{array}$ & $\begin{array}{c}1.37 \\
(1.13,0.83)\end{array}$ & $\begin{array}{c}2.13 \\
(1.47,2.3)\end{array}$ & $\begin{array}{c}2.33 \\
(1.59,2.61)\end{array}$ & $\begin{array}{c}2.37 \\
(1.65,2.80)\end{array}$ \\
\hline Textiles, Apparel, \& Leather & $\begin{array}{c}0.04 \\
(0.06,0.09)\end{array}$ & $\begin{array}{c}0.05 \\
(0.06,0.09)\end{array}$ & $\begin{array}{c}0.05 \\
(0.06,0.09)\end{array}$ & $\begin{array}{c}0.7 \\
(0.56,0.49)\end{array}$ & $\begin{array}{c}0.8 \\
(0.68,0.54)\end{array}$ & $\begin{array}{c}0.88 \\
(0.80,0.56)\end{array}$ & $\begin{array}{c}2.57 \\
(1.70,2.76)\end{array}$ & $\begin{array}{c}2.97 \\
(2.27,3.12)\end{array}$ & $\begin{array}{c}3.13 \\
(2.37,3.35)\end{array}$ \\
\hline Paper \& Publishing & $\begin{array}{c}0.06 \\
(0.05,0.08)\end{array}$ & $\begin{array}{c}0.06 \\
(0.06,0.07)\end{array}$ & $\begin{array}{c}0.07 \\
(0.06,0.06)\end{array}$ & $\begin{array}{c}0.73 \\
(0.68,0.39)\end{array}$ & $\begin{array}{c}0.78 \\
(0.74,0.39)\end{array}$ & $\begin{array}{c}0.81 \\
(0.77,0.40)\end{array}$ & $\begin{array}{c}0.97 \\
(0.86,0.96)\end{array}$ & $\begin{array}{c}1.05 \\
(0.91,1.03)\end{array}$ & $\begin{array}{c}1.11 \\
(0.94,1.07)\end{array}$ \\
\hline Chemicals \& Plastics & $\begin{array}{c}0.03 \\
(0.07,0.28)\end{array}$ & $\begin{array}{c}0.04 \\
(0.08,0.29)\end{array}$ & $\begin{array}{c}0.04 \\
(0.08,0.30)\end{array}$ & $\begin{array}{c}1.32 \\
(0.88,1.41)\end{array}$ & $\begin{array}{c}1.4 \\
(0.96,1.50)\end{array}$ & $\begin{array}{c}1.5 \\
(1.05,1.49)\end{array}$ & $\begin{array}{c}1.97 \\
(1.34,4.71)\end{array}$ & $\begin{array}{c}1.99 \\
(1.64,5.2)\end{array}$ & $\begin{array}{c}2.01 \\
(1.75,6.09)\end{array}$ \\
\hline Metal & $\begin{array}{c}0.03 \\
(0.04,0.13)\end{array}$ & $\begin{array}{c}0.05 \\
(0.05,0.10)\end{array}$ & $\begin{array}{c}0.06 \\
(0.05,0.08)\end{array}$ & $\begin{array}{c}0.83 \\
(0.69,0.67)\end{array}$ & $\begin{array}{c}0.89 \\
(0.68,0.75)\end{array}$ & $\begin{array}{c}0.97 \\
(0.81,0.90)\end{array}$ & $\begin{array}{c}2.06 \\
(1.52,3.21)\end{array}$ & $\begin{array}{c}2.23 \\
(1.55,3.19)\end{array}$ & $\begin{array}{c}2.45 \\
(1.70,3.39)\end{array}$ \\
\hline Machinery & $\begin{array}{c}-0.02 \\
(0.05,0.31)\end{array}$ & $\begin{array}{c}0.02 \\
(0.06,0.21)\end{array}$ & $\begin{array}{c}0.04 \\
(0.07,0.18)\end{array}$ & $\begin{array}{c}0.87 \\
(0.74,0.76)\end{array}$ & $\begin{array}{c}0.99 \\
(0.84,0.83)\end{array}$ & $\begin{array}{c}1.10 \\
(0.94,0.85)\end{array}$ & $\begin{array}{c}1.6 \\
(1.67,5.09)\end{array}$ & $\begin{array}{c}1.88 \\
(1.96,5.05)\end{array}$ & $\begin{array}{c}2.07 \\
(2.19,4.86)\end{array}$ \\
\hline Computer, Electr., \& Equip. & $\begin{array}{c}-0.07 \\
(0.01,0.4)\end{array}$ & $\begin{array}{c}-0.04 \\
(0.03,0.38)\end{array}$ & $\begin{array}{c}-0.02 \\
(0.03,0.32)\end{array}$ & $\begin{array}{c}0.97 \\
(0.66,1.33)\end{array}$ & $\begin{array}{c}1.14 \\
(0.77,1.64)\end{array}$ & $\begin{array}{c}1.24 \\
(0.86,1.84)\end{array}$ & $\begin{array}{c}1.41 \\
(1.59,9.23)\end{array}$ & $\begin{array}{c}1.52 \\
(1.87,10.46)\end{array}$ & $\begin{array}{c}1.64 \\
(2.10,11.48)\end{array}$ \\
\hline Transportation Equipment & $\begin{array}{c}0.01 \\
(0.02,0.19)\end{array}$ & $\begin{array}{c}0.03 \\
(0.04,0.16)\end{array}$ & $\begin{array}{c}0.04 \\
(0.05,0.14)\end{array}$ & $\begin{array}{c}0.78 \\
(0.60,0.97)\end{array}$ & $\begin{array}{c}0.87 \\
(0.71,1.08)\end{array}$ & $\begin{array}{c}0.97 \\
(0.76,1.24)\end{array}$ & $\begin{array}{c}1.17 \\
(1.33,4.41)\end{array}$ & $\begin{array}{c}1.21 \\
(1.44,4.99)\end{array}$ & $\begin{array}{c}1.28 \\
(1.40,5.44)\end{array}$ \\
\hline Other & $\begin{array}{c}0.02 \\
(0.05,0.18)\end{array}$ & $\begin{array}{c}0.03 \\
(0.06,0.17)\end{array}$ & $\begin{array}{c}0.03 \\
(0.05,0.19)\end{array}$ & $\begin{array}{c}0.98 \\
(0.81,0.77)\end{array}$ & $\begin{array}{c}1.06 \\
(0.86,0.90)\end{array}$ & $\begin{array}{c}1.13 \\
(0.89,0.93)\end{array}$ & $\begin{array}{c}1.47 \\
(1.42,4.75)\end{array}$ & $\begin{array}{c}1.58 \\
(1.56,5.12)\end{array}$ & $\begin{array}{c}1.73 \\
(1.64,4.79)\end{array}$ \\
\hline Total & $\begin{array}{c}-0.01 \\
(0.04,0.3)\end{array}$ & $\begin{array}{c}0.01 \\
(0.05,0.28)\end{array}$ & $\begin{array}{c}0.02 \\
(0.06,0.25)\end{array}$ & $\begin{array}{c}1.00 \\
(0.73,1.11)\end{array}$ & $\begin{array}{c}1.11 \\
(0.83,1.29)\end{array}$ & $\begin{array}{c}1.2 \\
(0.89,1.40)\end{array}$ & $\begin{array}{c}1.63 \\
(1.48,6.42)\end{array}$ & $\begin{array}{c}1.77 \\
(1.65,7.17)\end{array}$ & $\begin{array}{c}1.87 \\
(1.78,7.79)\end{array}$ \\
\hline
\end{tabular}

(b) Financial performance

$|N I D|_{+}^{P}$ : Integral Positive Error of Normalized Inventory Days up to period $P ;|N I D|_{-}^{P}$ : Integral Negative Error of Normalized Inventory Days up to period $P$; ROS: Return on Sales; TobQ: Tobin's Q; AltZ: Altman's Z.

data, and this specification has shown the best results in prior studies (Rumyantsev and Netessine 2007b). Additionally, note that even though our dataset is a balanced panel, Equation (2) uses aggregate variables per firm to construct a series of cross-sectional snapshots at one, two and three years after the onset of the crisis. Thus, we do not include period- or firm-specific controls.

\subsubsection{Inventory agility - constraining factor model}

The regression specification of Equation (2) assumes independent effects for each of the independent variables. In operations management, however, we often find the concept of resource constraints to explain complex interactions among variables. The literature in the context of project management and resource scheduling is extensive (Morris 2013, Sommer et al. 2014, Svejvig and Andersen 2015). In such applications, the interpretation is immediate; in scheduling and planning, identifying a bottleneck implies identifying the most logical aspect of a system to improve. In behavioral 
Table 4 Summary statistics and correlation table.

\begin{tabular}{|c|c|c|c|c|c|c|c|c|c|c|c|c|c|c|c|c|c|c|c|c|c|c|c|}
\hline & Mean & SD & 1 & 2 & 3 & 4 & 5 & 6 & 7 & 8 & 9 & 10 & 11 & 12 & 13 & 14 & 15 & 16 & 17 & 18 & 19 & 20 & 21 \\
\hline $1 \operatorname{ROS}^{12}$ & 0.02 & 0.25 & 1 & & & & & & & & & & & & & & & & & & & & \\
\hline $2 R O S^{0}$ & 0.03 & 0.24 & 0.75 & 1 & & & & & & & & & & & & & & & & & & & \\
\hline $3 \quad \operatorname{Tob} Q^{12}$ & 1.20 & 1.40 & -0.37 & -0.39 & 1 & & & & & & & & & & & & & & & & & & \\
\hline $4 T o b Q^{0}$ & 1.59 & 1.46 & -0.18 & -0.25 & 0.74 & 1 & & & & & & & & & & & & & & & & & \\
\hline $5 \quad$ Alt $Z^{12}$ & 1.88 & 7.79 & 0.54 & 0.55 & -0.41 & -0.09 & 1 & & & & & & & & & & & & & & & & \\
\hline $6 \quad$ Alt $Z^{0}$ & 3.43 & 7.31 & 0.14 & 0.14 & -0.03 & 0.26 & 0.57 & 1 & & & & & & & & & & & & & & & \\
\hline $7|N S A L E|_{+}^{4}$ & 0.26 & 0.62 & -0.02 & -0.17 & 0.10 & 0.13 & 0.01 & 0.07 & 1 & & & & & & & & & & & & & & \\
\hline $8|N S A L E|_{-}^{4}$ & 0.70 & 0.65 & -0.20 & 0.03 & -0.14 & -0.13 & -0.05 & -0.05 & -0.36 & 1 & & & & & & & & & & & & & \\
\hline $9|N I D|_{+}^{4}$ & 0.84 & 1.31 & -0.14 & -0.06 & 0.02 & 0.06 & -0.02 & -0.04 & -0.03 & 0.32 & 1 & & & & & & & & & & & & \\
\hline $11 \mathrm{MktO}$ & 0.29 & 0.24 & -0.41 & -0.63 & 0.35 & 0.35 & -0.24 & 0.09 & 0.15 & -0.11 & 0.07 & 0.19 & 1 & & & & & & & & & & \\
\hline 12 TechO & 0.07 & 0.10 & -0.36 & -0.46 & 0.24 & 0.18 & -0.14 & 0.05 & 0.12 & 0.02 & 0.13 & 0.12 & 0.68 & 1 & & & & & & & & & \\
\hline 13 Gross $M$ & 0.38 & 0.19 & 0.21 & 0.17 & 0.17 & 0.24 & 0.14 & 0.23 & -0.01 & -0.12 & 0.01 & -0.02 & 0.61 & 0.40 & 1 & & & & & & & & \\
\hline $14 \mathrm{Liq}$ & 3.15 & 2.64 & -0.09 & -0.08 & -0.04 & 0.05 & 0.25 & 0.50 & 0.06 & 0.01 & 0.02 & 0.08 & 0.28 & 0.29 & 0.24 & 1 & & & & & & & \\
\hline 15 Inv Cap & 0.88 & 0.12 & 0.35 & 0.37 & -0.17 & -0.19 & 0.17 & -0.01 & -0.25 & -0.01 & -0.34 & -0.29 & -0.32 & -0.27 & -0.02 & -0.11 & 1 & & & & & & \\
\hline $16 \operatorname{Res} A v$ & 1590.52 & 5004.64 & 0.14 & 0.14 & -0.03 & 0.03 & -0.01 & -0.05 & -0.06 & 0.03 & -0.04 & -0.05 & -0.04 & -0.01 & 0.10 & -0.15 & 0.10 & 1 & & & & & \\
\hline $17 I D$ & 102.5 & 66.48 & -0.02 & -0.05 & 0.07 & 0.10 & 0.03 & 0.10 & 0.11 & -0.09 & -0.11 & 0.19 & 0.41 & 0.26 & 0.45 & 0.26 & -0.14 & -0.01 & 1 & & & & \\
\hline $18 L T$ & 55.60 & 38.86 & -0.20 & -0.27 & 0.29 & 0.18 & -0.33 & -0.14 & 0.08 & -0.08 & 0.03 & 0.20 & 0.42 & 0.26 & 0.31 & -0.13 & -0.20 & 0.12 & 0.26 & 1 & & & \\
\hline 19 EnvUncert & 0.09 & 0.02 & -0.07 & -0.08 & 0.03 & 0.06 & -0.02 & 0.02 & -0.04 & 0.07 & 0.06 & 0.03 & 0.18 & 0.19 & 0.14 & 0.09 & -0.10 & 0.00 & 0.12 & 0.11 & 1 & & \\
\hline
\end{tabular}

Note: Correlations significant at the 0.01 level are shown in bold. See Table 2 for full variable names and descriptions.

operations and firm-level decision-making, similar approaches exist that study diverse aspects of management, such as the need for employee motivation for successful TQM processes, the relationship between collaborative competence and project and market performance, and bottlenecks in lean implementations (Mishra and Shah 2009, Scherrer-Rathje et al. 2009, Pinder 2014). To the best of our knowledge, such models have not been applied to explain firm-level behavior in inventory models.

We propose that in general, and particularly in times of crisis or exogenous shocks, the effect of predictor variables need not be independent of other variables. Rather, we suggest an approach based on constraining factors to explain the complementarity among independent variables. In this view, for example, the effect of resource availability on inventory agility has several dimensions; the effect described in Equation (2), as well as a constraining effect: the size of the effect of the other independent variables will be contingent on whether a firm has ample resources. In other words, firms with different bottlenecks react differently and use different levers to pursue inventory agility.

To this end, we implement the CFM, originally developed by Siemsen et al. (2008), to account for complementarity in knowledge-sharing behavior. The CFM model allows for an intercept and slope effects of the AMC variables, as well as independent intercept and changes of the AMC variables based on which variable is the constraint for any given firm in the sample. In terms of the AMC framework, the intuition behind this model is that, for example, the effect of capabilities is not necessarily the same for a firm that is highly motivated as it is for one without motivation.

Formally, we define the following econometric specification (model II) based on the CFM:

$$
D P M=\beta_{0}+\beta_{1} \log (M k t O)+\beta_{2} \log (\operatorname{Tech} O)+\beta_{3} \log (\operatorname{Gross} M)+\beta_{4} \log (\operatorname{Liq})+\beta_{5} \log (\operatorname{Inv} C a p)+\beta_{6} \log (\operatorname{Res} A v)
$$




$$
\begin{aligned}
& +\theta_{\text {TechO }}\left(\beta_{7}+\beta_{8} \log (M k t O)+\beta_{9} \log (\text { TechO })+\beta_{10} \log (\operatorname{Gross} M)+\beta_{11} \log (\operatorname{Liq})+\beta_{12} \log (\operatorname{Inv} \operatorname{Cap})+\beta_{13} \log (\operatorname{Res} A v)\right) \\
& +\theta_{\text {Gross } M}\left(\beta_{14}+\beta_{15} \log (M k t O)+\beta_{16} \log (\text { TechO })+\beta_{17} \log (\operatorname{Gross} M)+\beta_{18} \log (\operatorname{Liq})+\beta_{19} \log (\operatorname{Inv} \operatorname{Cap})+\beta_{20} \log (\operatorname{Res} A v)\right) \\
& +\theta_{\text {Liq }}\left(\beta_{21}+\beta_{22} \log (M k t O)+\beta_{23} \log (\operatorname{TechO})+\beta_{24} \log (\operatorname{Gross} M)+\beta_{25} \log (\operatorname{Liq})+\beta_{26} \log (\operatorname{Inv} \operatorname{Cap})+\beta_{27} \log (\operatorname{Res} A v)\right) \\
& +\theta_{\text {InvCap }}\left(\beta_{28}+\beta_{29} \log (M k t O)+\beta_{30} \log (\operatorname{TechO})+\beta_{31} \log (\operatorname{Gross} M)+\beta_{32} \log (\operatorname{Liq})+\beta_{33} \log (\operatorname{Inv} \operatorname{Cap})+\beta_{34} \log (\operatorname{Res} A v)\right) \\
& +\theta_{\text {ResAv }}\left(\beta_{35}+\beta_{36} \log (M k t O)+\beta_{37} \log (\text { TechO })+\beta_{38} \log (\operatorname{Gross} M)+\beta_{39} \log (\operatorname{Liq})+\beta_{40} \log (\operatorname{Inv} \operatorname{Cap})+\beta_{41} \log (\operatorname{Res} A v)\right) \\
& +\beta_{42} \log (I D)+\beta_{43} \log (L T)+\beta_{44} \log (\text { EnvUncert })+\beta_{45} \log (\text { MktShare })+\beta_{46} \log (\text { CapInt }) \\
& +\beta_{47} \log \left(|N S A L E|_{+}^{P}\right)+\beta_{48} \operatorname{Ind}+\epsilon,
\end{aligned}
$$

where $D P M$ is defined as above, and $\theta_{\text {TechO }}, \theta_{\text {Gross } M}, \theta_{\text {Liq }}, \theta_{\text {Inv Cap }}$, and $\theta_{\text {ResAv }}$ are dummy variables, defined as 1 if the associated independent variable is considered the constraining factor for a given firm, and 0 otherwise. To quantify the constraining factors we calculate the percentile that each firm belongs to in terms of each independent variable, and define as constraining factor the independent variable associated with the minimum of all percentiles. In keeping with the interpretation of constraining factors based on the AMC framework, the motivation components are defined as the bottleneck when a firm has no motivation and, thus, high gross margin and/or liquidity.

Since one group is omitted from the specification, when marketing intensity is the constraining factor for a given firm, then $\theta_{\text {TechO }}=\theta_{\text {Gross } M}=\theta_{\text {Liq }}=\theta_{\text {InvCap }}=\theta_{\text {ResAv }}=0$. Thus, the interpretation of the coefficients of the CFM model is as follows. The effect of each independent variable on the agility of firm $i$, when marketing intensity is the bottleneck is given by coefficients $\beta_{1}$ through $\beta_{6}$. However, when the constraint is one of the other variables, the effects are given by a linear combination of coefficients. For example, the effect of inventory capabilities if the constraining variable is gross margin is given by $\beta_{5}+\beta_{19}$. Likewise, the intercept when marketing intensity is the constraining factor is given by $\beta_{0}$, whereas the intercept when the constraint is resource availability is given by $\beta_{0}+\beta_{35}$.

\subsubsection{Financial performance}

We use a regression model (model III) with three different dependent variables to estimate the impact of inventory agility on the financial performance of the firms in the sample. Each centers on one dimension of financial performance, as quantified in Section 4.1.2: profitability, market performance, and financial health. The econometric specification of model III is as follows:

$$
\begin{aligned}
F P M^{P}=\beta_{0} & +\beta_{1}|N S A L E|_{+}^{P}+\beta_{2}|N S A L E|_{-}^{P}+\beta_{3}|N S A L E|_{+}^{P} \times|N S A L E|_{-}^{P}+\beta_{4}|N I D|_{+}^{P} \\
& +\beta_{5}|N I D|_{-}^{P}+\beta_{6}|N I D|_{+}^{P} \times|N I D|_{-}^{P}+\beta_{7} F P M^{0}+\beta_{8} \text { IndustrySector }+\epsilon,
\end{aligned}
$$


where FPM refers to one of the financial performance metrics $(F P M=\{R O S, A l t Z, T o b Q\})$. We include interaction terms for the IPE and INE metrics due to their construction. These metrics measure the cumulative inventory overage and underage, and thus it is possible for a given firm to incur in both within a given time frame. As illustrated in Figure 4, firms with high overage and underage within a period experience substantial inventory dynamics - which can be interpreted as an indication of sales variability during the period. By including the interaction term we relax the implicit assumption that the effect of inventory overage (underage) is constant. Therefore, we condition the marginal effect of inventory overage (underage) on the amount of underage (overage) a firm experienced in the same period. Using this specification, the marginal effect of inventory underage is measured by $\beta_{5}+\beta_{6}\left|N I D_{i}\right|_{+}^{4}$, and the marginal effect of inventory overage by $\beta_{4}+$ $\beta_{6}\left|N I D_{i}\right|_{-}^{4}$. We use an additive regression model due to the number of dependent variables that take negative values during the period; partial estimation of a multiplicative model using the positive sub-sample reveals consistent results.

\section{Results}

As discussed in the previous section, we estimated three different models for a total of seven dependent variables with dynamic snapshots 4,8 , and 12 periods following the crisis. Therefore, in this section, we present the results of 21 individual regressions estimated using OLS with HuberWhite standard errors. We used the regress command in Stata 14 to run all the regression models. Moreover, we conducted a conservative outlier analysis. To control for the effect of outliers on the regression results, we calculated the DFBeta statistics for all independent variables in each regression. As suggested by Siemsen et al. (2008), we dropped all observations that influenced any of the effect estimates by more than 0.3 standard deviations (i.e., $D F_{\max }>0.30$ ). (This estimate is conservative and twice as large as the recommended value (Bollen and Jackman 1985).) As a result, 11 observations were dropped from the dataset for models I and II and 21 observations were dropped from the dataset for model III.

\subsection{Inventory dynamics - model I}

Table 5 provides the results for the estimation of the dynamic inventory models specified by Equation (2). We find support for H3, H5, and H6 in all models, H4 is partially supported, but we find no support for $\mathrm{H} 1$ or $\mathrm{H} 2$.

$\mathrm{H} 1$ and $\mathrm{H} 2$ relate to the awareness dimension of the AMC framework. The coefficients of market orientation are positive but not significant $(p>0.1)$ for all cross-sectional snapshots for normalized inventory agility and absolute inventory agility. Thus, we cannot reject the null hypothesis (H1) 
Table 5 Inventory agility regression analysis.

\begin{tabular}{|c|c|c|c|c|c|c|c|}
\hline \multirow[b]{2}{*}{ Variable } & & \multicolumn{3}{|c|}{ Normalized Inventory Agility } & \multicolumn{3}{|c|}{ Absolute Inventory Agility } \\
\hline & & $\log \left(\operatorname{Inv} \overline{A g)^{4}}\right.$ & $\log (\operatorname{Inv} A g)^{8}$ & $\overline{\log (\operatorname{In} v A g)^{12}}$ & $\log (A b s \operatorname{Inv} A g)^{\overline{4}}$ & $\log (A b \operatorname{Inv} A g)^{8}$ & $\overline{l o g}(A b s \operatorname{Inv} A g)^{12}$ \\
\hline \multirow[t]{2}{*}{$\log (\mathrm{MktO})$} & $(\mathbf{H} 1+)$ & 0.83 & 1.33 & 1.67 & 2.90 & 4.33 & 3.99 \\
\hline & & $(0.71)$ & $(1.05)$ & $(1.33)$ & $(2.92)$ & $(3.16)$ & $(3.24)$ \\
\hline \multirow[t]{2}{*}{$\log (\mathrm{TechO})$} & $(\mathrm{H} 2+)$ & -1.63 & $-3.82^{\#}$ & $-5.66^{*}$ & -4.25 & $-10.10^{\#}$ & $-11.70^{\#}$ \\
\hline & & $(1.40)$ & $(2.07)$ & $(2.67)$ & $(5.20)$ & $(5.91)$ & $(6.30)$ \\
\hline \multirow[t]{2}{*}{$\log ($ GrossM $)$} & (H3-) & $-2.04 * * *$ & $-2.99^{* * *}$ & $-3.78^{* * *}$ & $-7.94^{* *}$ & $-7.63^{* *}$ & $-7.71^{* *}$ \\
\hline & & $(0.60)$ & $(0.87)$ & $(1.07)$ & $(2.54)$ & $(2.59)$ & $(2.66)$ \\
\hline \multirow[t]{2}{*}{$\log (\operatorname{Liq})$} & (H4-) & -0.08 & -0.14 & -0.14 & -0.42 & $-0.65^{*}$ & $-0.66^{*}$ \\
\hline & & $(0.07)$ & $(0.11)$ & $(0.14)$ & $(0.28)$ & $(0.31)$ & $(0.32)$ \\
\hline \multirow[t]{2}{*}{$\log (\operatorname{InvCap})$} & $(\mathbf{H} 5+)$ & $8.54^{* * *}$ & $11.02^{* * *}$ & $12.09^{* * *}$ & $17.25^{* * *}$ & $18.27^{* * *}$ & $19.87^{* * *}$ \\
\hline & & $(1.11)$ & $(1.92)$ & $(2.28)$ & $(4.11)$ & $(4.97)$ & $(5.55)$ \\
\hline \multirow[t]{2}{*}{$\log (\operatorname{Res} A v)$} & $(\mathrm{H} 6+)$ & $0.02^{*}$ & $0.03^{* *}$ & $0.04^{* *}$ & $0.06^{*}$ & $0.08^{*}$ & $0.07^{*}$ \\
\hline & & $(0.01)$ & $(0.01)$ & $(0.01)$ & $(0.03)$ & $(0.03)$ & $(0.04)$ \\
\hline \multirow[t]{2}{*}{$\log (\mathrm{ID})$} & & $0.13^{* * *}$ & $0.22^{* * *}$ & $0.32^{* * *}$ & $-0.60 * * *$ & $-0.50 * * *$ & $-0.41 * * *$ \\
\hline & & $(0.03)$ & $(0.04)$ & $(0.05)$ & $(0.09)$ & $(0.10)$ & $(0.11)$ \\
\hline \multirow[t]{2}{*}{$\log (\mathrm{LT})$} & & 0.01 & 0.01 & 0.02 & 0.13 & 0.11 & 0.06 \\
\hline & & $(0.03)$ & $(0.04)$ & $(0.05)$ & $(0.13)$ & $(0.14)$ & $(0.14)$ \\
\hline \multirow[t]{2}{*}{$\log ($ EnvUncert $)$} & & -2.94 & -9.73 & -14.08 & -35.29 & -35.98 & -30.55 \\
\hline & & $(4.90)$ & $(7.23)$ & $(9.17)$ & $(22.16)$ & $(24.91)$ & $(26.08)$ \\
\hline \multirow[t]{2}{*}{$\log ($ MktShare $)$} & & $-6.97^{*}$ & $-11.92^{*}$ & $-11.12^{\#}$ & $-31.55^{* *}$ & $-32.41^{*}$ & $-25.27^{\#}$ \\
\hline & & $(3.28)$ & $(4.92)$ & $(6.44)$ & $(11.57)$ & $(13.52)$ & (14.69) \\
\hline \multirow[t]{2}{*}{$\log$ (CapInt) } & & -0.07 & -0.10 & -0.12 & -0.31 & -0.39 & -0.39 \\
\hline & & $(0.08)$ & $(0.11)$ & $(0.14)$ & $(0.32)$ & $(0.35)$ & $(0.36)$ \\
\hline \multirow[t]{2}{*}{$\log \left(|N S A L E|_{-}^{4}\right)$} & & $-0.46^{* * *}$ & & & $-1.69^{* * *}$ & & \\
\hline & & $(0.04)$ & & & $(0.13)$ & & \\
\hline \multirow[t]{2}{*}{$\log \left(|N S A L E|_{-}^{8}\right)$} & & & $-0.28^{* * *}$ & & & $-0.93^{* * *}$ & \\
\hline & & & $(0.04)$ & & & $(0.10)$ & \\
\hline \multirow[t]{2}{*}{$\log \left(|N S A L E|_{-}^{12}\right)$} & & & & $-0.21 * * *$ & & & $-0.66^{* * *}$ \\
\hline & & & & $(0.03)$ & & & $(0.09)$ \\
\hline Ind & & 4 significant & 4 significant & 5 significant & 4 significant & 3 significant & 4 significant \\
\hline \multirow[t]{2}{*}{ Intercept } & & 8.69 & $30.19^{\#}$ & $38.82^{\#}$ & $112.95^{*}$ & $121.51^{*}$ & $99.23^{\#}$ \\
\hline & & $(11.37)$ & (16.99) & $(21.73)$ & $(45.13)$ & $(51.24)$ & $(55.08)$ \\
\hline Adjusted $R^{2}$ & & 0.27 & 0.20 & 0.17 & 0.22 & 0.17 & 0.15 \\
\hline $\mathrm{N}$ & & 1,252 & 1,252 & 1,252 & 1,252 & 1,252 & 1,252 \\
\hline
\end{tabular}

${ }^{\#} p<0.1 ;^{*} p<0.05 ;^{* *} p<0.01,{ }^{* * *} p<0.001$. See Table 2 for full variable names and descriptions.

that market orientation is not associated with inventory agility. The coefficients for technology orientation, however, are significant and negative for four out of the six cross-sectional snapshots of normalized and absolute inventory agility $(p<0.1$ for $P: 8,12)$, which suggests that higher technology orientation is (partially) associated with lower inventory agility during the crisis, thus contradicting $\mathrm{H} 2$.

H3 and H4 relate to the motivation dimension of the AMC framework. The coefficients of aggregate gross margins are negative and highly significant for all cross-sectional snapshots for normalized inventory agility and absolute inventory agility $(p<0.001)$. This finding provides support for H3; higher gross margins are negatively associated with inventory agility during the crisis. The coefficients for liquidity are negative and significant $(p<0.05)$ for two of the three cross-sectional 
snapshots for absolute inventory agility. Thus, we find partial support for $\mathrm{H} 4$.

$\mathrm{H} 5$ and $\mathrm{H} 6$ relate to the capability dimension of the AMC framework. The coefficients for inventory management capability are negative and significant $(p<0.001)$ for all cross-sectional snapshots of normalized and absolute inventory agility. This finding lends partial support for H5; higher inventory management capability before the crisis is positively associated with inventory agility during the crisis. The coefficients for resource availability are negative and significant $(p<0.05)$ for all crosssectional snapshots of normalized and absolute inventory agility. This finding lends support for H6; higher resource availability before the crisis is positively associated with inventory agility during the crisis.

Turning our attention to control variables, results show that the inventory agility is positively associated with pre-crisis inventory days $(p<0.001)$ and negatively associated with market share $(p<0.05)$ and the measure of lower than expected sales in the period $(p<0.001)$. These controls are also significant for the absolute inventory agility regressions. However, the inventory days control is negatively associated with absolute inventory agility. This finding suggests that firms operating with large inventories before the crisis react in an agile manner in relative terms but not in absolute terms. In terms of the heterogeneity of the response across industries, three industries (Machinery; computer, electronics, and electrical equipment; and transportation equipment) are negatively associated with normalized and absolute inventory agility. In addition, the Metal industry is negatively associated with normalized inventory agility. We do not find any major differences across industries. Finally, we observe no effect of pre-crisis lead time, environmental uncertainty, or capital intensity on the normalized or absolute inventory agility metrics.

Based on these results, we can derive that all three dimensions of the AMC framework affect inventory agility. However, while the results for motivation and capabilities are in line with the proposed hypothesis, we find no support for one of the awareness hypotheses (H1) and find results opposite of the expected direction for the other (H2). Therefore, we turn to the constraining factor model for a more nuanced analysis of the effects.

\subsection{Inventory dynamics - model II}

Table 6 shows the simplified regression results of the constraining factor model. The table shows the total coefficients for each independent variable under each individual constraining factor. (See Table 13 in the Appendix for the full regression output.) The distribution of the constraining factors is as follows. Seventeen percent of the sample (215 firms) have market orientation as a constraint, $25.9 \%$ (327 firms) have technology orientation as a constraint, 18.2\% (230 firms) have gross margin as a constraint, $14.3 \%$ (180 firms) have liquidity as a constraint ${ }^{2}, 12.3 \%$ (156 firms) have 
Table 6 Inventory dynamics CFM regression analysis: simplified output.

\begin{tabular}{|c|c|c|c|c|c|c|c|c|c|c|c|c|}
\hline \multirow[b]{2}{*}{ Variable } & \multicolumn{6}{|c|}{ Normalized Inventory Agility } & \multicolumn{6}{|c|}{ Absolute Inventory Agility } \\
\hline & \multicolumn{2}{|c|}{$\log (\operatorname{InvAg})^{4}$} & \multicolumn{2}{|c|}{$\log (\operatorname{InvAg})^{8}$} & \multicolumn{2}{|c|}{$\log (\operatorname{InvAg})^{12}$} & \multicolumn{2}{|c|}{$\log (A b \operatorname{Inv} A g)^{4}$} & \multicolumn{2}{|c|}{$\log (A b s \operatorname{Inv} A g)^{8}$} & \multicolumn{2}{|c|}{$\log (A b \operatorname{Inv} A g)^{12}$} \\
\hline \multicolumn{13}{|c|}{ MktO is the Constraint. } \\
\hline $\log (\mathrm{MktO})$ & 2.26 & $(2.92)$ & 3.17 & $(4.03)$ & 4.92 & $(5.09)$ & 2.49 & $(11.25)$ & 9.25 & $(10.26)$ & 10.20 & $(10.32)$ \\
\hline $\log (\mathrm{TechO})$ & 4.12 & $(3.06)$ & 5.98 & $(4.44)$ & 7.86 & $(5.62)$ & 6.62 & $(14.98)$ & 4.77 & $(16.86)$ & 4.60 & $(18.20)$ \\
\hline $\log (\mathrm{Gross} M)$ & $-4.57^{\#}$ & $(2.42)$ & $-6.18^{\#}$ & $(3.16)$ & $-7.18^{\#}$ & $(3.78)$ & $-12.36^{\#}$ & $(7.01)$ & $-14.66^{*}$ & $(7.00)$ & $-13.95^{*}$ & $(7.01)$ \\
\hline $\log (\mathrm{Liq})$ & -0.07 & $(0.32)$ & -0.56 & $(0.46)$ & -0.76 & $(0.56)$ & 0.17 & $(1.07)$ & -1.23 & $(1.13)$ & -1.55 & $(1.24)$ \\
\hline $\log ($ InvCap $)$ & $19.19^{* * *}$ & $(3.61)$ & $26.47^{* * *}$ & $(5.02)$ & $28.99^{* * *}$ & $(6.27)$ & $67.50^{* * *}$ & $(10.89)$ & $72.10^{* * *}$ & $(11.62)$ & $70.63^{* * *}$ & $(12.20)$ \\
\hline $\log (\operatorname{Res} A v)$ & 0.00 & $(0.02)$ & 0.00 & $(0.02)$ & 0.00 & $(0.03)$ & 0.02 & $(0.06)$ & 0.03 & $(0.07)$ & 0.05 & $(0.07)$ \\
\hline \multicolumn{13}{|c|}{ TechO is the Constraint. } \\
\hline $\log (\mathrm{MktO})$ & $5.18^{* *}$ & $(1.91)$ & $8.22^{* *}$ & $(2.79)$ & $9.93^{* *}$ & $(3.39)$ & 9.76 & $(7.57)$ & $15.08^{\#}$ & $(7.92)$ & $13.97^{\#}$ & $(8.04)$ \\
\hline $\log (\mathrm{TechO})$ & 25.59 & $(40.34)$ & 9.01 & $(65.02)$ & -11.22 & $(82.45)$ & 11.88 & $(170.86)$ & -45.55 & $(200.54)$ & -117.01 & $(208.61)$ \\
\hline $\log (\mathrm{Gross} M)$ & $-5.88^{* *}$ & $(1.80)$ & $-9.02^{* * *}$ & $(2.46)$ & $-11.07^{* * *}$ & $(2.90)$ & $-13.59^{*}$ & $(6.70)$ & $-17.53^{*}$ & $(6.93)$ & $-17.11^{*}$ & (7.11) \\
\hline $\log (\mathrm{Liq})$ & -0.05 & $(0.12)$ & -0.04 & $(0.17)$ & -0.06 & $(0.22)$ & -0.59 & $(0.44)$ & -0.48 & $(0.48)$ & -0.69 & $(0.53)$ \\
\hline $\log (\operatorname{InvCap})$ & $10.02^{* *}$ & $(3.27)$ & $13.75^{* *}$ & $(5.29)$ & $15.52^{*}$ & $(6.75)$ & $28.19^{* *}$ & (8.78) & $31.58^{* *}$ & $(10.78)$ & $36.85^{* * *}$ & $(10.10)$ \\
\hline $\log (\operatorname{Res} A v)$ & 0.01 & $(0.02)$ & 0.03 & $(0.02)$ & 0.03 & $(0.03)$ & 0.07 & $(0.06)$ & $0.11^{\#}$ & $(0.06)$ & 0.10 & $(0.07)$ \\
\hline \multicolumn{13}{|c|}{ GrossM is the Constraint. } \\
\hline $\log (\mathrm{MktO})$ & -1.23 & $(1.55)$ & -3.92 & $(2.43)$ & -3.84 & (3.04) & -3.52 & $(6.58)$ & -4.66 & $(7.67)$ & -0.99 & $(7.73)$ \\
\hline $\log (\mathrm{TechO})$ & -0.17 & $(2.13)$ & -0.87 & $(3.06)$ & -2.47 & $(3.97)$ & -3.68 & $(9.77)$ & -10.13 & $(11.07)$ & -12.17 & $(11.71)$ \\
\hline $\log (\operatorname{Gross} M)$ & -0.62 & (1.79) & 0.57 & $(2.70)$ & -0.31 & $(3.47)$ & -2.24 & (8.13) & 0.22 & $(9.23)$ & -5.14 & $(9.01)$ \\
\hline $\log (\mathrm{Liq})$ & -0.26 & $(0.18)$ & $-0.65^{*}$ & $(0.26)$ & $-0.71^{*}$ & $(0.34)$ & -1.15 & $(0.79)$ & $-1.91^{*}$ & $(0.88)$ & $-1.73^{\#}$ & $(0.89)$ \\
\hline $\log ($ InvCap $)$ & 2.79 & $(3.70)$ & 4.50 & $(5.89)$ & 5.35 & $(7.76)$ & 10.40 & $(13.65)$ & 10.15 & $(16.39)$ & 10.86 & $(16.46)$ \\
\hline $\log (\operatorname{Res} A v)$ & $0.04^{* *}$ & $(0.02)$ & $0.05^{*}$ & $(0.02)$ & $0.07^{*}$ & $(0.03)$ & 0.07 & $(0.07)$ & 0.07 & $(0.08)$ & 0.10 & $(0.09)$ \\
\hline \multicolumn{13}{|c|}{ Liq is the Constraint. } \\
\hline $\log (\mathrm{MktO})$ & 1.69 & $(1.66)$ & 3.27 & $(2.48)$ & 4.50 & $(3.20)$ & 4.43 & $(7.64)$ & 3.87 & $(8.05)$ & 4.72 & $(8.79)$ \\
\hline $\log (\mathrm{TechO})$ & -2.83 & $(3.36)$ & -2.72 & $(4.64)$ & -4.82 & $(6.27)$ & -6.18 & $(10.62)$ & -5.39 & $(10.84)$ & -9.36 & $(11.93)$ \\
\hline $\log (\mathrm{Gross} M)$ & -0.69 & $(1.60)$ & -1.01 & $(2.32)$ & 0.05 & $(3.04)$ & -0.38 & (7.79) & 2.13 & $(7.70)$ & 6.00 & $(8.31)$ \\
\hline $\log (\mathrm{Liq})$ & -0.14 & $(0.18)$ & -0.21 & $(0.24)$ & -0.22 & $(0.30)$ & -0.36 & $(0.64)$ & -0.88 & $(0.64)$ & $-1.12^{\#}$ & $(0.66)$ \\
\hline $\log (\operatorname{InvCap})$ & 4.75 & $(4.56)$ & 8.84 & $(6.60)$ & 11.16 & $(8.56)$ & 0.43 & $(16.70)$ & 2.39 & $(16.60)$ & 5.94 & $(17.83)$ \\
\hline $\log (\operatorname{Res} A v)$ & 0.02 & $(0.03)$ & 0.03 & $(0.04)$ & 0.03 & $(0.05)$ & 0.07 & $(0.12)$ & -0.01 & $(0.11)$ & -0.05 & $(0.12)$ \\
\hline \multicolumn{13}{|c|}{ InvCap is the Constraint. } \\
\hline $\log (\mathrm{MktO})$ & $4.51^{* *}$ & (1.68) & $6.15^{* *}$ & $(2.34)$ & $7.67^{* *}$ & $(2.93)$ & $17.54^{* *}$ & $(6.43)$ & $19.95^{* *}$ & $(7.12)$ & $15.96^{*}$ & (7.34) \\
\hline $\log (\mathrm{TechO})$ & $-10.01^{* *}$ & $(3.74)$ & $-15.92^{* *}$ & $(5.42)$ & $-19.31^{* *}$ & $(6.75)$ & -23.74 & $(14.67)$ & $-34.39^{*}$ & $(16.81)$ & -28.46 & $(18.21)$ \\
\hline $\log ($ GrossM $)$ & $-3.07^{\#}$ & $(1.72)$ & -3.39 & $(2.44)$ & -3.35 & $(3.02)$ & -10.65 & $(7.56)$ & -4.76 & $(6.76)$ & -3.98 & $(6.78)$ \\
\hline $\log (\mathrm{Liq})$ & -0.05 & $(0.36)$ & 0.11 & $(0.51)$ & 0.20 & (0.63) & -0.59 & (1.34) & -0.66 & $(1.52)$ & -1.29 & $(1.50)$ \\
\hline $\log (\operatorname{InvCap})$ & $11.84^{* * *}$ & $(3.01)$ & $14.52^{* *}$ & $(4.73)$ & $15.87^{* *}$ & $(6.14)$ & $39.35^{* * *}$ & (9.65) & $41.50^{* * *}$ & $(11.48)$ & $43.10^{* * *}$ & $(12.62)$ \\
\hline $\log (\operatorname{Res} A v)$ & 0.00 & $(0.03)$ & 0.02 & $(0.04)$ & 0.05 & $(0.05)$ & 0.00 & $(0.12)$ & 0.03 & $(0.12)$ & 0.03 & $(0.13)$ \\
\hline \multicolumn{13}{|c|}{ ResAv is the Constraint. } \\
\hline $\log (\mathrm{MktO})$ & -1.12 & $(1.57)$ & -1.13 & $(2.47)$ & -1.62 & (3.43) & -3.64 & (5.58) & -1.86 & (6.33) & -1.68 & $(6.92)$ \\
\hline $\log (\mathrm{TechO})$ & 1.06 & $(2.99)$ & 0.18 & $(5.18)$ & -1.03 & $(7.09)$ & 3.20 & (11.16) & -1.85 & (13.30) & -6.94 & $(14.36)$ \\
\hline $\log ($ GrossM $)$ & 1.02 & $(2.00)$ & 1.47 & $(3.15)$ & 2.11 & (3.83) & 3.43 & $(7.21)$ & 3.22 & $(7.90)$ & 2.42 & $(7.86)$ \\
\hline $\log (\mathrm{Liq})$ & 0.17 & $(0.29)$ & -0.05 & $(0.45)$ & -0.18 & $(0.55)$ & 0.56 & $(1.19)$ & 0.06 & $(1.28)$ & -0.21 & (1.38) \\
\hline $\log ($ InvCap $)$ & $14.23^{* * *}$ & (3.39) & $18.54^{* * *}$ & $(4.83)$ & $19.56^{* *}$ & $(6.05)$ & $41.53^{* * *}$ & $(11.01)$ & $41.30^{* * *}$ & $(12.01)$ & $38.05^{* *}$ & $(12.24)$ \\
\hline $\log (\operatorname{Res} A v)$ & -0.05 & $(0.04)$ & -0.06 & $(0.06)$ & -0.07 & $(0.07)$ & -0.17 & $(0.16)$ & -0.20 & $(0.17)$ & -0.17 & $(0.17)$ \\
\hline Adjusted $R^{2}$ & 0.28 & & 0.22 & & 0.19 & & 0.22 & & 0.18 & & 0.15 & \\
\hline $\mathrm{N}$ & 1,252 & & 1,252 & & 1,252 & & 1,252 & & 1,252 & & 1,252 & \\
\hline
\end{tabular}

${ }^{\#} p<0.1 ;{ }^{*} p<0.05 ;{ }^{* *} p<0.01,{ }^{* * *} p<0.001$. See Table 2 for full variable names and descriptions.

inventory management capability as a constraint, and 12.3\% (155 firms) have resource availability as a constraint.

Results show a small increase in the fit of model II, but the qualitative insights offer a much more nuanced view of the role of the antecedents of inventory agility. We discuss three striking results. First, none of the linear coefficients for the independent variables is statistically significant under all conditions; their effect is conditional on the variable acting as a constraint. Second, we observe that motivation (i.e., the lack of a gross margin and/or liquidity) plays a crucial role as a bottleneck because the linear effect of all other variables changes when these variables are the

${ }^{2}$ Note that the interpretation of gross margin and liquidity as "motivation bottlenecks" is such that firms with high gross margin and/or liquidity are constrained in terms of motivation. 
constraining factor. The insights from the base model suggest that the gross margin, and liquidity under certain conditions, are negatively associated with inventory agility. The CFM model shows that, in addition to these direct effects, gross margin and liquidity act as bottlenecks: none of the independent variables shows a significant effect on inventory agility for firms characterized by high liquidity. For firms characterized by high gross margins, resource availability is positively associated with normalized inventory agility and liquidity is negatively associated with inventory agility in the medium to long term. Third, we see that awareness (i.e., market and/or technical orientation) plays a relevant role, but only under certain conditions. When inventory management capability is the constraint, market orientation is positively associated with inventory agility, whereas technology orientation is negatively associated with inventory agility. This finding suggests that when firms do not have the capabilities to manage inventory in an agile manner, they benefit from higher awareness of customer developments.

Testing for differences among the coefficient estimates, we see that the constraining factor also influences the size of the effects. By observing the effect of inventory capabilities, for example, we see that its effect size when market orientation is the constraining factor is significantly larger than for all other constraining factors $(p<0.05$ when the constraints are gross margin, liquidity, or inventory capabilities; $p<0.1$ otherwise).

\subsection{Financial performance - model III}

Table $7 \quad$ Financial performance regression analysis.

\begin{tabular}{|c|c|c|c|c|c|c|c|c|c|}
\hline \multirow[b]{2}{*}{ Variable } & \multicolumn{3}{|c|}{ Profitability } & \multicolumn{3}{|c|}{ Market performance } & \multicolumn{3}{|c|}{ Financial health } \\
\hline & $\overline{R O S_{i}^{4}}$ & $\operatorname{ROS}_{i}^{8}$ & $\operatorname{ROS}_{i}^{12}$ & $\operatorname{Tob} Q_{i}^{4}$ & $\operatorname{Tob}_{i}^{8}$ & $\operatorname{Tob} Q_{i}^{12}$ & $A \overline{l t Z_{i}^{4}}$ & Alt $Z_{i}^{8}$ & $\operatorname{Alt}_{i}^{12}$ \\
\hline$|N S A L E|_{+}^{4}$ & $\begin{array}{l}0.02^{* *} \\
(0.01)\end{array}$ & $\begin{array}{l}0.02^{* *} \\
(0.01)\end{array}$ & $\begin{array}{l}0.02^{*} \\
(0.01)\end{array}$ & $\begin{array}{l}-0.01 \\
(0.02)\end{array}$ & $\begin{array}{l}-0.04 \\
(0.03)\end{array}$ & $\begin{array}{l}-0.05^{\#} \\
(0.03)\end{array}$ & $\begin{array}{l}-0.10 \\
(0.12)\end{array}$ & $\begin{array}{l}-0.10 \\
(0.14)\end{array}$ & $\begin{array}{l}-0.08 \\
(0.17)\end{array}$ \\
\hline$|N S A L E|_{-}^{4}$ & $\begin{array}{l}-0.11^{* * *} \\
(0.01)\end{array}$ & $\begin{array}{l}-0.08^{* * *} \\
(0.01)\end{array}$ & $\begin{array}{l}-0.07^{* * *} \\
(0.01)\end{array}$ & $\begin{array}{l}-0.11^{* * *} \\
(0.02)\end{array}$ & $\begin{array}{l}-0.09^{* * *} \\
(0.02)\end{array}$ & $\begin{array}{l}-0.07^{* *} \\
(0.03)\end{array}$ & $\begin{array}{l}-0.25^{*} \\
(0.12)\end{array}$ & $\begin{array}{l}-0.35^{*} \\
(0.14)\end{array}$ & $\begin{array}{l}-0.39^{*} \\
(0.16)\end{array}$ \\
\hline$|N S A L E|_{+}^{4} \times|N S A L E|_{-}^{4}$ & $\begin{array}{l}-0.01 \\
(0.03)\end{array}$ & $\begin{array}{l}-0.06^{\#} \\
(0.03)\end{array}$ & $\begin{array}{l}-0.03 \\
(0.03)\end{array}$ & $\begin{array}{l}-0.17 \\
(0.12)\end{array}$ & $\begin{array}{l}-0.18 \\
(0.13)\end{array}$ & $\begin{array}{l}-0.17 \\
(0.15)\end{array}$ & $\begin{array}{l}-0.79 \\
(0.66)\end{array}$ & $\begin{array}{l}-0.75 \\
(0.77)\end{array}$ & $\begin{array}{l}-1.04 \\
(0.91)\end{array}$ \\
\hline$|N I D|_{+}^{4}$ & $\begin{array}{l}-0.00 \\
(0.00)\end{array}$ & $\begin{array}{l}-0.00 \\
(0.00)\end{array}$ & $\begin{array}{l}-0.00 \\
(0.00)\end{array}$ & $\begin{array}{l}-0.04^{* *} \\
(0.01)\end{array}$ & $\begin{array}{l}-0.01 \\
(0.01)\end{array}$ & $\begin{array}{l}-0.00 \\
(0.01)\end{array}$ & $\begin{array}{l}-0.20^{* * * *} \\
(0.06)\end{array}$ & $\begin{array}{l}-0.17^{*} \\
(0.07)\end{array}$ & $\begin{array}{l}-0.16^{\#} \\
(0.08)\end{array}$ \\
\hline$|N I D|_{-}^{4}$ & $\begin{array}{c}-0.02^{*} \\
(0.01)\end{array}$ & $\begin{array}{l}-0.02^{\#} \\
(0.01)\end{array}$ & $\begin{array}{l}-0.03^{* *} \\
(0.01)\end{array}$ & $\begin{array}{l}-0.14^{* * * *} \\
(0.03)\end{array}$ & $\begin{array}{l}-0.05 \\
(0.04)\end{array}$ & $\begin{array}{l}-0.01 \\
(0.04)\end{array}$ & $\begin{array}{l}-1.17^{* * *} \\
(0.17)\end{array}$ & $\begin{array}{l}-1.03^{* * *} \\
(0.20)\end{array}$ & $\begin{array}{l}-1.01^{* * *} \\
(0.24)\end{array}$ \\
\hline$|N I D|_{+}^{4} \times|N I D|_{-}^{4}$ & $\begin{array}{l}-0.05^{*} \\
(0.02)\end{array}$ & $\begin{array}{l}-0.05^{\#} \\
(0.02)\end{array}$ & $\begin{array}{l}-0.06^{*} \\
(0.03)\end{array}$ & $\begin{array}{l}0.08 \\
(0.09)\end{array}$ & $\begin{array}{l}0.05 \\
(0.10)\end{array}$ & $\begin{array}{l}0.06 \\
(0.11)\end{array}$ & $\begin{array}{l}-0.61 \\
(0.49)\end{array}$ & $\begin{array}{l}-0.88 \\
(0.58)\end{array}$ & $\begin{array}{l}-0.71 \\
(0.68)\end{array}$ \\
\hline$R O S^{0}$ & $\begin{array}{l}0.81^{* * *} * \\
(0.02)\end{array}$ & $\begin{array}{l}0.73^{* * *} \\
(0.02)\end{array}$ & $\begin{array}{l}0.70^{* * *} \\
(0.02)\end{array}$ & & & & & & \\
\hline $\operatorname{Tob} Q^{0}$ & & & & $\begin{array}{l}0.56^{* * *} \\
(0.01)\end{array}$ & $\begin{array}{l}0.61^{* * * *} \\
(0.01)\end{array}$ & $\begin{array}{l}0.61^{* * *} \\
(0.01)\end{array}$ & & & \\
\hline Alt $Z^{0}$ & & & & & & & $\begin{array}{l}0.65^{* * *} \\
(0.01)\end{array}$ & $\begin{array}{l}0.67^{* * *} \\
(0.01)\end{array}$ & $\begin{array}{l}0.66^{* * * *} \\
(0.02)\end{array}$ \\
\hline Ind & 1 Significant & N.S & N.S & 8 significant & 7 significant & 7 significant & 1 significant & 1 significant & N.S \\
\hline Intercept & $\begin{array}{l}0.05^{* * *} \\
(0.01)\end{array}$ & $\begin{array}{l}0.05^{* * *} \\
(0.01)\end{array}$ & $\begin{array}{l}0.05^{* * *} \\
(0.01)\end{array}$ & $\begin{array}{l}0.41^{* * *} \\
(0.05)\end{array}$ & $\begin{array}{l}0.37^{* * *} \\
(0.05)\end{array}$ & $\begin{array}{l}0.42^{* * *} \\
(0.06)\end{array}$ & $\begin{array}{l}0.91^{* * *} \\
(0.25)\end{array}$ & $\begin{array}{l}1.03^{* * *} \\
(0.30)\end{array}$ & $\begin{array}{l}1.08^{* *} \\
(0.35)\end{array}$ \\
\hline Adjusted $R^{2}$ & 0.73 & 0.67 & 0.61 & 0.74 & 0.73 & 0.69 & 0.69 & 0.64 & 0.55 \\
\hline $\mathrm{N}$ & 1,243 & 1,243 & 1,243 & 1,243 & 1,243 & 1,243 & 1,242 & 1,242 & 1,242 \\
\hline
\end{tabular}

${ }^{\#} p<0.1 ;{ }^{*} p<0.05 ;{ }^{* *} p<0.01,{ }^{* * *} p<0.001 .|N S A L E|_{+}^{4}$ : Cumulative IPE of sales until period $4 ;|N S A L E|_{-}^{4}$ : Cumulative INE of sales until period $4 ;|N I D|_{+}^{4}$ : Cumulative overage until period $4 ;|N I D|_{-}^{4}$ : Cumulative underage until period 4; ROS: Return on Sales; TobQ: Tobin's Q; AltZ: Altman's Z. 


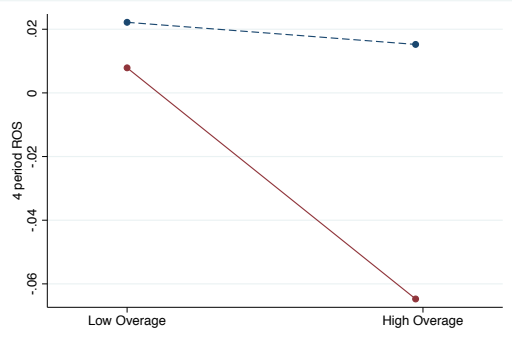

(a) Effect on profitability.

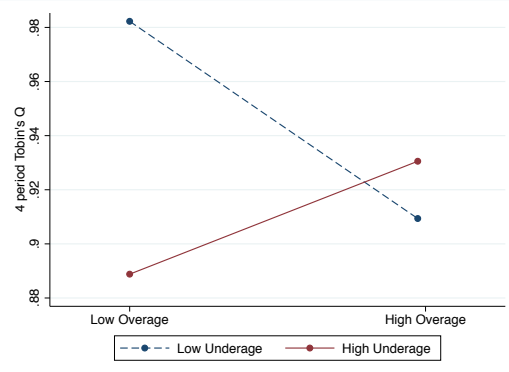

(b) Effect on market performance.

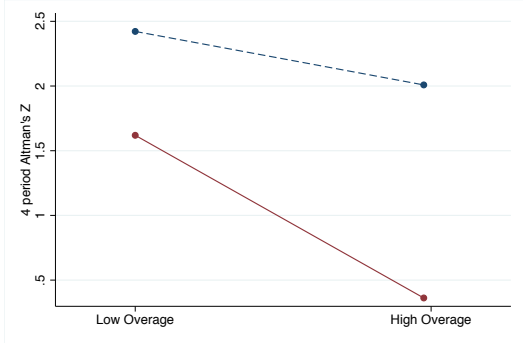

(c) Effect on financial health.

Figure 5 Interaction effect between inventory overage and underage on financial performance.

Table 7 shows the results for the estimation of the financial inventory models specified in Equation (4). Care must be taken in the interpretation of results, given that the significance level of the constitutive and interaction terms is not enough to provide all the information necessary (Brambor et al. 2006).

To establish an intuitive interpretation of the interaction between underage and overage, Figure 5 shows the interaction plots for inventory days for each of the financial metrics. We plot only the predicted financial performance for the 4 periods post-crisis as a function of changes in each variable; the plots for 8- and 12-period metrics are consistent and available from the authors upon request. We use high and low values of inventory underage and overage, defining the low values as no underage/overage and the high values as one standard deviation above the mean. Figures 5a, 5b, and $5 \mathrm{c}$ show the effect of the interaction between the underage and overage in inventory days on the 4-period return on sales, Tobin's Q, and Altman's Z score, respectively. The plots suggest that the interaction between underage and overage affects profitability and financial health in a qualitatively similar manner. When underage is low, overage has a negative but relatively small effect on the performance. When underage is high, the negative effect increases - suggesting that the performance is specially sensitive to fluctuations in inventory. The effect of overages on market performance, however, is different. Figure 5b shows a negative effect of overage when underage is low, but a positive effect when underage is high.

While the interaction plots provide an intuitive interpretation of the interactions between overage and underage, they do not allow us to disentangle the individual effects and their statistical significance. Therefore, following the recommendation of Berry et al. (2012) on testing interaction effects, we construct marginal effect plots for each aspect of financial performance. Figures 6a, 6b, and $6 \mathrm{c}$ show the marginal effect of overage conditional on underage for for the 4 periods post-crisis measures of profitability, market performance, and financial health respectively. Similarly, Figures 


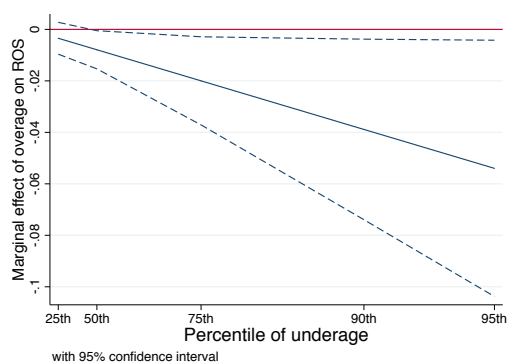

(a) ME of overage on profitability.

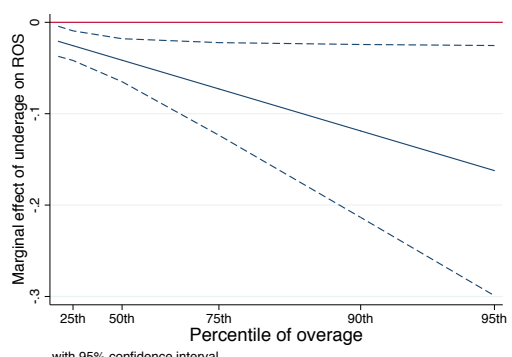

(d) ME of underage on profitability.

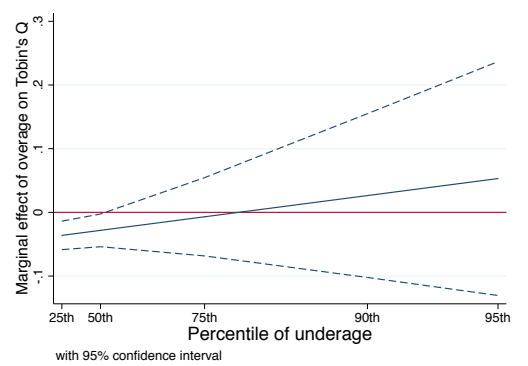

(b) ME of overage on market perf.

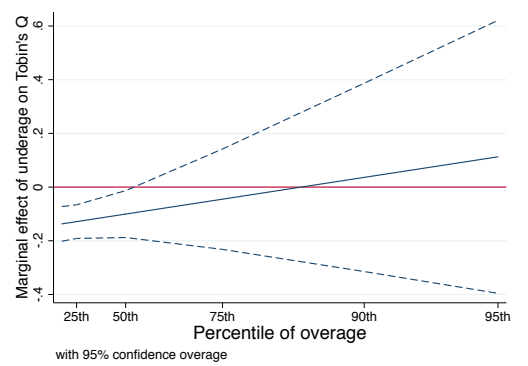

(e) ME of underage on market perf.

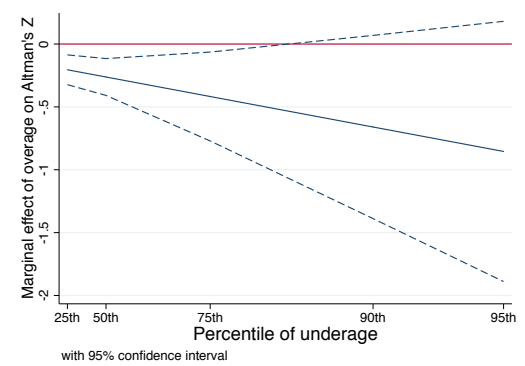

(c) ME of overage on fin. health.

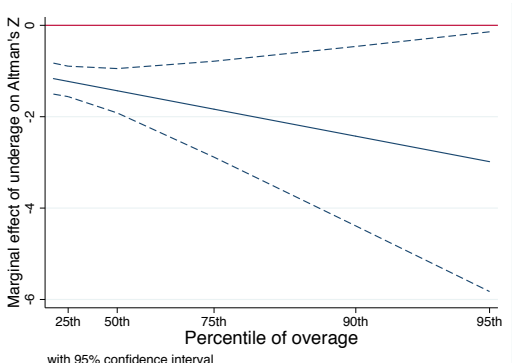

(f) ME of underage on fin. health.

Figure 6 Marginal effects (ME) conditional on the interaction between overage and underage.

$6 \mathrm{~d}, 6 \mathrm{e}$, and $6 \mathrm{f}$ show, respectively, the marginal effect of underage conditional on overage for profitability, market performance, and financial health. As an example, the solid downward sloping line in Figure 6a indicates how the marginal effect of overage changes when underage increases. Any particular point in this line specifies the predicted effect of overage on return on sales, conditional on the underage. The latter is measured in percentiles indicated in the x-axis. The dashed lines indicate the $95 \%$ confidence interval, which allow us to determine the conditions under which overage has a statistically significant effect on profitability (i.e., whenever the upper and lower bounds are both above or below zero).

Analysis of Figure 6 allows us to refine the intuition developed with the interaction plots. In terms of profitability (Figures 6a and 6d), we see that both overage and underage have downward sloping and negative marginal conditional effects, i.e., overage is negatively associated with profitability and its effect becomes more negative as underage increases - and vice versa. Observing the confidence intervals, however, we see that when the underage is lower than (approximately) its 50th percentile, the effect of overage on profitability is not statistically significant. Analyzing the effect of overage and underage on market performance (Figures $6 \mathrm{~b}$ and $6 \mathrm{e}$ ) we see that the slopes are positive and cross zero. The plots suggest that the effect of overage is negatively associated with market performance for underage values is lower than (approximately) the 80th percentile in the sample, and vice versa. However, analysis of the confidence bounds shows that the marginal effect of overage (underage) 
is statistically significant conditional to underage (overage) being below the median in our sample. Finally, we see that the slope of the marginal effects on financial health (Figures 6c and 6f) is negative, suggesting an increasingly negative association with overage (underage) conditional on underage (overage). Note, however, that the effect of overage is not significant for values of underage above the (approximately) 80th percentile.

The above analysis provides support for $\mathrm{H} 7$ and H8. Moreover, it also leads to three main additional insights. (1) The marginal effects of overage and underage are qualitatively symmetric for each of the performance metrics, i.e., the slopes of marginal effects of overage and underage for a given metric share the same sign. (2) The predicted effect of overage and underage on profitability and financial health is consistent with newsvendor theory and past empirical work (e.g., Eroglu and Hofer 2011); overage as well as underage have a negative effect on performance, suggesting an 'inventory sweet spot' outside of which performance degrades. This observation, however, does not hold for market performance. (3) Building on the above observation, we see evidence of subtle quantitative differences in the effect of overages and underages. Even though the confidence intervals for overage conditional on underage and underage conditional on overage mostly overlap, the results suggest that: (a) overage has a negative effect on profitability only if underage is also sufficiently high, (b) the negative effect of underage on market performance (when overage is low) is significantly larger (95\% confidence) than the negative effect of overage on market performance (when underage is low), and (c) the marginal effect of underage dominates the marginal effect of overage on financial health (i.e., when underage is sufficiently high, the marginal effect of overage is non-significant). Analysis of the 8 and 12 periods post-crisis profitability and financial health is in line with the above. However, we see no effect of overages and underages on the 8 and 12 periods post-crisis market performance, suggesting that the market rewards/penalizes short-term events.

Industry controls are partially significant for every specification. Interestingly, the Chemicals and Plastics segment shows above-average profitability but below-average market performance and the Computer, Electronics, \& Electrical Equipment segment shows below-average market performance and financial health. Pre-crisis performance is a highly significant predictor of crisis performance.

\subsection{Post-hoc Analysis}

To further examine whether those firms in our sample that are relatively agile exhibit better financial performance than those with substantial inventory dynamics, and to quantify the conditional effects of overage and underage, we conduct a post-hoc analysis. We rank the firms in our sample along the overage $\left(|N I D|_{+}^{4}\right)$ and underage $\left(|N I D|_{-}^{4}\right)$ metrics and group them into increasing terciles (tercile 1, T1, being the lowest and tercile 3, T3, the highest). We perform two-tailed t-tests with 


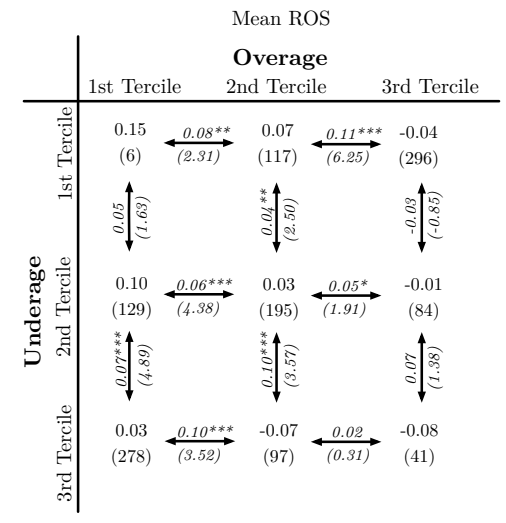

(a) Effect on profitability.

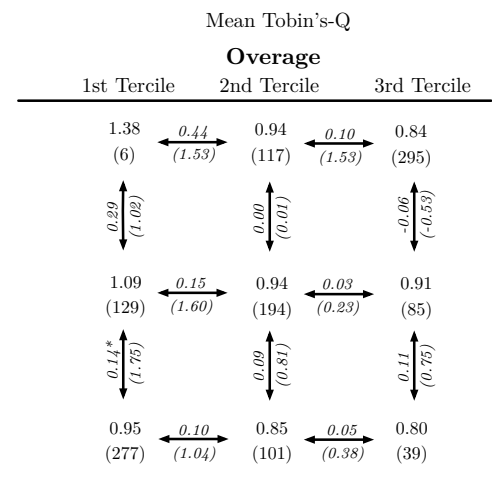

(b) Effect on market performance.

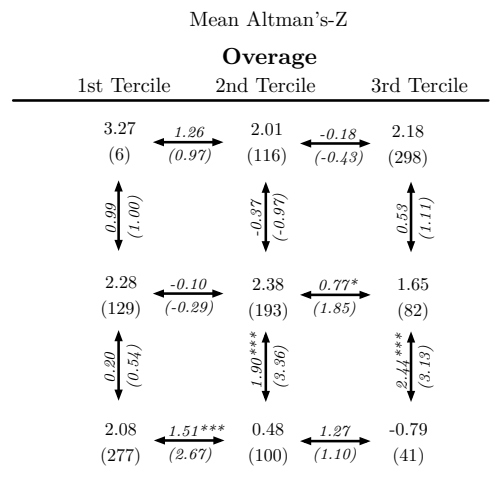

(c) Effect on financial health.

Figure 7 Post-hoc analysis.

unequal variances to determine the significance of the difference between subsamples. Figure 7 shows the mean performance and number of firms (in parenthesis) in each subsample. Arrows connecting neighboring terciles indicate the difference in means, significance level, and t-statistics (in parenthesis). The firms showing either substantial overage or underage are the most represented in our sample. Our post-hoc analysis confirms that firms with either substantial overage or substantial underage exhibit lower performance, and that this effect is particularly severe when both are present (differences between T1-T1 and T3-T3 are all significant at the $\mathrm{p}<0.1$ level).

\subsection{Robustness tests}

To check the robustness of our results, we performed alternative analyses with different model specifications. A linear model (without logged variables) performs similarly in terms of the direction of the effects. However, since the linear specification results in a worse goodness-of-fit, we report exclusively the results of the multiplicative regression. We also tested interactions among the independent variables using an industry indicator based on 4- and 6-digit NAICS codes. We see no additional improvement in the model fit or changes in the direction of the main effects. To test for potential censoring issues due to the non-negativity of the dependent variable, we perform a robustness check by using a Tobit regression specification for the inventory dynamics models of Equations (2) and (3). Tobit regressions (Tobin 1958) explicitly account for non-negative dependent variables and are widely used in the economics and insurance literature (e.g., Bourassa et al. 2008, Anastasopoulos 2016). Results from the Tobit model are consistent with the results reported in this paper. In particular, the results for signs and significance are unchanged. Moreover, given that zero is a legitimate value for the independent variables of the model defined by Equation 4, we test the robustness of the financial performance results to zeros on the right-hand side. To rule out artifacts 
stemming from zero-valued IVs, we perform two additional regressions. First, we use a subsample of the data containing positive IVs. Second, we follow the approach of Battese (1997) to estimate production functions when a number of explanatory variables have zero values. The approach is relatively simple and consists in adding, for each IV, a dummy variable equal to 1 when the IV is 0 , and 0 otherwise. The results using these two approaches are consistent with those reported in this paper. Given the weak results of the IV liquidity, we test an alternative specification of model I, using Altman's-Z score as a proxy for motivation. We find no significant association between Altman's-Z score and inventory agility. Given their relatively high correlation, we also performed robustness analysis to test whether MktO and TechO are partialing each other. Regressions on the model with $\mathrm{MktO}$ and $\mathrm{TechO}$ dropped show consistent results, indicating that multicollinearity between the variables is not an issue. Furthermore, we also test an alternative proxy for the MktO construct that is common in the literature: Advertising spending (Dutta et al. 1999, Özturan et al. 2014). The results are aligned with those reported in this paper, however, the data availability for advertising expenditures is lower than SGA, thus the dataset loses 703 firms.

The methodology used thus far requires all firms to report financial numbers for the entire period, as we disregard any firms with incomplete observations. Therefore, we cannot rule out survivor bias since firms that have filed for bankruptcy or have been acquired are not considered in our dataset. To control for the effect of survivor bias, we re-run the analysis on the dataset including all non-survivor firms. The results are qualitatively consistent with those reported. We also performed robustness tests to determine whether the results of our analyses hold if we did not drop the outliers. For model I, we see no significant different in the parameter estimates for the main effects. For model III, however, we see a difference in the parameter estimates. This confirms that outliers are influential. In particular, the coefficient of the interaction of underage and overage is positive and significant in the market performance regression. All other substantive results, however, continue to hold when the outliers are retained. All additional results and robustness tests are available from the authors upon request.

\section{Conclusion}

In this paper, we used the 2008 financial crisis as a setting to investigate inventory agility following a large demand shock. We analyzed the antecedents associated with inventory agility and the influence of the latter on financial performance during the resulting turbulence. We motivated our study with the observation that firms belonging to the same industrial sector and experiencing similar declines in demand responded differently to the demand shock. There is ample prior research on 
the topics of firm agility and inventory efficiency in times of economic stability, but their insights have not been studied in a crisis context thus far. We built on methodologies from operations and strategic management to propose a theoretical model based on the AMC framework for antecedents of inventory agility and its impact on return on sales, Altman's Z, and Tobin's Q. We proposed that firms that with high awareness, motivation, and capability before the crisis, would also show high inventory agility during the crisis. Moreover, we integrated the AMC framework with a theoretical model that explains the interaction of its different dimensions: the CFM. In line with extant theories, we also proposed that high inventory agility is associated with high financial performance. We tested our hypothesis through secondary data from 1,263 U.S.-based public firms comprising 12 quarters before and 12 quarters after the onset of the crisis (2005-2011).

Our descriptive analysis shows that the median number of inventory days during the first year of the crisis was significantly higher than that for the year before; firms required six quarters on average to align their inventories with the new demand realities. Manufacturers rapidly aligned their WIP materials but required additional time to bring raw materials and finished goods inventories in line with the demand. Our research helps illuminate the mechanisms behind these observations and the impact of inventory agility on financial performance.

In terms of modeling, we contribute to the literature by adapting the AMC framework into an inventory management setting and by further refining its application as part of the constraintsbased CFM model. We find that all three elements must be considered when assessing the link to inventory agility. The results from our base model (model I) confirm that motivation and capabilities before the crisis are generally associated with higher inventory agility during the crisis. Contrary to our expectations, however, we do not find empirical evidence of a positive association between awareness and inventory agility. A possible explanation for this observation is that the financial crisis was a very severe economic situation, and thus, a firm's individual awareness might not have played an important role here. In terms of firms' motivation to react in an agile manner, our results are in line with the OM literature. We find that low gross margins and (to a lesser extent) liquidity, both associated with lower inventory levels, are associated with inventory agility during the crisis. Inventory management capability and resource availability before the crisis are also positively associated with inventory agility. This finding implies that inventory agility can be influenced by operational performance and may be dependent on environmental and firm characteristics.

Nevertheless, our application of the CFM (model II) allows for a substantially richer interpretation of the results, confirming its applicability to inventory-related decision-making, as speculated by Siemsen et al. (2008). We find that the interaction of AMC components as explanatory variables of 
inventory agility is consistent with the theory of constraints; the effect of awareness when motivation is the bottleneck differs from its effect when capability is the bottleneck, and so on. The CFM approach allowed us to empirically measure a secondary effect related to the complementarity of the variables. Take, for example, market orientation. As mentioned above, we cannot measure an effect of market orientation on inventory agility. The CFM model, however, shows that firms whose bottleneck is market orientation are significantly more sensitive to their inventory capabilities. This implies that antecedents for agility depend on firm characteristics and cannot, thus, be analysed independently.

Regarding the financial impact of inventory agility (model III), we confirmed several past findings based on stable conditions, but also found several key differences. Most notably, our results expand on prior empirical results that found an 'inverted U' shape in the relationship between inventory leanness and firm performance (Rumyantsev and Netessine 2007b, Eroglu and Hofer 2011). We confirm the newsvendor-based view that deviating from an inventory 'sweet spot' negatively affects financial performance. Our analysis, however, shows that in a multi-period setting, cumulative inventory-underage conditions the effect of cumulative inventory-overage, and vice versa. This implies that even though deviations from the 'sweet spot' negatively affect performance, the impact increases when substantial dynamics are present. Furthermore, our analysis also suggests that different aspects of financial performance respond to overages and underages differently, e.g., financial health appears to be particularly sensitive to underages, whereas market performance appears to reward substantial inventory dynamics. The latter point is particularly interesting because it suggests that market perfomance is driven by a fundamentally different set of principles. This finding complements recent work (Steinker and Hoberg 2013, Bendig et al. 2018) showing a positive association between inventory volatility and stock returns. From the lens of the newsvendor model, our results imply that not only are costs of overage and underage not symmetric, but that these costs vary along different financial dimensions.

Our results have several implications for managers. We show that managers used inventories to navigate the crisis. In particular, our results indicate that different aspects of financial performance are affected differently by a firm's inventory agility. This finding raises the question of who the principal stakeholder is - in other words, what is the priority when the crisis hits? Our results suggest that, in general, firms should manage inventories in an agile manner but not reduce inventories below the normal 'sweet spot'. However, in the short term, aggressive inventory reductions increase the firm's liquidity. Our analysis shows that firms making this tradeoff will not necessarily fare better in terms of financial health. Therefore, for managers, an important question is, 'how much 
is agile enough?' Our results suggest that every firm will have a different answers to this question. Different costs and operational structures in fact lead to different target responses that could also be related to the type of economic crisis the firm faces.

In addition to these insights for managers, our results have deep implications for market analysts and firm stakeholders. In showing the complex relationship between the AMC constructs, their role as constraining factors, and inventory agility, we highlight the danger associated with analyzing performance metrics without an adequate context. Without an understanding of the awareness, motivation, and capabilities of a firm, particularly which dimension is or is not a bottleneck, the use of inventory agility as a measure of performance can lead to sub-optimal decisions.

Our study has some limitations. While our research allows us to gain valuable insights into inventory management dynamics during the financial crisis, the methodology is certainly limited in various respects. First, we apply secondary firm-level data from S\&P Compustat's database that allow us to analyze the inventory practices of more than 1,200 firms in the given period. However, the data are available only on a quarterly basis, and we cannot gain detailed insights into weekly or monthly dynamics. In particular, early in the crisis, events were very dynamic, and the ability to examine smaller units of time would allow for additional analysis. Further, Compustat contains financial metrics but does not explicitly reveal any information on management decisions and intentions, which would be valuable add-ons. Finally, we must acknowledge that each firm was potentially affected by the crisis at a different point in time. In line with the economics literature, we defined Q3/2008 as the onset of the crisis period. However, certain industries might have been hit by the crisis earlier or later. We opted for an approach with a common timeline to reduce the complexity of the analysis rather than defining individual crisis periods. However, our analysis considers longer time windows to calculate the performance metrics and to study the aggregate dynamics (i.e., two years before the onset of the crisis and three years into the crisis). Thus, any deviations from Q3/2008 should be smoothed out.

Our findings suggest several directions for future research. First, our analysis of the financial impact on inventories opens up the discussion on the appropriate levels of inventory in crisis situations. Eroglu and Hofer (2011) investigate optimal inventory levels over a long period and identify different relationships by industry. It would be interesting to better understand the optimal inventory response in times of demand shocks. To do so, a methodology could be developed that identifies response patterns in separate industries and then analyzes the financial impact of these patterns. Managers would then be able to use this information to benchmark their firm with respect to their industry/segment and act accordingly. Another interesting research question that could be 
addressed in future research is the role of supply chain partners taking over inventory. Although we were unable to observe such behavior in the aggregate data, there is anecdotal evidence that during the financial crisis, firms shifted inventories to suppliers or customers to reduce working capital requirements. By doing so, financially healthy firms could support their less-stable partners. However, the same could also occur due to power. Leveraging supplier-customer information, it would be interesting to investigate the extent to which inventories were shifted and to quantify the magnitude of this shift. An additional research idea relates to the origin of our problem; despite the significant loss in economic welfare, the financial crisis also represents a large-scale case for testing firms' inventory management capabilities. There are other shocks in the recent past that can be used to investigate the inventory management capabilities of affected firms (e.g., the flooding in Thailand or the Japanese tsunami). Since the events might trigger less media attention, they could also be used to further test the influence of awareness.

\section{Acknowledgements}

The authors would like to express their deep gratitude for the extensive reviews and in-depth feedback by the Department Editor John Gray, the anonymous Associate Editor, and the three anonymous referees. Throughout the process, they have provided questions and suggestions that helped improve the quality of the paper.

\section{References}

Abrahamsen, Y., J. Hartwig. 2011. Inventory investment and production in europe during the "great recession": Is there a pattern? International Journal of Production Economics 132(2) 174-177.

Ak, B. K., P. N. Patatoukas. 2016. Customer-base concentration and inventory efficiencies: Evidence from the manufacturing sector. Production and Operations Management 25(2) 258-272.

Aksen, D. 2007. Loss of customer goodwill in the uncapacitated lot-sizing problem. Computers $\&$ operations research 34(9) 2805-2823.

Altman, E. I. 1968. Financial ratios, discriminant analysis and the prediction of corporate bankruptcy. The Journal of Finance 23(4) 589-609.

Anastasopoulos, P. C. 2016. Random parameters multivariate tobit and zero-inflated count data models: addressing unobserved and zero-state heterogeneity in accident injury-severity rate and frequency analysis. Analytic methods in accident research 11 17-32.

Arrow, K. J., T. Harris, J. Marschak. 1951. Optimal inventory policy. Econometrica: Journal of the Econometric Society 250-272.

Axsäter, S. 1990. Modelling emergency lateral transshipments in inventory systems. Management Science 36(11) 1329-1338. 
Bagliano, F. C., A. Sembenelli. 2004. The cyclical behaviour of inventories: European cross-country evidence from the early 1990s recession. Applied Economics 36(18) 2031-2044.

Bahadir, S. C., S. G. Bharadwaj, R. K. Srivastava. 2008. Financial value of brands in mergers and acquisitions: Is value in the eye of the beholder? Journal of Marketing 72(6) 49-64.

Ballou, R. H. 2010. Evaluating inventory management performance using a turnover curve. International Journal of Physical Distribution \& Logistics Management 30(1).

Baños-Caballero, S., P. J. García-Teruel, P. Martínez-Solano. 2014. Working capital management, corporate performance, and financial constraints. Journal of Business Research 67(3) 332-338.

Battese, G. E. 1997. A note on the estimation of cobb-douglas production functions when some explanatory variables have zero values. Journal of agricultural Economics 48(1-3) 250-252.

Bendig, D., M. Brettel, B. Downar. 2018. Inventory component volatility and its relation to returns. Intern. Journal of Production Economics 200 37-49.

Bendig, D., S. Strese, M. Brettel. 2017. The link between operational leanness and credit ratings. Journal of Operations Management $\mathbf{5 2}$ 46-55.

Bennett, V. M., L. Pierce. 2016. Motivation matters: Corporate scope and competition in complementary product markets. Strategic Management Journal 37(7) 1304-1315.

Berling, P., K. Rosling. 2005. The effects of financial risks on inventory policy. Management Science 51(12) $1804-1815$.

Berry, W. D., M. Golder, D. Milton. 2012. Improving tests of theories positing interaction. The Journal of Politics 74(3) 653-671.

Bicer, I., V. Hagspiel, S. de Treville. 2018. Valuing Supply-Chain Responsiveness Under Demand Jumps. Swiss Finance Institute Research Paper No. 18-44. Available at SSRN: https://ssrn.com/abstract=3192942 .

Blinder, A. S. 1986. Can the production smoothing model of inventory behavior be saved? The Quarterly Journal of Economics 101(3) 431-453.

Blinder, A. S., L. J. Maccini. 1991. Taking stock: A critical assessment of recent research on inventories. Journal of Economic Perspectives 5(1) 73-96.

Bollen, K. A., R. W. Jackman. 1985. Regression diagnostics: An expository treatment of outliers and influential cases. Sociological Methods \& Research 13(4) 510-542.

Bourassa, S. C., M. Hoesli, D. F. Scognamiglio, P. Sormani. 2008. Constant-quality house price indexes for switzerland .

Brady, M. K., J. J. Cronin Jr. 2001. Some new thoughts on conceptualizing perceived service quality: a hierarchical approach. Journal of marketing 65(3) 34-49. 
Brainard, W. C., J. Tobin. 1968. Pitfalls in financial model building. The American Economic Review 58(2) $99-122$.

Brambor, T., W. R. Clark, M. Golder. 2006. Understanding interaction models: Improving empirical analyses. Political analysis 14(1) 63-82.

Brealey, R. A. 2012. Principles of corporate finance. Tata McGraw-Hill Education.

Bromiley, P., D. Rau. 2016. Operations management and the resource based view: Another view. Journal of Operations Management 41 95-106.

Buzacott, J. A., R. Q. Zhang. 2004. Inventory management with asset-based financing. Management Science 50(9) $1274-1292$.

Cachon, G., C. Terwiesch. 2009. Matching supply with demand, vol. 2. McGraw-Hill Singapore.

Cachon, G., M. Olivares. 2010. Drivers of finished-goods inventory in the U.S. automobile industry. Management Science 56(1) 202-216.

Campello, M., J. R. Graham, C. R. Harvey. 2010. The real effects of financial constraints: Evidence from a financial crisis. Journal of Financial Economics 97(3) 470-487.

Cano, C. R., F. A. Carrillat, F. Jaramillo. 2004. A meta-analysis of the relationship between market orientation and business performance: evidence from five continents. International Journal of research in Marketing 21(2) 179-200.

Capkun, V., A. P. Hameri, L. Weiss. 2009. On the relationship between inventory and financial performance in manufacturing companies. International Journal of Operations \& 3 Production Management 29(8) 789-806.

Carpenter, R. E., S. M. Fazzari, B. C. Petersen. 1998. Financing constraints and inventory investment: A comparative study with high-frequency panel data. Review of Economics and Statistics 80(4) 513-519.

Carpenter, R. E., S. M. Fazzari, B. C. Petersen, A. K. Kashyap, B. M. Friedman. 1994. Inventory investment, internal-finance fluctuations, and the business cycle. Brookings Papers on Economic Activity 75-138.

Chen, H., M. Z. Frank, O. Q. Wu. 2005. What actually happened to the inventories of american companies between 1981 and 2000? Management Science 51(7) 1015-1031.

Chen, L., H. Lee. 2009. Information Sharing and Order Variability Control Under a Generalized Demand Model. Management Science 55(5) 781-797.

Chen, M.-J. 1996. Competitor Analysis and Interfirm Rivalry: Toward A Theoretical Integration. Academy of Management Review 21(1) 100-134.

Chen, M.-J., S. Kuo-Hsien, W. Tsai. 2007. Competitive tension: The awareness-motivation-capability perspective. Academy of Management Journal 50(1) 101-118.

Chen, M.-J., D. Miller. 2012. Competitive dynamics: Themes, trends, and a prospective research platform. The Academy of Management Annals 6(1) 135-210. 
Chen, M., H. Lin, J. Michel. 2010. Prospering in a hypercompetitive environment: The roles of action aggressiveness and tmt integration. Strategic Management Journal 31(13) 1410-1430.

Chen, T., M. A. Tribbitt, Y. Yang, X. Li. 2017. Does rivals' innovation matter? A competitive dynamics perspective on firms' product strategy. Journal of Business Research 76(C) 1-7.

Chen, W.-R. 2008. Determinants of firms' backward-and forward-looking r\&d search behavior. Organization Science 19(4) 609-622.

Chikán, A., E. Kovács, Z. Matyusz, M. Sass, P. Vakhal. 2018. Inventories in National Economies: A CrossCountry Analysis of Macroeconomic Data. Springer.

Chuang, H. H.-C., R. Oliva. 2016. Erratum to 'inventory record inaccuracy: Causes and labor effects'. Journal of Operations Management 42 96-110.

DeHoratius, N., A. Raman. 2008. Inventory record inaccuracy: an empirical analysis. Management Science 54(4) $627-641$.

Demeter, K., Z. Matyusz. 2011. The impact of lean practices on inventory turnover. International Journal of Production Economics 133(1) 154-163.

Derfus, P. J., P. G. Maggitti, C. M. Grimm, K. G. Smith. 2008. The red queen effect: Competitive actions and firm performance. Academy of Management Journal 51(1) 61-80.

Dimelis, S. P. 2001. Inventory investment over the business cycle in the eu and the us. International Journal of Production Economics 71(1) 1-8.

Duchin, R., O. Ozbas, B. A. Sensoy. 2010. Costly external finance, corporate investment, and the subprime mortgage credit crisis. Journal of Financial Economics 97(3) 418-435.

Duncan, G. 2008. Lehman brothers collapse sends shockwave round world. The Times, September 16th .

Dutta, S., O. Narasimhan, S. Rajiv. 1999. Success in High-Technology Markets: Is Marketing Capability Critical? Marketing Science 18(4) 547-568.

Ellinger, A. E., M. Natarajarathinam, F. G. Adams, J. B. Gray, D. Hofman, K. O’Marah. 2011. Supply chain management competency and firm financial success. Journal of Business Logistics 32(3) 214-226.

Eroglu, C., C. Hofer. 2011. Lean, leaner, too lean? The inventory-performance link revisited. Journal of Operations Management 29(4) 356-369.

Eroglu, C., C. Hofer. 2014. The effect of environmental dynamism on returns to inventory leanness. Journal of Operations Management 32(6) 347-356.

Escaith, H., N. Lindenberg, S. Miroudot. 2010. International supply chains and trade elasticity in times of global crisis. World trade organization: Economic research and statistics division (Staff working paper ERSD-2010-08).

Farasyn, I., S. Humair, J. I. Kahn, J. J. Neale, O. Rosen, J. Ruark, W. Tarlton, W. Van de Velde, G. Wegryn, S. P. Willems. 2011. Inventory optimization at procter \& gamble: Achieving real benefits through user adoption of inventory tools. Interfaces 41(1) 66-78. 
Ferguson, M., V. Jayaraman, G. C. Souza. 2007. Note: An application of the eoq model with nonlinear holding cost to inventory management of perishables. European Journal of Operational Research 180(1) $485-490$.

Ferrier, W. J. 2001. Navigating the competitive landscape: The drivers and consequences of competitive aggressiveness. Academy of management journal 44(4) 858-877.

Ferrier, W. J., C. M. Fhionnlaoich, K. G. Smith, C. M. Grimm. 2002. The impact of performance distress on aggressive competitive behavior: A reconciliation of conflicting views. Managerial and Decision Economics 23(4-5) 301-316.

Gatignon, H., J.-M. Xuereb. 1997. Strategic orientation of the firm and new product performance. Journal of marketing research 77-90.

Gaur, V., M. Fisher, A. Raman. 2005. An econometric analysis of inventory turnover performance in retail services. Management Science 51(2) 181-194.

Gaur, V., S. Kesavan. 2008. The effects of firm size and sales growth rate on inventory turnover performance in the U.S retail sector. In Retail Supply Chain Management, International Series in Operations Research \& Management Science, vol. 122. Springer US.

Gaur, V., S. Kesavan. 2015. The effects of firm size and sales growth rate on inventory turnover performance in the us retail sector. Retail Supply Chain Management. Springer, 25-52.

Gavirneni, S., L. W. Robinson. 2017. Risk aversion and implicit shortage cost explain the anchoring and insufficient adjustment bias in human newsvendors. Operations Research Letters 45(3) 191-198.

George, G. 2005. Slack resources and the performance of privately held firms. Academy of Management Journal 48(4) $661-676$.

Gligor, D. M., M. C. Holcomb, T. P. Stank. 2013. A multidisciplinary approach to supply chain agility: Conceptualization and scale development. Journal of Business Logistics 34(2) 94-108.

Gompers, P., J. Lerner, D. Scharfstein. 2005. Entrepreneurial spawning: Public corporations and the genesis of new ventures, 1986 to 1999. The Journal of Finance 60(2) 577-614.

Grawe, S. J., H. Chen, P. J. Daugherty. 2009. The relationship between strategic orientation, service innovation, and performance. International Journal of Physical Distribution 85 Logistics Management 39(4) $282-300$.

Grinstein, A. 2008. The relationships between market orientation and alternative strategic orientations: A meta-analysis. European Journal of Marketing 42(1/2) 115-134.

Guariglia, A. 1999. The effects of financial constraints on inventory investment: Evidence from a panel of uk firms. Economica 66(261) 43-62.

Gupta, V. K., G. Atav, D. K. Dutta. 2017. Market orientation research: a qualitative synthesis and future research agenda. Review of Managerial Science 1-22. 
Gyulavári, T., K. Kolos. 2015. The impact of proactive strategies on market performance in economic downturn: the case of hungary .

Hamel, G., C. K. Prahalad. 1991. Corporate imagination and expeditionary marketing. Harvard business review 69(4) 81-92.

Heese, H. S. 2007. Inventory record inaccuracy, double marginalization, and rfid adoption. Production and Operations Management 16(5) 542-553.

Heisz, A., S. LaRochelle-Côté. 2004. Corporate financial leverage in canadian manufacturing: consequences for employment and inventories. Canadian Journal of Administrative Sciences/Revue Canadienne des Sciences de l'Administration 21(2) 111-128.

Hendel, I. 1996. Competition under financial distress. The Journal of Industrial Economics 309-324.

Hendricks, K. B., V. R. Singhal. 2005a. Association between supply chain glitches and operating performance. Management Science 51(5) 695-711.

Hendricks, K. B., V. R. Singhal. 2005b. An empirical analysis of the effect of supply chain disruptions on long-run stock price performance and equity risk of the firm. Production and Operations Management 14(1) $35-52$.

Hendricks, K. B., V. R. Singhal. 2009. Demand-supply mismatches and stock market reaction: Evidence from excess inventory announcements. Manufacturing 83 Service Operations Management 11(3) 509-524.

Hitt, M. A., K. Xu, C. M. Carnes. 2016. Resource based theory in operations management research. Journal of Operations Management 41 77-94.

Hoberg, K., J. Bradley, U. Thonemann. 2007. Analyzing the effect of inventory policies on the nonstationary performance with transfer functions. IIE Transactions 39(9) 911-924.

Hoberg, K., U. Thonemann. 2015. Analyzing Variability, Cost, and Responsiveness of Base-Stock Inventory Policies with Linear Control Theory. IIE Transactions 47(8) 865-879.

Hoberg, K., F. Badorf, L. Lapp. 2017. The inverse hockey stick effect: an empirical investigation of the fiscal calendar's impact on firm inventories. International Journal of Production Research 1-26.

Hofmann, E., D. Maucher, S. Piesker, P. Richter. 2011. Ways out of the working capital trap: Empowering self-financing growth through modern supply management, vol. 1. Springer Science \& Business Media.

Holt, C., F. Modigliani, J. Muth, H. Simon. 1960. Planning Production, Inventory and Work Force.. Prentice Hall, Englewood Cliffs, NJ.

Huh, W. T., G. Janakiraman, J. A. Muckstadt, P. Rusmevichientong. 2009. Asymptotic optimality of orderup-to policies in lost sales inventory systems. Management Science 55(3) 404-420.

Isaksson, O. H. D., R. W. Seifert. 2014. Inventory leanness and the financial performance of firms. Production Planning \& Control 25(12) 999-1014. 
Ivashina, V., D. Scharfstein. 2010. Bank lending during the financial crisis of 2008. Journal of Financial Economics $97(3)$ 319-338.

Kahn, J., M. M. McConnell. 2002. Has inventory volatility returned? A look at the current cycle. Current Issues in Economics and Finance - Federal Reserve Bank of New York 8(5) 1-6.

Kashyap, A. K., O. A. Lamont, J. C. Stein. 1994. Credit conditions and the cyclical behavior of inventories. The Quarterly Journal of Economics 109(3) 565-592.

Kesavan, S., V. Gaur, A. Raman. 2010. Do inventory and gross margin data improve sales forecasts for U.S. public retailers? Management Science 56(9) 1519-1533.

Kesavan, S., T. Kushwaha. 2014. Differences in retail inventory investment behavior during macroeconomic shocks: Role of service level. Production and Operations Management 23(12) 2118-2136.

Kesavan, S., T. Kushwaha, V. Gaur. 2016. Do high and low inventory turnover retailers respond differently to demand shocks? Manufacturing \& Service Operations Management 18(2) 198-215.

Kesavan, S., V. Mani. 2013. The relationship between abnormal inventory growth and future earnings for us public retailers. Manufacturing 8 Service Operations Management 15(1) 6-23.

Kirca, A. H., S. Jayachandran, W. O. Bearden. 2005. Market orientation: A meta-analytic review and assessment of its antecedents and impact on performance. Journal of marketing 69(2) 24-41.

Kohli, A. K., B. J. Jaworski. 1990. Market orientation: the construct, research propositions, and managerial implications. The Journal of Marketing 1-18.

Kovach, J. J., M. Hora, A. Manikas, P. C. Patel. 2015. Firm performance in dynamic environments: The role of operational slack and operational scope. Journal of Operations Management 37 1-12.

Lai, R. K. 2008. Is inventory's fiscal year end effect caused by sales timing? a test using a natural experiment from germany. A Test Using a Natural Experiment from Germany (January 26, 2008). Harvard Business School Technology $\&$ Operations Mgt. Unit Research Paper (08-086).

Lamberg, J.-A., H. Tikkanen, T. Nokelainen, H. Suur-Inkeroinen. 2009. Competitive dynamics, strategic consistency, and organizational survival. Strategic Management Journal 30(1) 45-60.

Larson, C. R., D. Turcic, F. Zhang. 2015. An empirical investigation of dynamic ordering policies. Management Science 61(9) 2118-2138. doi:10.1287/mnsc.2014.2077. URL https://doi.org/10.1287/mnsc. 2014.2077 .

Lee, H. L., S. Whang. 2000. Information sharing in a supply chain. International Journal of Manufacturing Technology and Management 1(1) 79-93.

Levinthal, D., C. Rerup. 2006. Crossing an apparent chasm: Bridging mindful and less-mindful perspectives on organizational learning. Organization science 17(4) 502-513.

Lieberman, M. B., S. Helper, L. Demeester. 1999. The empirical determinants of inventory levels in highvolume manufacturing. Production and Operations Management 8(1) 44-55. 
Lin, B.-W., Y. Lee, S.-C. Hung. 2006. R\&d intensity and commercialization orientation effects on financial performance. Journal of Business Research 59(6) 679-685.

Liu, H., W. Ke, K. K. Wei, Z. Hua. 2013. The impact of it capabilities on firm performance: The mediating roles of absorptive capacity and supply chain agility. Decision Support Systems 54(3) 1452-1462.

Livengood, R. S., R. K. Reger. 2010. That's our turf! identity domains and competitive dynamics. Academy of Management Review 35(1) 48-66.

Meyer, K. E., E. Sinani. 2009. When and where does foreign direct investment generate positive spillovers? a meta-analysis. Journal of International Business Studies 40(7) 1075-1094.

Miller, D., L. Breton-Miller, R. H. Lester, et al. 2011. Family and lone founder ownership and strategic behaviour: Social context, identity, and institutional logics. Journal of Management Studies 48(1) $1-25$.

Miller, D., M.-J. Chen. 1994. Sources and consequences of competitive inertia: A study of the us airline industry. Administrative science quarterly 1-23.

Miller, D., M.-J. Chen. 1996. Nonconformity in competitive repertoires: A sociological view of markets. Social Forces 74(4) 1209-1234.

Mishra, A. A., R. Shah. 2009. In union lies strength: Collaborative competence in new product development and its performance effects. Journal of Operations Management 27(4) 324-338.

Mishra, S., S. B. Modi, A. Animesh. 2013. The relationship between information technology capability, inventory efficiency, and shareholder wealth: A firm-level empirical analysis. Journal of Operations Management 31(6) 298-312.

Modi, S. B., S. Mishra. 2011. What drives financial performance-resource efficiency or resource slack?: Evidence from U.S. Based Manufacturing Firms from 1991 to 2006. Journal of Operations Management 29(3) 254-273.

Moritz, B. B., A. V. Hill, K. L. Donohue. 2013. Individual differences in the newsvendor problem: Behavior and cognitive reflection. Journal of Operations Management 31(1-2) 72-85.

Morris, P. 2013. Reconstructing project management reprised: A knowledge perspective. Project Management Journal 44(5) 6-23.

Moser, R., C. P. J.-W. Kuklinski, M. Srivastava. 2017. Information processing fit in the context of emerging markets: An analysis of foreign sbus in china. Journal of Business Research 70 234-247.

Nadkarni, S., T. Chen, J. Chen. 2016. The clock is ticking! executive temporal depth, industry velocity, and competitive aggressiveness. Strategic Management Journal 37(6) 1132-1153.

Nahmias, S., T. L. Olsen. 2015. Production and Operations Analysis. Waveland Press.

Narver, J. C., S. F. Slater. 1990. The effect of a market orientation on business profitability. The Journal of marketing 20-35. 
Newbert, S. L. 2008. Value, rareness, competitive advantage, and performance: a conceptual-level empirical investigation of the resource-based view of the firm. Strategic management journal 29(7) 745-768.

Nise, N. 2011. Control Systems Engineering. 6th ed. Wiley New York.

Olbert, H., M. Protopappa-Sieke, U. W. Thonemann. 2016. Analyzing the effect of express orders on supply chain costs and delivery times. Production and Operations Management 25(12) 2035-2050.

Özturan, P., A. Özsomer, R. Pieters, 2014. 2014. The role of market orientation in advertising spending during economic collapse: The case of Turkey in 2001. Journal of Marketing Research 51(2) 139-152.

Paterson, C., G. Kiesmüller, R. Teunter, K. Glazebrook. 2011. Inventory models with lateral transshipments: A review. European Journal of Operational Research 210(2) 125-136.

Pinder, C. C. 2014. Work motivation in organizational behavior. Psychology Press.

Randall, T., S. Netessine, N. Rudi. 2006. An empirical examination of the decision to invest in fulfillment capabilities: A study of internet retailers. Management Science 52(4) 567-580.

Rubio, M., S. Schuh. 2017. Monetary policy and the role of inventory investment. Applied Economics Letters 24(21) 1605-1612.

Rumyantsev, S., S. Netessine. 2007a. Should inventory policy be lean or responsive? evidence for u.s. public companies. Working Paper: The Wharton School, University of Pennsylvania, PA and Citigroup Global Markets, Inc., Pages:1-31.

Rumyantsev, S., S. Netessine. 2007b. What can be learned from classical inventory models? Across-industry exploratory investigation. Manufacturing \& Service Operations Management 9(4) 409-429.

Scherrer-Rathje, M., T. A. Boyle, P. Deflorin. 2009. Lean, take two! reflections from the second attempt at lean implementation. Business horizons 52(1) 79-88.

Serpa, J., H. Krishnan. 2017. The impact of supply chains on firm-level productivity. Management Science (Forthcoming).

Shapiro, J. F., S. N. Wagner. 2009. Strategic inventory optimization. Journal of Business Logistics 30(2) $161-173$.

Sharifi, H., Z. Zhang. 1999. A methodology for achieving agility in manufacturing organisations: An introduction. International Journal of Production Economics 62(1) 7-22.

Sichel, D. E. 1994. Inventories and the three phases of the business cycle. Journal of Business $\&$ Economic Statistics 12(3) 269-277.

Siemsen, E., A. V. Roth, S. Balasubramanian. 2008. How motivation, opportunity, and ability drive knowledge sharing: The constraining-factor model. Journal of Operations Management 26(3) 426-445.

Silver, E., D. Pyke, R. Peterson. 1998. Inventory Management and Production Planning and Scheduling. 3rd ed. John Wiley \& Sons. 
Sirmon, D. G., M. A. Hitt, R. D. Ireland. 2007. Managing firm resources in dynamic environments to create value: Looking inside the black box. Academy of management review 32(1) 273-292.

Smith, K. G., W. J. Ferrier, H. Ndofor. 2001. Competitive dynamics research: Critique and future directions. Handbook of strategic management 315-361.

Sommer, A. F., I. Dukovska-Popovska, K. Steger-Jensen. 2014. Barriers towards integrated product development - challenges from a holistic project management perspective. International Journal of Project Management 32(6) 970-982.

Song, L. Z., M. Song, C. A. Di Benedetto. 2011. Resources, supplier investment, product launch advantages, and first product performance. Journal of Operations Management 29(1) 86-104.

Song, Y., H. C. Lau. 2004. A periodic-review inventory model with application to the continuous-review obsolescence problem. European Journal of Operational Research 159(1) 110-120.

Srinivasan, R., A. Rangaswamy, G. L. Lilien. 2005. Turning adversity into advantage: Does proactive marketing during a recession pay off? International Journal of Research in Marketing 22(2) 109-125.

Stadtler, L., H. Lin. 2017. Moving to the Next Strategy Stage: Examining Firms' Awareness, Motivation and Capability Drivers in Environmental Alliances. Business Strategy and the Environment 26(6) 709-730.

Steenkamp, J. B. E. M., E. E. Fang. 2011. The Impact of Economic Contractions on the Effectiveness of R\&D and Advertising: Evidence from U.S. Companies Spanning Three Decades. Marketing Science 30(4) 628-645.

Steinker, S., K. Hoberg. 2013. The impact of inventory dynamics on long-term stock returns - an empirical investigation of U.S. manufacturing companies. Journal of Operations Management 31(5) 250 - 261.

Steinker, S., M. Pesch, K. Hoberg. 2016. Inventory management under financial distress: an empirical analysis. International Journal of Production Research 17(54) 5182-5207.

$\mathrm{Su}$, X. 2008. Bounded rationality in newsvendor models. Manufacturing \& Service Operations Management $\mathbf{1 0}(4) 566-589$.

Sudarsanam, S., J. Lai. 2001. Corporate financial distress and turnaround strategies: an empirical analysis. British Journal of Management 12(3) 183-199.

Svejvig, P., P. Andersen. 2015. Rethinking project management: A structured literature review with a critical look at the brave new world. International Journal of Project Management 33(2) 278-290.

Swafford, P. M., S. Ghosh, N. N. Murthy. 2006. A framework for assessing value chain agility. International Journal of Operations \& Production Management 26(2) 118-140.

Swamidass, P. 2007. The effect of tps on U.S. manufacturing during 1981-1998: inventory increased or decreased as a function of plant performance. International Journal of Production Research 45(16) $3763-3778$. 
Thomas, J. K., H. Zhang. 2002. Inventory changes and future returns. Review of Accounting Studies 7(2-3) $163-187$.

Tobin, J. 1958. Estimation of relationships for limited dependent variables. Econometrica: journal of the Econometric Society 24-36.

Tribó, J. A. 2001. Inventories, financial structure and market structure. International Journal of Production Economics 71(1) 79-89.

Uçkun, C., F. Karaesmen, S. Savaş. 2008. Investment in improved inventory accuracy in a decentralized supply chain. International Journal of Production Economics 113(2) 546-566.

Udenio, M., J. C. Fransoo, R. Peels. 2015. Destocking, the bullwhip effect, and the credit crisis: Empirical modeling of supply chain dynamics. International Journal of Production Economics 160 34-46.

Van Biesebroeck, J., T. J. Sturgeon. 2010. Effects of the 2008-09 crisis on the automotive industry in developing countries: a global value chain perspective. Washington DC: World Bank.

Vissa, B., H. R. Greve, W.-R. Chen. 2010. Business group affiliation and firm search behavior in india: Responsiveness and focus of attention. Organization Science 21(3) 696-712.

Wuyts, S., S. Dutta, S. Stremersch. 2004. Portfolios of interfirm agreements in technology-intensive markets: Consequences for innovation and profitability. Journal of marketing 68(2) 88-100.

Yin, R., Y. Aviv, A. Pazgal, C. S. Tang. 2009. Optimal markdown pricing: Implications of inventory display formats in the presence of strategic customers. Management Science 55(8) 1391-1408.

York, K. M., C. E. Miree. 2004. Causation or covariation: an empirical re-examination of the link between tqm and financial performance. Journal of Operations Management 22(3) 291-311.

Zaman, A. 2017. Cash holding and technological development: Evidence from it-mediated improvement in inventory management. (Working Paper Presented at the 2017 FMA Meetings) .

Zhou, H., W. Benton Jr. 2007. Supply chain practice and information sharing. Journal of Operations management 25(6) 1348-1365. 
Table 8 Summary statistics (Quarterly data, values in million \$, 2005-2011 period).

\begin{tabular}{|c|c|c|c|c|c|c|c|c|}
\hline Segment & $\begin{array}{l}\text { NAICS } \\
\text { Codes }\end{array}$ & Firms & $\begin{array}{l}\text { COGS Mean } \\
\text { (Median, SD) }\end{array}$ & $\begin{array}{l}\text { Inventory Mean } \\
(\text { Median, SD) }\end{array}$ & $\begin{array}{l}\text { Fixed Assets Mean } \\
\text { (Median, SD) }\end{array}$ & $\begin{array}{l}\text { Tobins Q Mean } \\
\text { (Median, SD) }\end{array}$ & $\begin{array}{l}\text { Altmans Z Mean } \\
\text { (Median, SD) }\end{array}$ & $\begin{array}{l}\text { ROS Mean } \\
\text { (Median, SD) }\end{array}$ \\
\hline $\begin{array}{l}\text { Food, Beverage, } \\
\text { and Tobacco }\end{array}$ & 311,312 & 89 & $\begin{array}{c}922.32 \\
(181.31,2180.81)\end{array}$ & $\begin{array}{c}619.23 \\
(107.81,1301.46)\end{array}$ & $\begin{array}{c}5728.75 \\
(800.68,13041.47)\end{array}$ & $\begin{array}{c}1.59 \\
(1.23,1.34)\end{array}$ & $\begin{array}{c}3.13 \\
(2.08,4.02)\end{array}$ & $\begin{array}{c}0.07 \\
(0.08,0.44)\end{array}$ \\
\hline $\begin{array}{l}\text { Textiles, Apparel, } \\
\text { and Leather }\end{array}$ & $\begin{array}{l}313,314 \\
315,316\end{array}$ & 49 & $\begin{array}{c}226.95 \\
(91.16,403.02)\end{array}$ & $\begin{array}{c}249.3 \\
(110.92,397.44)\end{array}$ & $\begin{array}{c}1333.34 \\
(440.61,2262.36)\end{array}$ & $\begin{array}{c}1.17 \\
(0.92,1.02)\end{array}$ & $\begin{array}{c}4.08 \\
(2.85,4.31)\end{array}$ & $\begin{array}{c}0.06 \\
(0.08,0.11)\end{array}$ \\
\hline Paper and Publishing & 322,323 & 46 & $\begin{array}{c}668.77 \\
(212.52,1056.5)\end{array}$ & $\begin{array}{c}420.04 \\
(125.95,699.4)\end{array}$ & $\begin{array}{c}4155.59 \\
(1402.14,6778.54)\end{array}$ & $\begin{array}{c}0.97 \\
(0.87,0.46)\end{array}$ & $\begin{array}{c}1.69 \\
(1.52,1.27)\end{array}$ & $\begin{array}{c}0.08 \\
(0.08,0.07)\end{array}$ \\
\hline Chemicals and Plastics & 325,326 & 199 & $\begin{array}{c}586.16 \\
(92.13,1546.45)\end{array}$ & $\begin{array}{c}614.57 \\
(81.25,1458.96)\end{array}$ & $\begin{array}{c}6951.79 \\
(702.18,19706.82)\end{array}$ & $\begin{array}{c}1.85 \\
(1.23,2.20)\end{array}$ & $\begin{array}{c}3.56 \\
(2.17,12.25)\end{array}$ & $\begin{array}{c}0.01 \\
(0.09,0.52)\end{array}$ \\
\hline Metal & 331,332 & 89 & $\begin{array}{c}634.34 \\
(128.19,2065.48)\end{array}$ & $\begin{array}{c}443.97 \\
(125.01,1022.58)\end{array}$ & $\begin{array}{c}3626.6 \\
(625.4,12970.54)\end{array}$ & $\begin{array}{c}1.23 \\
(0.96,1.39)\end{array}$ & $\begin{array}{c}3.14 \\
(2.19,4.81)\end{array}$ & $\begin{array}{c}0.08 \\
(0.09,0.13)\end{array}$ \\
\hline Machinery & 333 & 122 & $\begin{array}{c}395.88 \\
(70.83,942.00)\end{array}$ & $\begin{array}{c}420.72 \\
(88.31,960.27)\end{array}$ & $\begin{array}{c}3129.17 \\
(493.32,8925.68)\end{array}$ & $\begin{array}{c}1.36 \\
(1.11,1.19)\end{array}$ & $\begin{array}{c}3.01 \\
(2.66,5.62)\end{array}$ & $\begin{array}{c}0.05 \\
(0.09,0.28)\end{array}$ \\
\hline $\begin{array}{l}\text { Computer, Electronics, } \\
\text { and Electrical Equipment }\end{array}$ & 334,335 & 441 & $\begin{array}{c}480.21 \\
(26.65,2018.00)\end{array}$ & $\begin{array}{c}284.58 \\
(27.18,971.13)\end{array}$ & $\begin{array}{c}3243.75 \\
(231.44,11691.93)\end{array}$ & $\begin{array}{c}1.54 \\
(1.04,2.38)\end{array}$ & $\begin{array}{c}2.91 \\
(2.59,12.73)\end{array}$ & $\begin{array}{c}-0.04 \\
(0.05,1.75)\end{array}$ \\
\hline Transportation Equipment & 336 & 75 & $\begin{array}{c}1793.24 \\
(158.46,4333.98)\end{array}$ & $\begin{array}{c}926.35 \\
(114.21,2048.87)\end{array}$ & $\begin{array}{c}9879.9 \\
(761.10,29647.26)\end{array}$ & $\begin{array}{c}1.16 \\
(0.86,1.40)\end{array}$ & $\begin{array}{c}1.95 \\
(1.92,5.72)\end{array}$ & $\begin{array}{c}0.06 \\
(0.07,0.15)\end{array}$ \\
\hline Other & & 153 & $\begin{array}{c}2856.03 \\
(76.85,11182.15) \\
\end{array}$ & $\begin{array}{c}619.29 \\
(71.04,1747.64) \\
\end{array}$ & $\begin{array}{c}12483.62 \\
(513.88,45063.93)\end{array}$ & $\begin{array}{c}1.44 \\
(1.09,1.28) \\
\end{array}$ & $\begin{array}{c}2.69 \\
(2.30,5.66) \\
\end{array}$ & $\begin{array}{c}0.04 \\
(0.07,0.21) \\
\end{array}$ \\
\hline Total & & 1263 & $\begin{array}{c}893.59 \\
(66.45,4411.68)\end{array}$ & $\begin{array}{c}466.76 \\
(61.26,1274.30)\end{array}$ & $\begin{array}{c}5491.46 \\
(455.39,21239.70)\end{array}$ & $\begin{array}{c}1.49 \\
(1.06,1.89)\end{array}$ & $\begin{array}{c}2.98 \\
(2.33,9.79)\end{array}$ & $\begin{array}{c}0.02 \\
(0.07,1.07)\end{array}$ \\
\hline
\end{tabular}

\section{Appendix}

\section{A. Additional descriptive statistics}

Table 8 summarizes our dataset. Note that the income statement item for sales and the cost of goods sold relate to quarterly values, whereas the balance sheet items of inventory and total assets relate to the actual values on the reporting date. Average values are typically above median values, highlighting the positive skewness of the data for most variables. Table 9 shows the dynamic sales performance (see §4.2). Table 10 shows the evolution of inventory days and normalized inventory days split among raw material, WIP, and finished goods components. The table also shows the average values of the pre-crisis period and short-, medium- and long-term crisis periods. In all cases, the differences between pre- and post-crisis averages are significant at the $p=0.05$ level (two-sample Wilcoxon Mann-Whitney rank-sum test). Raw material and finished goods component inventories increased significantly following the onset of the crisis, and it took manufacturers nearly 6 quarters to return to pre-crisis levels. WIP inventories, by contrast, were managed responsively - manufacturing firms pulled operational levers to keep WIP inventories under control. This action helped mitigate the effect of the increase in raw material and finished goods components, which required a longer time to be reverted. At this level, we see no evidence of widespread inventory takeovers of suppliers, which would skew the sample further in the direction of finished goods rather than raw material inventories.

\section{B. Sales and inventory forecasting}

To calculate abnormal inventory days and sales in the crisis period, we must first calculate the normal inventory days and sales. Each firm might have a different preferred way to build up and reduce inventories throughout the year, as well as different sales patterns. We therefore forecast sales and inventory days individually for each firm based on the pre-crisis period. Thus, rather than using a fixed a priori defined forecasting methodology, we test alternative forecasting approaches for each firm to fit the inventory days (and sales) during the pre-crisis period. Following this, we use the best-fit forecast per firm to produce an 
Table 9 Descriptive statistics of dynamic sales performance.

\begin{tabular}{|c|c|c|c|c|c|c|}
\hline Industry & $\begin{array}{l}|N S A L E|_{+}^{4} \\
\text { Mean (Median, SD) }\end{array}$ & $\begin{array}{l}|N S A L E|_{+}^{8} \\
\text { Mean (Median, SD) }\end{array}$ & $\begin{array}{l}|N S A L E|_{+}^{12} \\
\text { Mean (Median, SD) }\end{array}$ & $\begin{array}{l}|N S A L E|_{-}^{4} \\
\text { Mean (Median, SD) }\end{array}$ & $\begin{array}{l}|N S A L E|_{-}^{8} \\
\text { Mean (Median, SD) }\end{array}$ & $\begin{array}{l}|N S A L E|_{-}^{12} \\
\text { Mean (Median, SD) }\end{array}$ \\
\hline Food, Beverage, \& Tobacco & $0.43(0.12,1.05)$ & $0.98(0.22,2.39)$ & $1.87(0.46,4.48)$ & $0.33(0.16,0.46)$ & $0.77(0.49,0.98)$ & $1.22(0.62,1.64)$ \\
\hline Textiles, Apparel, \& Leather & $0.20(0.01,0.45)$ & $0.59(0.04,1.17)$ & $1.16(0.15,2.21)$ & $0.45(0.42,0.39)$ & $1.04(0.94,0.91)$ & $1.56(1.19,1.48)$ \\
\hline Paper \& Publishing & $0.21(0.02,0.48)$ & $0.49(0.02,1.21)$ & $1.05(0.06,2.47)$ & $0.57(0.49,0.47)$ & $1.20(1.03,0.98)$ & $1.79(1.58,1.51)$ \\
\hline Chemicals \& Plastics & $0.34(0.06,0.61)$ & $0.78(0.13,1.44)$ & $1.48(0.28,2.67)$ & $0.53(0.36,0.62)$ & $1.14(0.88,1.34)$ & $1.74(1.17,2.13)$ \\
\hline Metal & $0.15(0.00,0.28)$ & $0.26(0.02,0.68)$ & $0.55(0.05,1.39)$ & $0.96(0.91,0.6)$ & $2.23(2.03,1.30)$ & $3.25(3.26,2.09)$ \\
\hline Machinery & $0.27(0.02,0.82)$ & $0.66(0.04,2.01)$ & $1.41(0.12,3.79)$ & $1.01(0.76,1.15)$ & $2.22(1.89,1.98)$ & $3.09(2.52,2.79)$ \\
\hline Computer, Electr., \& Equip. & $0.24(0.03,0.51)$ & $0.60(0.1,1.17)$ & $1.29(0.26,2.42)$ & $0.81(0.59,0.88)$ & $1.72(1.21,1.86)$ & $2.57(1.71,2.98)$ \\
\hline Transportation Equipment & $0.09(0.00,0.3)$ & $0.25(0.00,0.65)$ & $0.67(0.04,1.47)$ & $0.80(0.74,0.65)$ & $1.63(1.74,1.18)$ & $2.22(2.09,1.66)$ \\
\hline Other & $0.16(0.01,0.33)$ & $0.40(0.02,0.98)$ & $0.83(0.05,2.08)$ & $0.65(0.53,0.71)$ & $1.45(1.04,1.52)$ & $2.23(1.62,2.33)$ \\
\hline Total & $0.24(0.02,0.58)$ & $0.58(0.06,1.38)$ & $1.21(0.16,2.69)$ & $0.72(0.54,0.80)$ & $1.56(1.18,1.63)$ & $2.31(1.71,2.52)$ \\
\hline
\end{tabular}

Table 10 Development of inventory components in manufacturing firms, 2005-2011.

\begin{tabular}{|c|c|c|c|c|c|c|c|c|c|c|c|c|c|c|}
\hline \multirow[b]{2}{*}{ Year } & \multirow[b]{2}{*}{ Quarter } & \multirow[b]{2}{*}{ Period } & \multicolumn{3}{|c|}{ Raw Material } & \multicolumn{3}{|c|}{ WIP } & \multicolumn{3}{|c|}{ Finished Goods } & \multicolumn{3}{|c|}{ Total } \\
\hline & & & Mean & Median & SD & Mean & Median & SD & Mean & Median & SD & Mean & Median & SD \\
\hline \multirow[t]{2}{*}{2005} & 3 & -12 & 37.3 & 27.7 & 34.8 & 23.4 & 13.4 & 29.4 & 43.7 & 32.1 & 40.1 & 100.3 & 81.9 & 70.1 \\
\hline & 4 & -11 & 35.5 & 25.7 & 32.8 & 22.3 & 12.4 & 29.2 & 41.4 & 31.8 & 37.8 & 96.5 & 78.8 & 66.7 \\
\hline \multirow[t]{4}{*}{2006} & 1 & -10 & 36.8 & 27.8 & 33.2 & 23.4 & 14.2 & 29.2 & 43.9 & 33.4 & 39.8 & 101.1 & 84.9 & 67.0 \\
\hline & 2 & -9 & 36.8 & 28.6 & 32.0 & 22.9 & 13.2 & 28.3 & 44.9 & 33.3 & 41.5 & 100.2 & 84.3 & 66.8 \\
\hline & 3 & -8 & 37.6 & 28.7 & 33.3 & 23.0 & 13.4 & 28.3 & 45.2 & 34.1 & 41.0 & 102.2 & 84.3 & 69.0 \\
\hline & 4 & -7 & 37.1 & 27.6 & 34.0 & 22.9 & 12.5 & 29.8 & 43.2 & 33.2 & 38.7 & 99.3 & 82.1 & 66.7 \\
\hline \multirow[t]{4}{*}{2007} & 1 & -6 & 38.8 & 29.5 & 35.5 & 23.9 & 13.6 & 30.2 & 46.1 & 35.1 & 40.6 & 104.9 & 87.6 & 69.0 \\
\hline & 2 & -5 & 38.2 & 28.3 & 35.2 & 23.6 & 13.0 & 29.9 & 46.4 & 34.7 & 42.3 & 103.8 & 85.3 & 69.8 \\
\hline & 3 & -4 & 37.1 & 28.0 & 33.1 & 23.1 & 13.7 & 29.1 & 45.9 & 32.7 & 41.9 & 101.9 & 84.3 & 68.3 \\
\hline & 4 & -3 & 36.6 & 27.0 & 33.4 & 22.2 & 11.5 & 29.6 & 43.7 & 32.6 & 40.2 & 99.3 & 82.2 & 65.4 \\
\hline \multirow[t]{4}{*}{2008} & 1 & -2 & 38.5 & 29.0 & 34.1 & 23.5 & 13.1 & 30.3 & 47.9 & 36.1 & 43.1 & 106.4 & 88.9 & 70.2 \\
\hline & 2 & -1 & 38.8 & 28.5 & 36.2 & 22.8 & 12.4 & 28.8 & 46.7 & 35.3 & 42.3 & 104.8 & 87.1 & 68.6 \\
\hline & 3 & 1 & 39.3 & 28.5 & 36.1 & 23.7 & 13.0 & 30.3 & 46.8 & 35.0 & 42.7 & 107.3 & 87.9 & 72.4 \\
\hline & 4 & 2 & 41.0 & 29.4 & 38.0 & 23.4 & 11.9 & 30.8 & 50.1 & 37.2 & 45.3 & 111.2 & 92.2 & 74.4 \\
\hline \multirow[t]{4}{*}{2009} & 1 & 3 & 45.0 & 32.8 & 40.7 & 25.6 & 13.8 & 32.4 & 55.8 & 42.4 & 49.7 & 122.0 & 98.6 & 80.9 \\
\hline & 2 & 4 & 42.5 & 31.3 & 38.6 & 24.4 & 12.5 & 31.4 & 51.6 & 38.5 & 46.2 & 116.0 & 92.8 & 78.1 \\
\hline & 3 & 5 & 39.9 & 28.7 & 36.8 & 23.3 & 12.1 & 30.1 & 48.2 & 34.9 & 43.5 & 108.4 & 86.5 & 74.1 \\
\hline & 4 & 6 & 37.6 & 28.3 & 34.4 & 22.7 & 10.6 & 30.9 & 44.3 & 32.9 & 39.7 & 103.1 & 82.6 & 71.4 \\
\hline \multirow[t]{4}{*}{2010} & 1 & 7 & 38.3 & 29.0 & 34.3 & 23.9 & 12.5 & 30.6 & 46.5 & 34.3 & 41.4 & 105.2 & 87.6 & 69.7 \\
\hline & 2 & 8 & 36.7 & 28.0 & 33.0 & 22.5 & 11.5 & 29.3 & 44.7 & 32.5 & 41.1 & 101.1 & 84.1 & 67.0 \\
\hline & 3 & 9 & 37.4 & 28.7 & 33.0 & 23.2 & 12.2 & 30.2 & 45.4 & 34.2 & 41.4 & 103.0 & 85.6 & 68.6 \\
\hline & 4 & 10 & 36.7 & 28.3 & 32.4 & 22.3 & 10.8 & 30.1 & 43.9 & 32.8 & 39.3 & 101.6 & 86.7 & 66.4 \\
\hline \multirow[t]{2}{*}{2011} & 1 & 11 & 38.9 & 30.9 & 33.1 & 23.9 & 12.3 & 31.0 & 47.6 & 35.9 & 42.4 & 107.1 & 93.8 & 68.0 \\
\hline & 2 & 12 & 38.7 & 30.1 & 33.9 & 23.8 & 12.0 & 30.8 & 46.6 & 35.1 & 41.5 & 106.3 & 90.9 & 68.2 \\
\hline \multicolumn{3}{|c|}{ Pre-Crisis $(-12 \leq p \leq-1)$} & 37.4 & 27.9 & 33.9 & 23.1 & 13.1 & 29.3 & 45.0 & 33.8 & 41.0 & 101.8 & 84.4 & 68.3 \\
\hline \multicolumn{3}{|c|}{ Crisis short-term $(1<p<4)$} & 42.0 & 30.5 & 38.3 & 24.3 & 12.8 & 31.2 & 51.1 & 38.3 & 45.9 & 114.1 & 92.9 & 76.4 \\
\hline \multicolumn{3}{|c|}{ Crisis med-term $(1 \leq p \leq 8)$} & 40.0 & 29.5 & 36.5 & 23.7 & 12.2 & 30.7 & 48.5 & 36.0 & 43.7 & 109.3 & 89.0 & 73.5 \\
\hline \multicolumn{3}{|c|}{ Crisis long-term $(1 \leq p \leq 12)$} & 39.3 & 29.5 & 35.4 & 23.5 & 12.1 & 30.7 & 47.6 & 35.5 & 42.8 & 107.7 & 89.1 & 71.6 \\
\hline \multicolumn{3}{|c|}{$\Delta$ Crisis med-term/Pre-Crisis } & $7.0 \%$ & $5.5 \%$ & $7.6 \%$ & $2.4 \%$ & $-6.5 \%$ & $4.8 \%$ & $7.7 \%$ & $6.3 \%$ & $6.6 \%$ & $7.3 \%$ & $5.5 \%$ & $7.6 \%$ \\
\hline
\end{tabular}

Note: Only for manufacturing firms with inventory breakdown available for all quarters (991 firms, 27,748 firm-quarters).

out-of-sample forecast for each crisis period $\left(\widehat{I D}_{p} ; \widehat{S A L E}_{p}\right)$. We apply four standard forecasting approaches with/without a linear trend and with/without seasonality: a simple moving average forecast (no trend, no seasonality) (Silver et al. 1998); Holt-Winters double exponential smoothing (trend, no seasonality) (Silver et al. 1998); a percentage moving average seasonal estimation method (no trend, seasonality) (Nahmias and Olsen 2015); and Holt-Winters triple exponential smoothing (trend, seasonality) (Nahmias and Olsen 2015) Based on the forecast errors of these approaches, we identify the approach with the best fit for each firm. As an example, Table 11 shows the percentage of firms for which we use each forecasting method for inventory days per sub-sector. We see that the inventory trajectory for a majority of the firms has a trend and a 
seasonality component. Results for sales are similar.

Table 11 Forecasting methodologies applied for crisis period inventory projection.

\begin{tabular}{|c|c|c|c|c|}
\hline \multirow[b]{2}{*}{ Industry } & \multicolumn{4}{|c|}{$\begin{array}{c}\text { Inventory Projection } \\
\text { (Trend / Seasonality) }\end{array}$} \\
\hline & $\mathrm{No} / \mathrm{No}$ & $\mathrm{Yes} / \mathrm{No}$ & $\mathrm{No} / \mathrm{Yes}$ & Yes/Yes \\
\hline Food, Beverage \& Tobacco & $1.1 \%$ & $12.4 \%$ & $22.5 \%$ & $64.0 \%$ \\
\hline Textiles, Apparel \& Leather & $0.0 \%$ & $8.2 \%$ & $26.5 \%$ & $65.3 \%$ \\
\hline Paper \& Publishing & $0.0 \%$ & $21.7 \%$ & $23.9 \%$ & $54.3 \%$ \\
\hline Chemicals \& Plastics & $2.5 \%$ & $18.3 \%$ & $27.7 \%$ & $51.5 \%$ \\
\hline Metal & $4.4 \%$ & $16.5 \%$ & $18.7 \%$ & $60.4 \%$ \\
\hline Machinery & $0.8 \%$ & $18.5 \%$ & $27.4 \%$ & $53.2 \%$ \\
\hline Computer, Electronics \& Electrical Equipment & $4.1 \%$ & $27.4 \%$ & $20.4 \%$ & $48.2 \%$ \\
\hline Transportation Equipment & $3.8 \%$ & $20.0 \%$ & $26.3 \%$ & $50.0 \%$ \\
\hline Other & $0.0 \%$ & $16.2 \%$ & $26.6 \%$ & $57.1 \%$ \\
\hline Total & $1.8 \%$ & $17.7 \%$ & $24.4 \%$ & $56.0 \%$ \\
\hline
\end{tabular}

Table 12 shows the projection errors in the data. For the crisis period, the inventory day projection error is an indicator of abnormal firm inventories, controlling for trends and seasonality present in the data.

Table 12 Deviation of firm-level inventory levels from projections.

\begin{tabular}{|c|c|c|c|c|c|c|}
\hline \multirow[b]{2}{*}{ Year } & \multirow[b]{2}{*}{ Quarter } & \multirow[b]{2}{*}{ Period } & \multicolumn{2}{|c|}{$\Delta \mathrm{ID}$} & \multicolumn{2}{|c|}{$\Delta N I D$} \\
\hline & & & Mean & Median & Mean & Median \\
\hline \multirow[t]{2}{*}{2005} & 3 & -12 & 1.65 & 0.88 & $0.97 \%$ & $1.74 \%$ \\
\hline & 4 & -11 & 0.95 & 0.39 & $-4.59 \%$ & $0.50 \%$ \\
\hline \multirow[t]{4}{*}{2006} & 1 & -10 & -0.80 & -0.24 & $-1.21 \%$ & $-0.51 \%$ \\
\hline & 2 & -9 & -0.22 & 0.24 & $0.67 \%$ & $0.33 \%$ \\
\hline & 3 & -8 & 0.51 & 0.21 & $1.12 \%$ & $0.59 \%$ \\
\hline & 4 & -7 & 1.93 & 0.50 & $-2.70 \%$ & $0.61 \%$ \\
\hline \multirow[t]{4}{*}{2007} & 1 & -6 & 1.75 & 0.34 & $0.46 \%$ & $0.69 \%$ \\
\hline & 2 & -5 & 1.91 & 0.14 & $0.93 \%$ & $0.36 \%$ \\
\hline & 3 & -4 & -0.91 & -0.08 & $-0.63 \%$ & $0.06 \%$ \\
\hline & 4 & -3 & 0.15 & -0.14 & $-0.63 \%$ & $-0.48 \%$ \\
\hline \multirow[t]{4}{*}{2008} & 1 & -2 & 1.61 & 0.41 & $-1.01 \%$ & $0.66 \%$ \\
\hline & 2 & -1 & 0.91 & 0.07 & $-1.97 \%$ & $0.00 \%$ \\
\hline & 3 & 1 & 2.11 & 0.00 & $6.28 \%$ & $0.64 \%$ \\
\hline & 4 & 2 & 8.23 & 3.75 & $15.36 \%$ & $5.58 \%$ \\
\hline \multirow[t]{4}{*}{2009} & 1 & 3 & 13.26 & 5.04 & $21.18 \%$ & $8.55 \%$ \\
\hline & 2 & 4 & 9.61 & 3.53 & $21.52 \%$ & $5.63 \%$ \\
\hline & 3 & 5 & 1.43 & 0.23 & $11.88 \%$ & $1.33 \%$ \\
\hline & 4 & 6 & -1.81 & -0.76 & $13.17 \%$ & $-1.17 \%$ \\
\hline \multirow[t]{2}{*}{2010} & 1 & 7 & -2.40 & -1.53 & $13.00 \%$ & $-2.04 \%$ \\
\hline & 2 & 8 & -2.25 & -2.07 & $17.45 \%$ & $-3.51 \%$ \\
\hline \multicolumn{3}{|c|}{ Pre-Crisis $(-12 \leq p \leq-1)$} & 0.79 & 0.18 & $-0.71 \%$ & $0.29 \%$ \\
\hline \multicolumn{3}{|c|}{ Crisis $(1 \leq \bar{p} \leq 8)$} & 3.53 & 1.22 & $14.98 \%$ & $2.20 \%$ \\
\hline
\end{tabular}


Blinded for Peer Review

Table 13 Inventory dynamics CFM regression analysis: full output.

\begin{tabular}{|c|c|c|c|c|c|c|c|c|c|c|c|c|}
\hline \multirow{3}{*}{$\begin{array}{l}\text { Variable } \\
\log (\mathrm{MktO})\end{array}$} & \multicolumn{6}{|c|}{ Normalized Inventory Agility } & \multicolumn{6}{|c|}{ Absolute Inventory Agility } \\
\hline & \multicolumn{2}{|c|}{$\log \left(\operatorname{InvAg)^{4}}\right.$} & \multicolumn{2}{|c|}{$\log \left(\operatorname{InvAg)^{8}}\right.$} & \multicolumn{2}{|c|}{$\log (\operatorname{InvAg})^{12}$} & \multicolumn{2}{|c|}{$\log (A b s \operatorname{InvAg})^{4}$} & \multicolumn{2}{|c|}{$\log (A b s \operatorname{Inv} A g)^{8}$} & \multicolumn{2}{|c|}{$\log (A b s I n v A g)^{12}$} \\
\hline & 2.26 & $(2.92)$ & 3.17 & $(4.03)$ & 4.92 & $(5.09)$ & -0.58 & $(10.51)$ & 5.69 & $(10.01)$ & 8.64 & $(10.44)$ \\
\hline $\log (\operatorname{techO})$ & 4.12 & $(3.06)$ & 5.98 & (4.44) & 7.86 & $(5.62)$ & 12.88 & $(13.26)$ & 11.03 & $(15.12)$ & 12.01 & $(16.47)$ \\
\hline $\log ($ GrossM $)$ & $-4.57^{*}$ & $(2.42)$ & $-6.18^{*}$ & (3.16) & $-7.18^{*}$ & (3.78) & $-10.88^{*}$ & $(6.23)$ & $-12.98 * *$ & $(6.36)$ & $-12.50^{*}$ & $(6.62)$ \\
\hline $\log (\operatorname{Liq})$ & -0.07 & $(0.32)$ & -0.56 & $(0.46)$ & -0.76 & $(0.56)$ & -0.13 & $(1.05)$ & -1.48 & (1.11) & -1.69 & $(1.22)$ \\
\hline $\log ($ InvCap $)$ & $19.19^{* * *}$ & $(3.61)$ & $26.47^{* * *}$ & $(5.02)$ & $28.99 * * *$ & $(6.27)$ & $66.08 * * *$ & $(10.77)$ & $70.74^{* * *}$ & $(11.53)$ & $69.21 * * *$ & $(12.15)$ \\
\hline $\log (\operatorname{Res} A v)$ & 0.00 & $(0.02)$ & 0.00 & $(0.02)$ & 0.00 & $(0.03)$ & 0.02 & $(0.06)$ & 0.02 & $(0.07)$ & 0.04 & $(0.07)$ \\
\hline$\theta_{\text {Techo }}$ & -23.76 & $(72.29)$ & 13.98 & $(115.89)$ & 56.65 & $(146.85)$ & -94.64 & $(307.64)$ & 8.78 & $(362.05)$ & 179.40 & $(368.22)$ \\
\hline$\theta_{\text {Techo }} \times \log ($ MktIntensity $)$ & 2.92 & $(2.66)$ & 5.05 & $(3.75)$ & 5.02 & $(4.84)$ & 5.97 & $(10.51)$ & 4.63 & $(9.29)$ & 3.57 & $(9.53)$ \\
\hline$\theta_{\text {Techo }} \times \log (R \&$ Dintensity $)$ & 21.47 & $(40.35)$ & 3.03 & $(65.04)$ & -19.08 & $(82.48)$ & 89.22 & $(172.65)$ & 34.20 & $(203.36)$ & -65.81 & $(206.60)$ \\
\hline$\theta_{\text {Techo }} \times \log ($ Gross $M)$ & -1.30 & $(2.65)$ & -2.84 & $(3.53)$ & -3.88 & $(4.22)$ & -1.97 & $(8.27)$ & -3.66 & $(8.38)$ & -4.33 & $(8.69)$ \\
\hline$\theta_{\text {TechO }} \times \log (\operatorname{Liq})$ & 0.02 & $(0.32)$ & 0.52 & $(0.47)$ & 0.70 & $(0.57)$ & -0.42 & $(1.09)$ & 1.03 & (1.14) & 1.24 & $(1.25)$ \\
\hline$\theta_{\text {Techo }} \times \log (\operatorname{Inv} C a p)$ & $-9.17^{*}$ & $(4.76)$ & $-12.72^{*}$ & $(7.09)$ & -13.47 & $(8.95)$ & $-37.02^{* * *}$ & $(13.70)$ & $-38.31 * *$ & $(15.45)$ & $-32.43^{* *}$ & $(15.46)$ \\
\hline$\theta_{\text {Techo }} \times \log (R E S)$ & 0.01 & $(0.02)$ & 0.03 & $(0.03)$ & 0.03 & $(0.03)$ & 0.02 & $(0.07)$ & 0.06 & $(0.08)$ & 0.04 & $(0.08)$ \\
\hline$\theta_{\text {Gross } M}$ & $38.66 * * *$ & $(13.12)$ & $55.22^{* * *}$ & $(19.55)$ & $67.09^{* * *}$ & $(25.50)$ & $124.92^{* *}$ & $(52.16)$ & $144.85^{* *}$ & $(60.19)$ & $154.63^{* *}$ & $(63.50)$ \\
\hline$\theta_{\text {Gross } M} \times \log ($ MktIntensity $)$ & -3.48 & $(3.33)$ & -7.08 & $(4.70)$ & -8.76 & $(5.91)$ & -3.99 & $(12.35)$ & -11.64 & $(12.52)$ & -10.90 & $(12.90)$ \\
\hline$\theta_{\text {Gross } M} \times \log (R \&$ Dintensity $)$ & -4.28 & $(3.62)$ & -6.85 & $(5.25)$ & -10.33 & $(6.68)$ & -13.78 & $(16.24)$ & -17.81 & $(18.49)$ & -20.52 & $(19.98)$ \\
\hline$\theta_{\text {Gross } M} \times \log ($ Gross $M)$ & 3.95 & $(2.97)$ & 6.75 & $(4.11)$ & 6.87 & $(5.08)$ & 7.67 & $(10.32)$ & 12.40 & $(11.27)$ & 5.97 & $(11.27)$ \\
\hline$\theta_{G r o s s M} \times \log (L i q)$ & -0.19 & $(0.36)$ & -0.09 & $(0.52)$ & 0.05 & $(0.64)$ & -1.00 & $(1.29)$ & -0.42 & $(1.38)$ & 0.06 & $(1.47)$ \\
\hline$\theta_{\text {Gross } M} \times \log (\operatorname{InvCap})$ & $-16.40^{* * *}$ & $(5.13)$ & $-21.98^{* * *}$ & $(7.69)$ & $-23.65^{* *}$ & $(9.91)$ & $-54.26 * * *$ & $(17.45)$ & $-58.78 * * *$ & $(20.04)$ & $-56.45 * * *$ & $(20.53)$ \\
\hline$\theta_{\text {Gross } M} \times \log (R E S)$ & $0.04^{*}$ & $(0.02)$ & 0.05 & $(0.03)$ & $0.07^{*}$ & $(0.04)$ & 0.04 & $(0.09)$ & 0.04 & $(0.10)$ & 0.06 & $(0.11)$ \\
\hline$\theta_{\text {Liq }}$ & $34.30^{* *}$ & $(14.27)$ & $38.99^{*}$ & $(20.27)$ & $43.22^{*}$ & $(26.21)$ & $126.54^{* *}$ & $(52.08)$ & $129.15^{* *}$ & $(54.88)$ & $126.40^{* *}$ & $(59.21)$ \\
\hline$\theta_{\text {Liq }} \times \log ($ MktIntensity $)$ & -0.57 & $(3.36)$ & 0.10 & $(4.73)$ & -0.42 & $(6.02)$ & 3.72 & $(13.13)$ & -3.27 & $(13.00)$ & -5.02 & $(13.79)$ \\
\hline$\theta_{L i q} \times \log (R \&$ Dintensity $)$ & -6.95 & $(4.49)$ & -8.70 & $(6.33)$ & -12.68 & $(8.30)$ & -16.58 & $(16.68)$ & -13.50 & $(18.23)$ & -18.60 & $(19.91)$ \\
\hline$\theta_{\text {Liq }} \times \log ($ Gross $M)$ & 3.88 & $(2.88)$ & 5.17 & $(3.89)$ & 7.23 & $(4.81)$ & 10.13 & $(10.09)$ & 14.78 & $(10.14)$ & $18.27^{*}$ & $(10.74)$ \\
\hline$\theta_{\text {Liq }} \times \log (L i q)$ & -0.07 & $(0.36)$ & 0.35 & $(0.51)$ & 0.54 & $(0.63)$ & -0.23 & $(1.22)$ & 0.61 & $(1.25)$ & 0.60 & $(1.36)$ \\
\hline$\theta_{\text {Liq }} \times \log (\operatorname{Inv} C a p)$ & $-14.44^{* *}$ & $(5.83)$ & $-17.63^{* *}$ & $(8.28)$ & $-17.84^{*}$ & (10.62) & $-63.14^{* * *}$ & $(19.95)$ & $-65.88 * * *$ & $(20.36)$ & $-61.29^{* * *}$ & $(21.81)$ \\
\hline$\theta_{L i q} \times \log (R E S)$ & 0.02 & $(0.03)$ & 0.03 & $(0.04)$ & 0.03 & $(0.06)$ & 0.04 & $(0.13)$ & -0.05 & $(0.12)$ & -0.08 & $(0.13)$ \\
\hline$\theta_{\text {InCCap }}$ & $32.76^{* * *}$ & $(11.96)$ & $50.34^{* * *}$ & $(17.41)$ & $59.80 * * *$ & (21.78) & $88.35^{*}$ & $(45.81)$ & $97.63^{*}$ & $(52.14)$ & $94.07^{*}$ & $(55.98)$ \\
\hline$\theta_{\text {IneCap }} \times \log ($ MktIntensity $)$ & 2.25 & $(3.33)$ & 2.98 & $(4.65)$ & 2.75 & (5.89) & 16.75 & $(12.38)$ & 12.74 & $(12.40)$ & 6.21 & $(12.91)$ \\
\hline$\theta_{\text {InwCap }} \times \log (R \&$ Dintensity $)$ & $-14.13^{* * *}$ & $(4.73)$ & $-21.90^{* * *}$ & $(6.92)$ & $-27.17^{* * *}$ & $(8.70)$ & $-34.22^{*}$ & $(19.52)$ & $-42.57^{*}$ & $(22.35)$ & -37.77 & $(24.38)$ \\
\hline$\theta_{\text {InvCap }} \times \log ($ Gross $M)$ & 1.50 & $(3.01)$ & 2.79 & $(4.06)$ & 3.83 & $(4.90)$ & -0.92 & $(9.65)$ & 7.14 & $(9.42)$ & 7.63 & $(9.65)$ \\
\hline$\theta_{I n v C a p} \times \log (L i q)$ & 0.02 & $(0.47)$ & 0.66 & $(0.67)$ & 0.96 & $(0.82)$ & -0.37 & (1.64) & 0.93 & $(1.82)$ & 0.52 & $(1.87)$ \\
\hline$\theta_{\text {InvCap }} \times \log (\operatorname{InvCap})$ & $-7.35 * *$ & $(3.56)$ & $-11.95^{* *}$ & $(5.09)$ & $-13.13^{* *}$ & (6.39) & $-28.02^{* *}$ & $(11.25)$ & $-30.50^{* *}$ & $(12.38)$ & $-26.94^{* *}$ & $(12.90)$ \\
\hline$\theta_{\text {InvCap }} \times \log (R E S)$ & -0.01 & $(0.03)$ & 0.02 & $(0.04)$ & 0.04 & $(0.05)$ & -0.02 & $(0.12)$ & 0.01 & $(0.13)$ & -0.01 & $(0.14)$ \\
\hline$\theta_{\text {ResAv }}$ & 10.60 & $(9.75)$ & 18.56 & $(14.98)$ & 27.95 & (19.41) & 43.97 & $(37.71)$ & 61.34 & $(43.23)$ & $83.58^{*}$ & $(46.54)$ \\
\hline$\theta_{\text {ResAv }} \times \log ($ MktIntensity $)$ & -3.37 & $(2.73)$ & -4.30 & $(3.97)$ & -6.53 & $(5.04)$ & -3.24 & $(11.11)$ & -7.51 & $(10.46)$ & -10.49 & $(10.79)$ \\
\hline$\theta_{\text {ResAv }} \times \log (R \&$ Dintensity $)$ & -3.06 & $(4.12)$ & -5.80 & $(6.54)$ & -8.89 & $(8.63)$ & -8.75 & $(16.96)$ & -11.88 & $(19.59)$ & -17.48 & $(21.16)$ \\
\hline$\theta_{\text {ResAv }} \times \log (\operatorname{Gross} M)$ & $5.59^{* *}$ & $(2.82)$ & $7.65^{*}$ & $(4.08)$ & $9.29^{*}$ & $(4.89)$ & 13.67 & $(9.00)$ & 15.44 & $(9.57)$ & 14.25 & $(9.68)$ \\
\hline$\theta_{\text {ResAv }} \times \log (L i q)$ & 0.24 & $(0.38)$ & 0.51 & $(0.58)$ & 0.59 & $(0.72)$ & 0.60 & $(1.45)$ & 1.48 & $(1.53)$ & 1.42 & $(1.67)$ \\
\hline$\theta_{\text {ResAv }} \times \log (\operatorname{Inv} C \mathrm{Cap})$ & $-4.97^{*}$ & $(2.77)$ & $-7.93^{*}$ & $(4.33)$ & $-9.44^{*}$ & $(5.65)$ & $-24.93^{* * *}$ & $(8.94)$ & $-29.61^{* * *}$ & $(10.61)$ & $-31.91 * * *$ & $(11.59)$ \\
\hline$\theta_{\text {ResAv }} \times \log (R E S)$ & -0.05 & $(0.04)$ & -0.06 & $(0.06)$ & -0.07 & $(0.07)$ & -0.18 & $(0.16)$ & -0.20 & $(0.17)$ & -0.18 & $(0.18)$ \\
\hline $\log (\mathrm{ID})$ & $0.12^{* * *}$ & $(0.03)$ & $0.22^{* * *}$ & $(0.04)$ & $0.32^{* * *}$ & $(0.05)$ & $-0.61 * * *$ & $(0.10)$ & $-0.51^{* * *}$ & $(0.11)$ & $-0.42^{* * *}$ & $(0.11)$ \\
\hline $\log (\mathrm{LT})$ & 0.00 & $(0.03)$ & 0.01 & $(0.05)$ & 0.02 & $(0.06)$ & 0.12 & $(0.13)$ & 0.11 & $(0.14)$ & 0.06 & $(0.15)$ \\
\hline $\log$ (EnvUncert) & -2.34 & $(5.25)$ & -6.86 & $(7.80)$ & -9.68 & $(9.76)$ & -31.45 & $(24.28)$ & -30.88 & $(27.57)$ & -23.96 & $(28.97)$ \\
\hline $\log$ (MktShare) & $-7.45^{*}$ & $(3.82)$ & $-12.90^{* *}$ & $(5.74)$ & $-12.93^{*}$ & (7.49) & $-31.85^{* *}$ & $(12.98)$ & $-37.40^{* *}$ & $(15.15)$ & $-33.04^{* *}$ & $(16.64)$ \\
\hline $\log ($ CapInt $)$ & -0.06 & $(0.09)$ & -0.08 & $(0.12)$ & -0.12 & $(0.15)$ & -0.40 & $(0.35)$ & -0.38 & $(0.39)$ & -0.40 & $(0.41)$ \\
\hline $\log \left(|N S A L E|_{-}^{4}\right)$ & $-0.47 * * *$ & $(0.04)$ & & & & & $-1.74^{* * *}$ & $(0.13)$ & & & & \\
\hline $\log \left(|N S A L E|_{-}^{8}\right)$ & & & $-0.30 * * *$ & $(0.04)$ & & & & & $-0.98 * * *$ & $(0.10)$ & & \\
\hline $\log \left(|N S A L E|_{-2}^{12}\right)$ & & & & & $-0.23 * * *$ & $(0.04)$ & & & & & $-0.71 * * *$ & $(0.09)$ \\
\hline Ind & 3 significant & 5 significant & 5 significant & 4 significant & 3 significant & 4 significant & & & & & & \\
\hline Intercept & -20.30 & $(16.15)$ & -17.12 & $(23.45)$ & -21.00 & $(29.69)$ & -7.11 & $(64.35)$ & -8.78 & $(72.80)$ & -34.03 & $(79.36)$ \\
\hline Adjusted $R^{2}$ & 0.28 & & 0.22 & & 0.19 & & 0.23 & & 0.18 & & 0.15 & \\
\hline $\mathrm{N}$ & 1,252 & & 1,252 & & 1,252 & & 1,252 & & 1,252 & & 1,252 & \\
\hline
\end{tabular}

${ }^{*} p<0.1 ; * * p<0.05 ; * * * p<0.01$ 